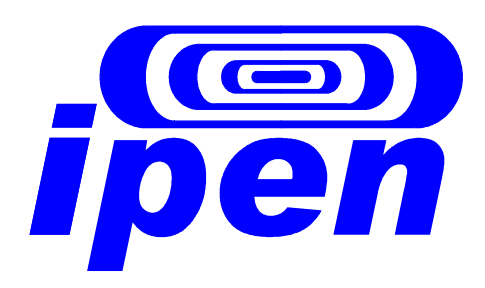

AUTARQUIA ASSOCIADA À UNIVERSIDADE DE SÃO PAULO

\title{
REMOÇÃO DE CÉSIO E AMERÍCIO UTILIZANDO FIBRA DE COCO PARA A APLICAÇÃO NO TRATAMENTO DE REJEITOS RADIOATIVOS
}

NELLA NELCI MUSSUGATI DE JESUS

Dissertação apresentada como parte dos requisitos para obtenção do Grau de Mestre em Ciências na Área de Tecnologia Nuclear - Aplicações.

Orientadora:

Profa. Dra. Solange Kazumi Sakata

São Paulo 2013 


\section{(ब्G)}

AUTARQUIA ASSOCIADA À UNIVERSIDADE DE SÃO PAULO

REMOÇÃO DE CÉSIO E AMERÍCIO UTILIZANDO FIBRA DE COCO PARA A APLICAÇÃO NO TRATAMENTO DE REJEITOS RADIOATIVOS

NELLA NELCI MUSSUGATI DE JESUS

Dissertação apresentada como parte dos requisitos para obtenção do Grau de Mestre em Ciências na Área de Tecnologia Nuclear - Aplicações.

Orientadora:

Profa. Dra. Solange Kazumi Sakata

São Paulo

2013 
$A$ alegria que se tem em pensar e aprender faz-nos pensar e aprender ainda mais.

(Aristóteles)

Valeu a pena? Tudo vale a pena Se a alma não é pequena. Quem quer passar além do Bojador Tem que passar além da dor. Deus ao mar o perigo e o abismo deu,

Mas nele é que espelhou o céu. (Fernando Pessoa) 
Aos meus pais: Alberto e Nelci Aos meus irmãos: Patrícia, Marcos e Marcelo 


\section{AGRADECIMENTOS}

A Deus, pelo dom da vida e pelo sustento diário, pela força e coragem para empreender essa grande realização.

À Dra. Solange Kazumi Sakata pela orientação e condução deste trabalho, pelos momentos de aprendizagem ao longo deste tempo, por toda a ajuda e compreensão, muitas vezes, pela minha limitação de tempo.

A todos os colaboradores da Gerência de Rejeitos Radioativos, pela disponibilização de equipamentos e recursos, em especial à Mirella, Luciana, Vanessa, Maurício, Heverton, Ademar e Roberto pela ajuda dispensada durante a realização dos experimentos e pelos conselhos.

Ao Instituto de Quimica em nome da Dra. Patrícia Busko Di Vitta pela análise de infravermelho, à Sarita e ao Capitão Olifiers pela análise de MEV e ao CQMA pela análise de DRX.

A todos os meus colegas da Parker e principalmente aos que trabalharam e ainda trabalham comigo no Departamento de Tecnologia, por darem suporte na minha ausência e ao meu supervisor Damião Antunes, pelo total apoio e compreensão em permitir que eu pudesse conciliar os estudos e o trabalho. Muito obrigada!

Aos meus queridos que estimo muito, Priscilla Garcia, amiga companheira, obrigada pela cumplicidade e por um dia dizer que eu chegaria até aqui, mesmo antes de ter começado; Daniel Hohl, Deise Casagrande, Elaine Rodrigues e Prof. Sandro de Oliveira, por me acompanharem de perto nesta jornada e terem me ajudado de diversas formas. À Claudenice, pelas sessões de acupuntura e pela ajuda precisa nos momentos difíceis, obrigada pelos conselhos e pelo ouvido sempre tão amigo.

À minha família, a base que me sustenta. Agradeço pela confiança depositada, pela compreensão e as palavras de encorajamento. À dedicação dos meus pais por me ensinarem a fazer sempre o melhor e que precisamos acreditar que podemos ir além do que imaginamos.

A todos, que de alguma maneira contribuíram para a realização deste trabalho, meus sinceros e mais profundos agradecimentos! 


\title{
REMOÇÃO DE CÉSIO E AMERÍCIO UTILIZANDO FIBRA DE COCO PARA A APLICAÇÃO NO TRATAMENTO DE REJEITOS RADIOATIVOS
}

\author{
Nella Nelci Mussugati de Jesus
}

\section{RESUMO}

A fibra de coco tem sido usada como um adsorvente alternativo e de baixo custo na remoção de diversos metais pesados. A biossorção é um processo que tem alcançado grande importância nas últimas décadas no tratamento de efluentes e de rejeitos radioativos. Este estudo apresenta a eficiência de remoção dos íons ${ }^{133} \mathrm{Cs}$ e ${ }^{241} \mathrm{Am}$ de soluções aquosas utilizando-se a biomassa bruta e ativada. Os estudos foram realizados em batelada e os parâmetros analisados foram: os efeitos do $\mathrm{pH}$ e da concentração da solução, tamanho de partícula do biomassa e tempo de contato. Os modelos de isotermas de Langmuir e Freundlich foram aplicados, bem como os modelos cinéticos de ordem de reação. A cinética que melhor representa o processo de adsorção dos íons estudados foi o modelo de pseudo-segunda ordem. $\mathrm{O}$ modelo de isotermas que se ajusta ao processo de adsorção do ${ }^{133} \mathrm{Cs}$ e do ${ }^{241} \mathrm{Am}$ é o de Freundlich. Verificou-se também que a melhor condição de remoção para $\circ{ }^{241} \mathrm{Am}$ foi de cerca de $94 \%$ a partir de 30 minutos tanto para a biomassa bruta quanto para a ativada ao passo que $0{ }^{133} \mathrm{Cs}$ foi de $75 \%$ a partir de 40 minutos com a biomassa ativada. Os resultados indicaram que a fibra de coco pode ser uma alternativa de tratamento de rejeitos radioativos líquidos que contenham, em sua composição, estes radionuclídeos.

Palavras Chave: biossorção, amerício, césio, fibra de coco bruta e ativada 


\title{
REMOVAL OF CESIUM E AMERICIUM USING COCONUT FIBER APPLICATION FOR THE TREATMENT OF RADIOACTIVE WASTES
}

\section{Nella Nelci Mussugati de Jesus}

\begin{abstract}
Sorption is one of the most studied methods to reduce the volume of radioactive waste streams. The coconut fibers have been used as an inexpensive alternative adsorbent to removal of several heavy metals from liquid wastes. The aim of this work is to evaluate the potential of coconut fiber, raw and chemically modified form, to remove ${ }^{133} \mathrm{Cs}$ and ${ }^{241} \mathrm{Am}$ from aqueous solutions. The studies were performed at batch conditions and the following parameters were analyzed: contact time, $\mathrm{pH}$ and concentration of ions in aqueous solution and the particle size. The Langmuir and Freundlich models were studied to describe the isotherms and the kinetic process was studied using the pseudo-first and pseudo-second orders. For ${ }^{241} \mathrm{Am}$ and ${ }^{133} \mathrm{Cs}$, the Freundlich isotherm described better the adsorption process. For ${ }^{241} \mathrm{Am}$, the best removal condition was achieved at 30 minutes with both biomasses. For ${ }^{133} \mathrm{Cs}$ the best condition was achieved from at 40 minutes with modified biomass. Removal kinetics for both ions was fitted by pseudo-second order model. The results indicate that coconut fiber can be used as an alternative sorbent in the treatment of liquid radioactive wastes containing these radionuclides.
\end{abstract}

Keywords: Biosorption, americium, cesium, coconut fiber raw and modified 


\section{SUMÁRIO}

Página

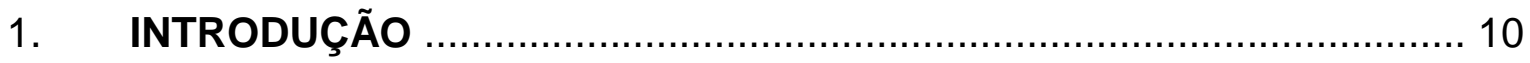

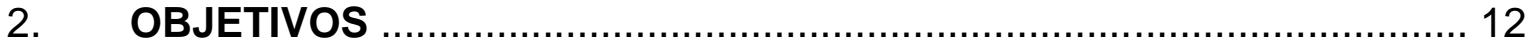

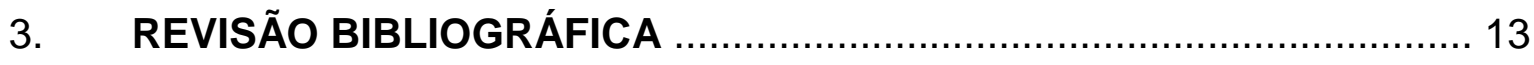

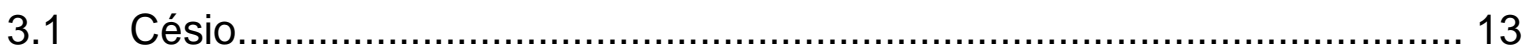

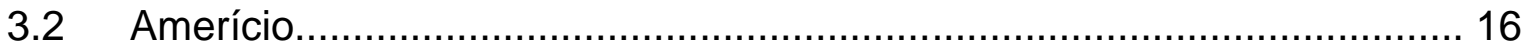

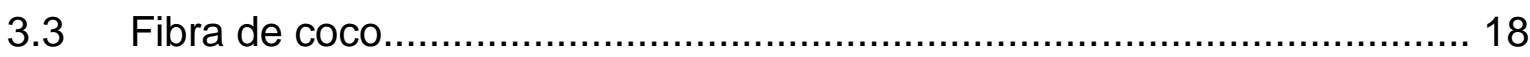

3.3.1 Produção do coco verde: impactos ambientais e sócio-econômicos ........ 22

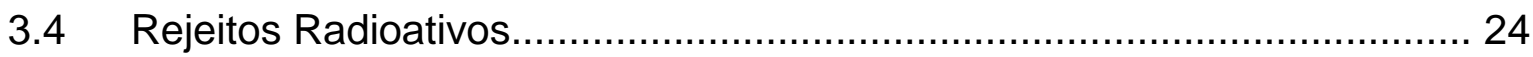

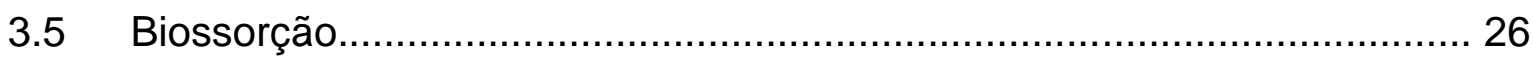

3.6 Remoção de metais pesados utilizando biomassa vegetal ....................... 27

3.7 Remoção de metais pesados utilizando fibra de coco ............................. 29

3.8 Métodos de remoção de ${ }^{137} \mathrm{Cs}$ de soluções aquosas ................................ 30

3.9 Métodos de remoção de ${ }^{241} \mathrm{Am}$ de soluções aquosas ............................... 31

3.10 Fundamentos sobre o processo de adsorção ……………………….... 31

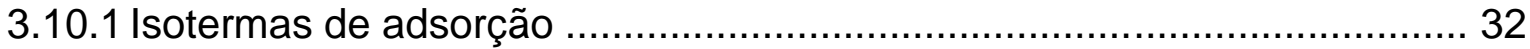

3.10.2 Cinética de adsorção e parâmetros termodinâmicos ............................... 35

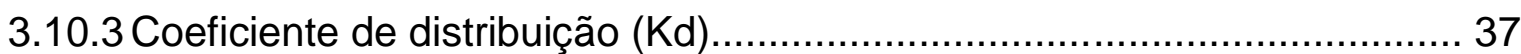

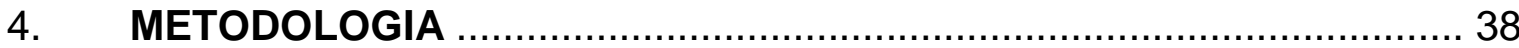

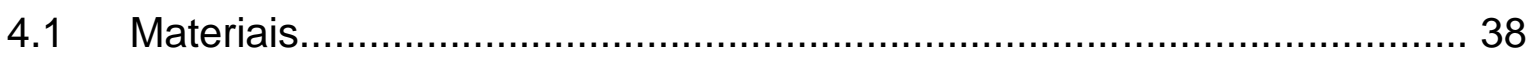

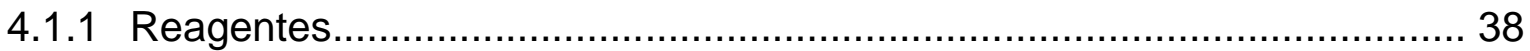

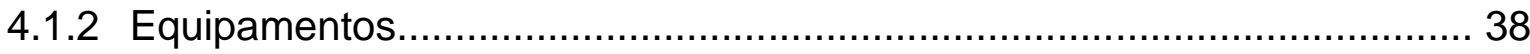

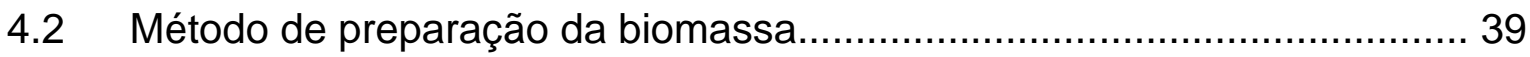

4.2.1 Ativação com peróxido de hidrogênio em meio alcalino.............................. 40

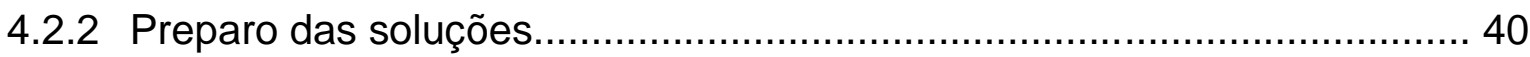

4.3 Processo de biossorção................................................................... 40

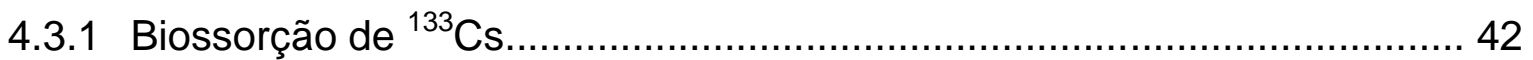

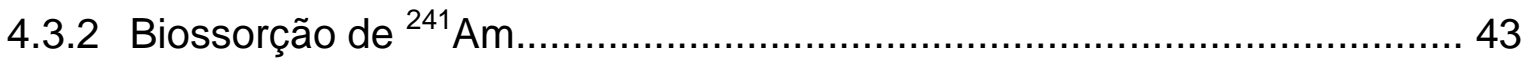


4.3.3 Cálculos de cinética, parâmetros termodinâmicos e de equilíbrio

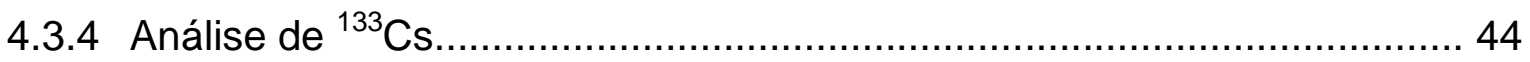

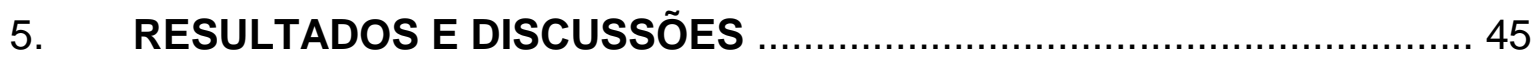

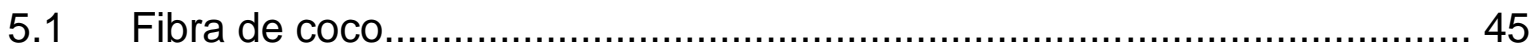

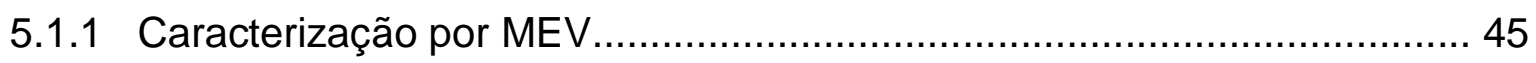

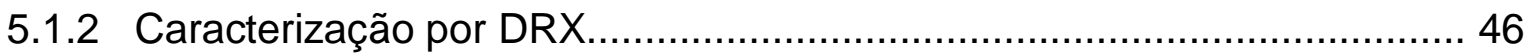

5.1.3 Caracterização por Infravermelho................................................ 47

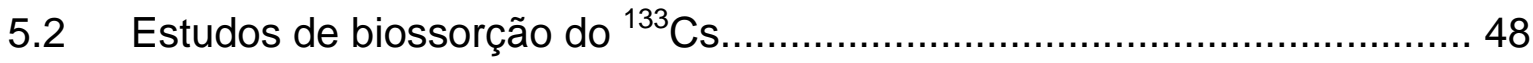

5.2.1 Influência do pH na adsorção........................................................... 48

5.2 .2 Influência do tempo de contato................................................... 50

5.2.3 Influência do tamanho de partícula da biomassa ................................ 51

5.2.4 Influência da concentração da solução ............................................ 52

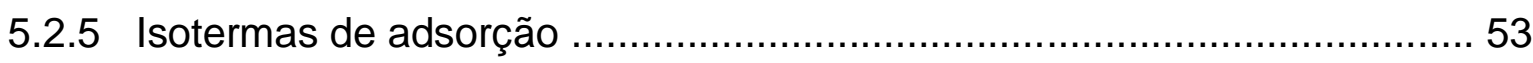

5.2 .6 Estudos de cinética química .................................................. 55

5.2.7 Caracterização da biomassa após contato com césio ............................ 58

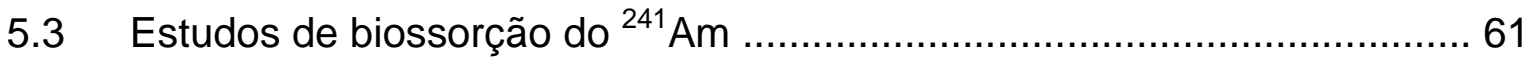

5.3.1 Influência do pH na adsorção........................................................ 61

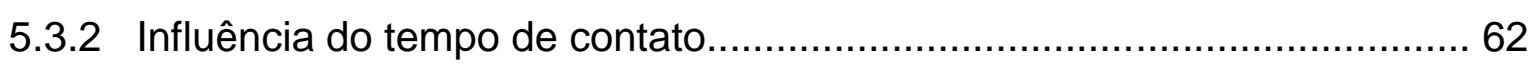

5.3.3 Influência do tamanho de partícula da biomassa ................................. 63

5.3.4 Influência da concentração da solução ............................................ 64

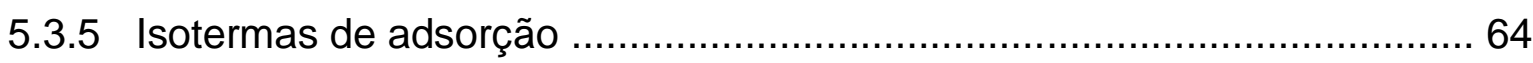

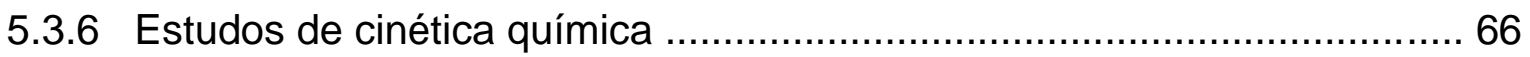

5.4 Coeficiente de distribuição e energia livre de Gibbs .............................6 69

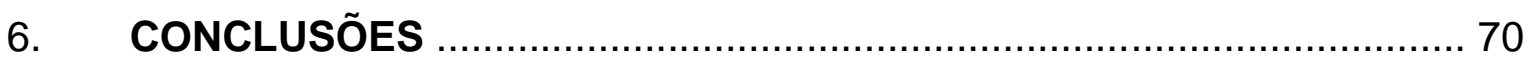

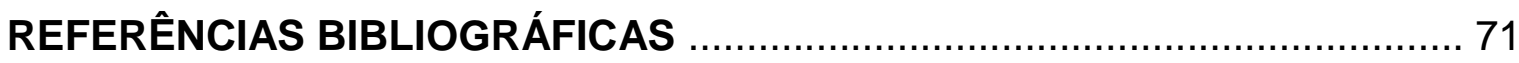




\section{1) INTRODUÇÃO}

A partir do século $\mathrm{XX}$, o desenvolvimento e aproveitamento da energia nuclear se intensificaram com os estudos realizados pelo físico italiano Enrico Fermi (1901-1954) sobre o decaimento beta. Fermi também fez previsões sobre a fusão e fissão nucleares, como descreveu em uma de suas citações:

"O único caminho que poderá permitir a agressão do núcleo do átomo é aquele que permite a aceleração artificial dos projéteis naturais dos elementos radioativos em grande número e com grande velocidade, o que exigirá tubos carregados e alimentados a uma diferença de potencial de dez milhões de volts. Somente dificuldades técnicas e financeiras, não a priori insuperáveis, se opõem a realização deste grande projeto. O objetivo não é somente a transmutação dos elementos químicos em quantidades sensíveis, mas a constatação da grande produção energética que deverá se manifestar na pulverização ou reconstituição dos núcleos atômicos" (CNEN, 2013).

O início da "Era Nuclear" foi marcado pela operação do primeiro reator nuclear em 1942, na Universidade de Chicago nos Estados Unidos e, desde então, os avanços tecnológicos têm proporcionado o aumento do uso de radioisótopos nas mais diversas atividades que incluem a tecnologia nuclear na agricultura, medicina, indústria e pesquisa.

Além dos benefícios produzidos pelo uso da energia nuclear há uma questão importante a ser avaliada, que é a geração de rejeitos radioativos. Esses rejeitos apresentam características peculiares e devem ser controlados e tratados, seguindo normas e procedimentos específicos (HIROMOTO et al., 1999).

O tratamento de rejeitos radioativos líquidos pode, em alguns casos, envolver as mesmas técnicas de tratamentos de resíduos contendo metais pesados, tais como ultrafiltração (XIONG et al, 2008), precipitação e evaporação (RAHMAN, et al., 2011), troca-iônica (SINHA et al, 1996), separação por membranas (DULAMA et al, 2008) e extração (GASSER et al, 2008) e por estarem em estado físico de fácil dispersão, cuidados adicionais devem ser considerados.

A busca de novas alternativas para o tratamento dos rejeitos radioativos líquidos que aliem baixo custo, eficiência e redução de volume tem 
apresentado grande importância nos últimos anos, destacando-se os adsorventes vegetais. Assim como os íons metálicos, as interações que ocorrem entre esses adsorventes e os radionuclídeos podem ser por meio de biossorção, processo que ocorre por interações físico-químicas (MALIK, 2004).

Para o melhor entendimento dos mecanismos de remoção é necessário investigar o comportamento de cada radionuclídeo separadamente em solução aquosa quando em contato com a biomassa vegetal. 


\section{2) OBJETIVOS}

O objetivo geral deste trabalho é avaliar o potencial da fibra de coco, na forma bruta e ativada quimicamente, em remover, separadamente, traços de ${ }^{133} \mathrm{Cs}$ e ${ }^{241} \mathrm{Am}$ de soluções aquosas.

Os objetivos específicos são: a) estudar os parâmetros que podem influenciar no processo de adsorção como: tamanho de partícula, $\mathrm{pH}$ e concentração da solução e tempo de contato; b) verificar os modelos de isotermas e de cinética que melhor representam o processo de adsorção; c) determinar as melhores condições de remoção de ${ }^{133} \mathrm{Cs}$ e ${ }^{241} \mathrm{Am}$ de soluções aquosas; d) determinar a energia livre de Gibbs e a constante de distribuição (Kd); d) avaliar o uso da fibra de coco para o tratamento de rejeitos radioativos líquidos diluídos de baixa concentração. 


\section{3) REVISÃo BIBLIOGRÁFICA}

\section{1 - Césio}

O césio (Cs) é um metal alcalino de cor branca prateada, mole e dúctil, localizado no grupo $1 \mathrm{~A}$ da classificação periódica dos elementos. Foi identificado por Gustav Kirchhoff e Robert Bunsen durante os estudos com metais alcalinos em 1860. O nome é de origem latina "Caesius" e significa azul celeste devido ao espectro característico de brilhantes linhas azuis (HART et al., 1975). As propriedades físicas e químicas deste elemento são: número atômico (Z): 55 ; massa molar: 132,91 g.mol ${ }^{-1}$; ponto de fusão: $28 \stackrel{\circ}{\circ}$; p ponto de ebulição: $678 \stackrel{\circ}{\circ}$; raio atômico: $265 \mathrm{pm}$; raio iônico: 0,184 nm, densidade: $1,87 \mathrm{~g}^{\mathrm{cm}}{ }^{-3}$; estado de oxidação: +1 e configuração eletrônica: [Xe]6s ${ }^{1}$. É o elemento mais eletropositivo e mais alcalino, reagindo explosivamente com a água. Da mesma forma que o gálio e o mercúrio, encontra-se no estado líquido em temperatura acima de $28 \stackrel{\circ}{ } \mathrm{C}$. (ATKINS, 2006)

Os sais de $\mathrm{Cs}^{+}$com a maioria dos ânions, como $\mathrm{F}^{-}, \mathrm{Cl}^{-} \mathrm{NO}_{3}^{-}, \mathrm{MnO}_{4}^{-}$, são muito solúveis em água, ao redor de centenas de gramas por litro, devido ao tamanho do raio iônico e a baixa energia reticular. Quando dissolvidos, os íons de $\mathrm{Cs}^{+}$tendem a ficar monodispersos, sem a formação de complexos ou colóides, mesmo na faixa de $\mathrm{pH}$ entre 4 e 10 em que ocorrem reações de complexação para a maioria dos cátions. (COLLINS et al., 1988)

A ocorrência deste elemento sobre a crosta terrestre é pouco abundante. Os minerais mais conhecidos do metal são: Pollucita (Aluminosilicato de césio hidratado $\left(2 \mathrm{Cs}_{2} \mathrm{O} .2 \mathrm{Al}_{2} \mathrm{O}_{3} \cdot 9 \mathrm{SiO}_{2} \cdot \mathrm{H}_{2} \mathrm{O}\right)$ ), conforme ilustrado na FIG.1, que contém cerca de $34 \%$ de $\mathrm{Cs}_{2} \mathrm{O}$, encontrado principalmente em Manitoba (Canadá), Dakota (USA), Elba (Itália), Casaquistão e Varutrask (Suécia); e Rhodizita (Borato de alumínio hidratado, berílio, potássio e césio - $\left.(\mathrm{KCs}) \mathrm{Al}_{4} \mathrm{Be}_{4}(\mathrm{BBe}){ }_{12} \mathrm{O}_{28}\right)$, ilustrado na FIG.2, encontrado em Madagascar e nos Montes Urais (Rússia) (HART et al., 1975). 


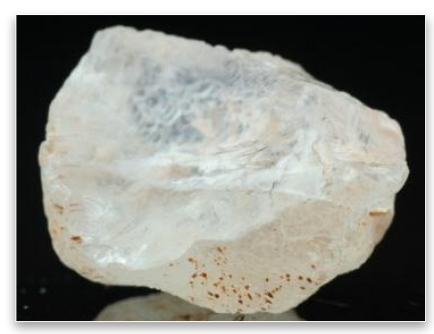

FIGURA 1 - Cristal de Pollucita

Fonte: Crystal Treasure, 2013

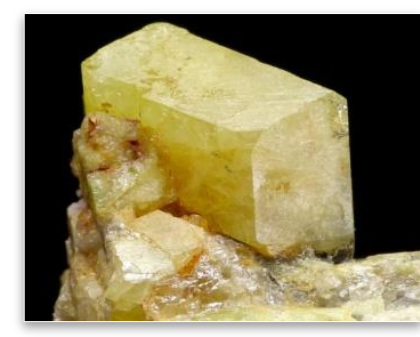

FIGURA 2 - Cristal de Rhodizita Fonte: Minfind, 2013

A primeira obtenção de césio metálico ocorreu em 1881, feita por Setterburg, pela eletrólise de uma mistura de cianeto de césio com cianeto de bário. Atualmente, o césio é obtido por eletrólise do cloreto $(\mathrm{CsCl})$ ou cianeto (CsCN) fundido e também pela decomposição térmica da azida de césio $\left(\mathrm{CsN}_{3}\right)$ (FINSTON and KINSLEY, 1961).

Os isótopos radioativos do césio são usados no tratamento de alguns tipos de câncer. $\mathrm{O}$ isótopo ${ }^{137} \mathrm{Cs}$ é também utilizado na indústria como sensor de umidade, nível e espessura, devido à emissão de radiação beta do isótopo ${ }^{137} \mathrm{Cs}$ (MÖLLER, 2013).

O ${ }^{133} \mathrm{Cs}$ é o único isótopo estável, porém há mais de 30 isótopos conhecidos, produzidos artificialmente, conforme é apresentado na TAB.1.

TABELA 1 - Isótopos do Césio

\begin{tabular}{cccc}
\hline Isótopo & Meia-Vida & $\begin{array}{c}\text { Modo de } \\
\text { Decaimento }\end{array}$ & $\begin{array}{c}\text { Energia } \\
\text { (MeV) }\end{array}$ \\
\hline $\mathbf{1 1 2}$ & $0,5 \mathrm{mseg}$ & $\mathrm{p}$ & \\
$\mathbf{1 1 3}$ & $17 \mu \mathrm{seg}$ & $\mathrm{p}$ & \\
$\mathbf{1 1 4}$ & $0,58 \mathrm{seg}$ & $\beta^{+}, \mathrm{EC}$ & 11,8 \\
$\mathbf{1 1 5}$ & $\sim 1,4 \mathrm{seg}$ & $\beta^{+}, \mathrm{EC}$ & 8,4 \\
$\mathbf{1 1 6 m}$ & $0,7 \mathrm{seg}$ & $\beta, \mathrm{EC}$ & \\
$\mathbf{1 1 6}$ & $3,8 \mathrm{seg}$ & $\beta^{+}, \mathrm{EC}$ & 10,8 \\
$\mathbf{1 1 7 m}$ & $6,5 \mathrm{seg}$ & $\beta^{+}, \mathrm{EC}$ & \\
$\mathbf{1 1 7}$ & $\sim 8,4 \mathrm{seg}$ & $\beta^{+}, \mathrm{EC}$ & 7,5 \\
$\mathbf{1 1 8 m}$ & $17 \mathrm{seg}$ & $\beta^{+}, \mathrm{EC}$ & \\
$\mathbf{1 1 8}$ & $14 \mathrm{seg}$ & $\beta^{+}, \mathrm{EC}$ & 9,0 \\
$\mathbf{1 1 9 m}$ & $29 \mathrm{seg}$ & & \\
$\mathbf{1 1 9}$ & $43 \mathrm{seg}$ & $\beta^{+}, \mathrm{EC}$ & 6,3 \\
$\mathbf{1 2 0 m}$ & $60 \mathrm{seg}$ & $\beta^{+}, \mathrm{EC}$ & \\
$\mathbf{1 2 1} \mathbf{m}$ & $2 \mathrm{~min}$ & $\mathrm{IT} / 60 /, \beta^{+} / 40 /$ &
\end{tabular}


TABELA 1 - Isótopos do Césio

\begin{tabular}{|c|c|c|c|}
\hline 121 & $2,3 \mathrm{~min}$ & $\beta^{+}, E C$ & 5,4 \\
\hline $122 \mathrm{~m} 2$ & $4,4 \min$ & $\beta^{+}, E C$ & \\
\hline $122 \mathrm{~m} 1$ & 0,36 seg & IT & \\
\hline 122 & $21 \mathrm{seg}$ & $\beta^{+}, E C$ & 7,1 \\
\hline $123 m$ & $1,6 \mathrm{seg}$ & IT & \\
\hline 123 & $5,87 \mathrm{~min}$ & $\beta^{+} / 75 /, \mathrm{EC} / 25 /$ & 4,2 \\
\hline $124 \mathrm{~m}$ & $6,3 \mathrm{seg}$ & IT & \\
\hline 124 & 30 seg & $\beta^{+} / 9 /, E C / 8 /$ & 5,92 \\
\hline 125 & $45 \mathrm{~min}$ & $\beta^{+} / 40 /, \mathrm{EC} / 60 /$ & 3,09 \\
\hline 126 & $1,64 \mathrm{~min}$ & $\beta^{+} / 81 /, E C / 19 /$ & 4,83 \\
\hline 127 & $6,2 \mathrm{~h}$ & $\beta^{+} / 96 /, E C / 4 /$ & 2,08 \\
\hline 128 & $3,62 \mathrm{~min}$ & $\beta^{+} / 68 /, \mathrm{EC} / 32 /$ & 3,93 \\
\hline 129 & $1,336 \mathrm{~d}$ & EC & 1,195 \\
\hline $130 \mathrm{~m}$ & $3,5 \min$ & IT, $\beta^{+}$, EC & \\
\hline 130 & $29,21 \mathrm{~min}$ & $\beta^{+} / 55 /, \mathrm{EC} / 43 /$ & 2,98 \\
\hline 131 & $9,69 \mathrm{~d}$ & EC & 0,352 \\
\hline 132 & $6,48 d$ & EC/98/, & \\
\hline & & $\beta^{+} / 0,3 /, \beta^{-} / /$ & $2,12 / 1,28$ \\
\hline $134 \mathrm{~m}$ & $2,91 \mathrm{~h}$ & IT & 0,139 \\
\hline 134 & $2,065 \mathrm{a}$ & $\beta^{-}, E C$ & $2,059 / 1,22$ \\
\hline $135 \mathrm{~m}$ & $53 \mathrm{~min}$ & IT & 1,627 \\
\hline 135 & $2,3.10^{6} a$ & $\beta^{-}$ & 0,629 \\
\hline $136 m$ & $19 \mathrm{seg}$ & IT & \\
\hline 136 & $13,16 \mathrm{~d}$ & $\beta^{-}$ & 2,548 \\
\hline 137 & $30,2 \mathrm{a}$ & $\beta^{-}$ & 1,176 \\
\hline $138 m$ & $2,9 \mathrm{~min}$ & IT/75/, $\beta^{-} / 25 /$ & \\
\hline 138 & $32,2 \mathrm{~min}$ & $\beta^{-}$ & 5,37 \\
\hline 139 & $9,3 \mathrm{~min}$ & $\beta^{-}$ & 4,213 \\
\hline 140 & $1,06 \mathrm{~min}$ & $\beta^{-}$ & 6,22 \\
\hline 141 & $24,9 \mathrm{seg}$ & $\beta^{-}$ & 5,26 \\
\hline 142 & $1,8 \mathrm{seg}$ & $\beta^{-}$ & 7,31 \\
\hline 143 & $1,78 \mathrm{seg}$ & $\beta^{-}$ & 6,24 \\
\hline 144 & $1,01 \mathrm{seg}$ & $\beta^{-}$ & 8,47 \\
\hline 145 & $0,59 \mathrm{seg}$ & $\beta^{-}$ & 7,89 \\
\hline 146 & $0,322 \mathrm{seg}$ & $\beta,(n)$ & 9,38 \\
\hline 147 & $0,227 \mathrm{seg}$ & $\beta,(n)$ & 9,3 \\
\hline 148 & $0,15 \mathrm{seg}$ & $\beta,(n)$ & 10,5 \\
\hline 149 & $>50 \mathrm{mseg}$ & & \\
\hline 150 & $>50$ mseg & & \\
\hline 151 & $>50 \mathrm{mseg}$ & & \\
\hline
\end{tabular}

Fonte: Handbook of Chemistry and Physics, 2013

A formação do ${ }^{137} \mathrm{Cs}$ pela fissão do urânio ocorre com baixa captura de nêutrons e um alto rendimento, como é mostrado a seguir: 


$$
{ }^{235} \mathrm{U}+\mathrm{n} \rightarrow{ }^{137} \mathrm{Cs}(6,24 \%)
$$

A distribuição deste radionuclídeo no ambiente possui aspectos particulares: em água, a forma química predominante é o íon hidratado $\left({ }^{137} \mathrm{Cs}\left(\mathrm{H}_{2} \mathrm{O}\right)^{+}\right)$que permanece em solução até a sedimentação por meio da troca catiônica com solos dos rios e lagos ou em partículas suspensas na água. No solo, a migração do ${ }^{137} \mathrm{Cs}$ é lenta, pois o cátion é fortemente adsorvido pelos sítios ativos presentes nos ácidos húmicos (ANTUNES et al, 2010).

Sob aspectos da saúde humana, a exposição ao ${ }^{137}$ Cs causa um efeito global no organismo, pois é quimicamente semelhante ao cálcio e ao potássio, depositando-se nos músculos e ossos (JOE, 2013).

\section{2 - Amerício}

É um elemento transurânico que encontra-se na série dos actinídeos na classificação periódica dos elementos. Possui número atômico (Z): 95; peso atômico: 243 u.m.a, referente ao isótopo mais estável; ponto de fusão: $990 \stackrel{\circ}{ } \mathrm{C}$; ponto de ebulição: $2600^{\circ} \mathrm{C}$; raio atômico: $173 \mathrm{pm}$; densidade: $13,67 \mathrm{~g} \cdot \mathrm{cm}^{-3}$; estado de oxidação mais comum e estável é +3 e configuração eletrônica: [Rn] $5 f^{7} 7 s^{2}$ (ATKINS, 2006). A estrutura cristalina possui duas formas estabelecidas: hexagonal dupla fechada, que é estável a temperatura ambiente, e a cúbica de face centrada. Essa mudança de estrutura ocorre a $771^{\circ} \mathrm{C}\left(+/-15^{\circ} \mathrm{C}\right)$ (MORSS et al., 2006).

Esse metal artificial de cor prateada, cujo nome é uma homenagem ao continente americano, foi produzido em 1944 por Seaborg, James, Morgan e Ghiorso como resultado de sucessivas reações, como mostrado abaixo, de captura de nêutrons por isótopos de plutônio. Em 1945 foi isolado como ${ }^{241} \mathrm{Am}$ em $\mathrm{Am}(\mathrm{OH})_{3}$ por Cunningham (HYDE and SEABORG, 1956).

$$
{ }^{239} \mathrm{Pu}(\mathrm{n}, \mathrm{\gamma}) \rightarrow{ }^{240} \mathrm{Pu}(\mathrm{n}, \mathrm{y}) \rightarrow{ }^{241} \mathrm{Pu} \rightarrow \beta^{-}+{ }^{241} \mathrm{Am}
$$

$\mathrm{O}{ }^{241} \mathrm{Am}$, obtido em reatores de potência, sofre decaimento alfa com emissão de partículas com energia entre 5,38 e 5,54 MeV e com subsequente emissão de raios- $X$ e gama de baixa energia (em torno de 59,54 keV), convertendo-se em ${ }^{237} \mathrm{~Np}$ (SHULZ, 1976). Na TAB.2 são mostrados os isótopos 
deste elemento, sendo que os mais estáveis e importantes são o ${ }^{241} \mathrm{Am}$, com meia vida de 432 anos e o ${ }^{243} \mathrm{Am}$, com meia vida de 7.390 anos.

TABELA 2 - Isótopos do Amerício

\begin{tabular}{|c|c|c|c|}
\hline $\begin{array}{l}\text { Número } \\
\text { de massa }\end{array}$ & Meia-Vida & $\begin{array}{c}\text { Modo de } \\
\text { decaimento }\end{array}$ & $\begin{array}{c}\text { Radiação } \\
\text { (MeV) }\end{array}$ \\
\hline 232 & $1,4 \mathrm{~min}$ & Isômero - SF & \\
\hline 233 & $3,2 \mathrm{~min}$ & $\alpha$ & $\alpha 0,00678$ \\
\hline 234 & $2,6 \mathrm{~min}$ & EC & \\
\hline 235 & $15 \mathrm{~min}$ & EC & \\
\hline 236 & 4,4 $\min / 3,7 \mathrm{~min}$ & $\mathrm{EC}$ & \\
\hline 237 & $1,22 \mathrm{~h}$ & $\begin{array}{l}E C>99 \% \\
\alpha 0.025 \%\end{array}$ & $\begin{array}{c}\alpha 6,042 \\
\text { ү } 0,280(47 \%)\end{array}$ \\
\hline 238 & $1,63 h$ & $\begin{array}{c}E C>99 \% \\
\alpha 1.0 \times 10^{-4} \%\end{array}$ & $\begin{array}{c}\alpha 5,94 \\
\text { ү } 0,963(29 \%)\end{array}$ \\
\hline 239 & $11,9 \mathrm{~h}$ & EC>99\% & $\begin{array}{l}\alpha 5,776(84 \%) \\
5,734(13,8 \%)\end{array}$ \\
\hline 240 & $50,8 \mathrm{~h}$ & $\begin{array}{c}E C>99 \% \\
\alpha 1.9 \times 10^{-4} \%\end{array}$ & $\begin{array}{c}\text { a } 5,378(87 \%) \\
5,337(12 \%) \\
\text { y } 0,988(73 \%)\end{array}$ \\
\hline 241 & $\begin{array}{c}432,7 a \\
1,15 \times 10^{14} a\end{array}$ & $\begin{array}{c}\alpha \\
S F\end{array}$ & $\begin{array}{c}\alpha 5,486(84 \%) \\
5,443(13,1 \%) \\
\gamma 0,059(35,7 \%)\end{array}$ \\
\hline 242 & $16,01 \mathrm{~h}$ & $\begin{array}{c}\beta^{-} 82.7 \% \\
\text { EC } 17.3 \%\end{array}$ & $\begin{array}{l}\beta 0,667 \\
\text { ү } 0,042\end{array}$ \\
\hline $242 m$ & $\begin{array}{c}141 \mathrm{a} \\
9,5 \times 10^{11} \mathrm{a}\end{array}$ & $\begin{array}{c}\text { IT } 99.5 \% \\
\text { SF a }(0,45 \%)\end{array}$ & $\begin{array}{c}\alpha 5,207(89 \%) \\
5,141(6 \%) \\
\text { y } 0,0493(41 \%)\end{array}$ \\
\hline 243 & $\begin{array}{l}7,39 \times 10^{3} \mathrm{a} \\
2,0 \times 10^{14} \mathrm{a}\end{array}$ & $\begin{array}{l}\alpha \\
\text { SF }\end{array}$ & $\begin{array}{l}\alpha 5,277(88 \%) \\
5,234(10,6 \%) \\
\text { y } 0,075(68 \%)\end{array}$ \\
\hline 244 & $10,1 \mathrm{~h}$ & $\beta^{-}$ & $\begin{array}{c}\beta 0,387 \\
\gamma 0,746(67 \%)\end{array}$ \\
\hline $244 m$ & $26 \mathrm{~min}$ & $\begin{array}{c}\beta^{-}>99 \% \\
\text { EC } 0.041 \%\end{array}$ & $\beta^{-1,50}$ \\
\hline 245 & $2,05 \mathrm{~h}$ & $\beta^{-}$ & $\begin{array}{c}\beta^{-} 0,895 \\
\text { y } 0,253(6,1 \%)\end{array}$ \\
\hline 246 & $25 \mathrm{~min}$ & $\begin{array}{l}\beta^{-} \\
\gamma\end{array}$ & $\begin{array}{c}\beta^{-} 2,38 \\
0,799(25 \%)\end{array}$ \\
\hline $\begin{array}{l}246 \\
247\end{array}$ & $\begin{array}{l}29 \min \\
24 \min \end{array}$ & $\begin{array}{l}\beta^{-} \\
\beta^{-}\end{array}$ & $\begin{array}{l}\text { y } 0,679(52 \%) \\
\text { ү 0,285 (23\%) }\end{array}$ \\
\hline
\end{tabular}

Fonte: Adaptação - "The chemistry of the actinide and transactinide elements" (MORSS et al., 2006). 
A atividade específica do ${ }^{241} \mathrm{Am}$ é $1,258 \times 10^{11} \mathrm{~Bq} \cdot \mathrm{g}^{-1}$, o que representa ser 17 vezes maior que a do ${ }^{243} \mathrm{Am}$, cerca de $74 \times 10^{8} \mathrm{~Bq} \cdot \mathrm{g}^{-1}$ (ATSDR, 2013). Esses isótopos possuem o mesmo comportamento químico no meio ambiente. Enquanto o ${ }^{241} \mathrm{Am}$ é comumente utilizado em detectores de fumaça de ionização (CLAIN E AQUINO, 1999) e em para-raios (VICENTE et al., 2013), o ${ }^{243} \mathrm{Am}$ é usado apenas em laboratórios de pesquisa (STREET et al., 1950).

As partículas resultantes do processo de decaimento do ${ }^{241} \mathrm{Am}$ oferecem poucos riscos por irradiação externa e, no tecido do corpo humano, tem alcance de apenas alguns milionésimos de milímetros porém, é classificado como altamente radiotóxico, devido às suas propriedades toxicológicas quando ingerido ou inalado (TAUHATA et al., 2003).

A distribuição pelo corpo humano, quando inalado, afeta primeiramente o pulmão e, em seguida, é redistribuído para o fígado, ossos e músculos esqueléticos. Quando ingerido, a distribuição pela circulação a partir do trato gastrointestinal, é semelhante à da inalação. Há poucas informações sobre a disponibilidade ambiental do amerício: na água, há a formação de complexos e a precipitação do hidroxil-carbonato $\left(\mathrm{AmOHCO}_{3}\right)$; no solo, pode ocorrer transformações de complexação com ligantes orgânicos e inorgânicos e precipitação com ânions e outras substâncias presentes (ATSDR, 2013).

\section{3 - Fibra de Coco}

A espécie Cocos nucifera L., popularmente conhecida como coco verde, é uma palmeira tropical da classe das oleaginosas, de origem asiática e de grande importância econômica, pois é utilizada como fonte de alimentação, bebida, fibra, óleo, combustível, artesanato, dentre outros (PARROTTA, 1993).

A composição química do coco pode ser influenciada por fatores geográficos e climáticos, mas, em geral, além do carbono, oxigênio e hidrogênio, são encontrados elementos como nitrogênio, potássio, cálcio, magnésio, ferro, cobre, zinco e manganês (ROSA et al., 2001). A fibra é classificada como material ligno-celulósico composto por cerca de 35 a $45 \%$ de lignina; cerca de $30 \%$ de 
celulose e de outros componentes secundários como a hemicelulose, extrativos solúveis em água e teor de cinzas - a $650 \stackrel{\circ}{\circ}$ (CORRADINI et al., 2009).

O coco verde é dividido em três partes, conforme mostrado na FIG.3. O mesocarpo constitui a parte fibrosa da casca e é caracterizado por sua dureza, devido ao alto teor de lignina, que faz com que leve cerca de 8 anos para total decomposição (SILVA et al., 2006).

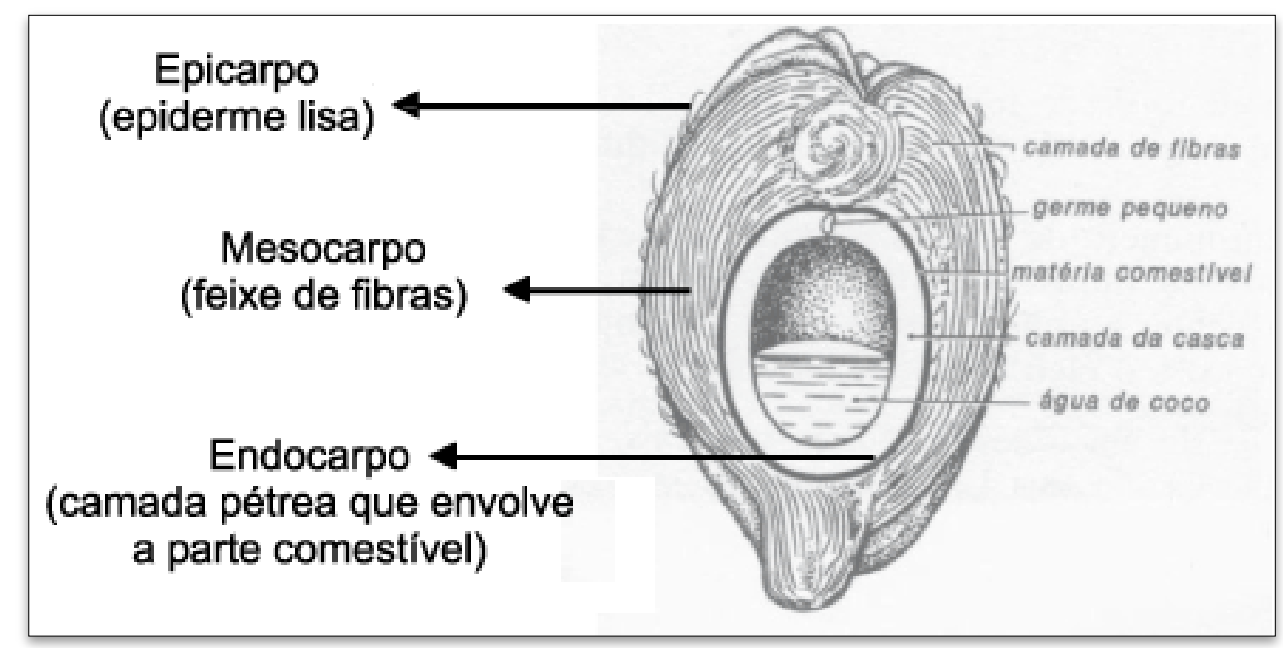

FIGURA 3 - Corte longitudinal do coco Fonte: ANDRADE et al., 2004

As fibras ligno-celulósicas podem ter diferentes origens, mas apresentam uma estrutura semelhante, como é mostrado na FIG.4. A estrutura cristalina das fibras naturais consiste de micro fibrilas de celulose que são conectadas pela região amorfa composta pela lignina e hemicelulose formando células (BLEDZKI, 1999). 


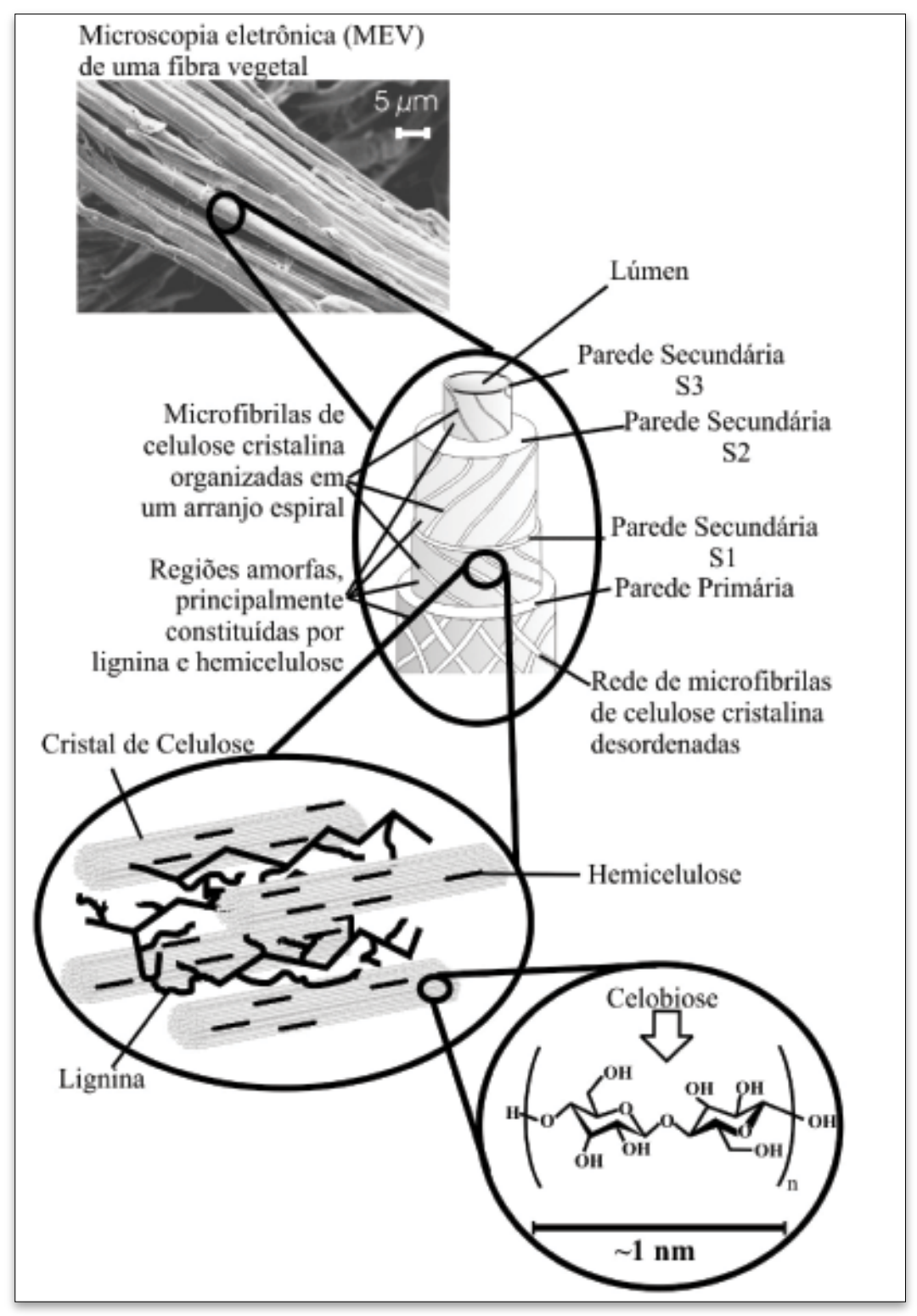

FIGURA 4 - Estrutura de uma fibra vegetal Fonte: SILVA, 2009

A celulose é um polissacarídeo com fórmula $\left(\mathrm{C}_{6} \mathrm{H}_{10} \mathrm{O}_{5}\right)_{n}$, conforme é mostrado na FIG.5. Possui uma cadeia linear com uma unidade repetida conhecida como celobiose que contém grupos hidroxilas que apresentam tendência em estabelecer ligações de hidrogênio intra e intermoleculares. Devido a essas ligações, há regiões cristalinas, altamente ordenadas com uma quantidade maior de ligações e também há regiões não cristalinas com uma quantidade menor de ligações formadas (SILVA, 2009). 


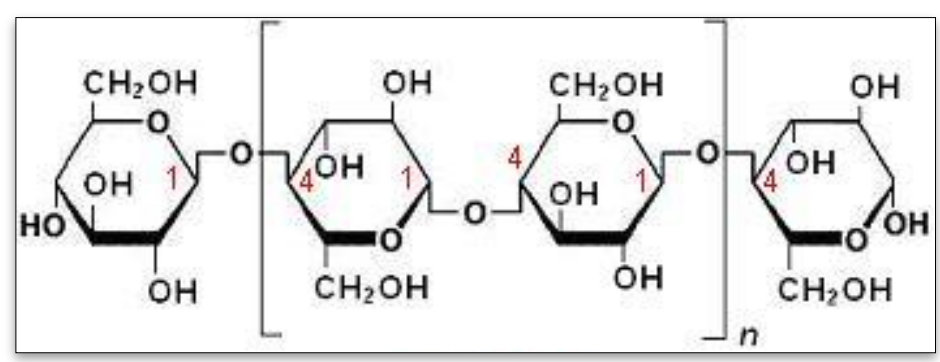

FIGURA 5 - Estrutura molecular da celulose

Fonte: GALLO, 2013

O grupo de polissacarídeos conhecido como hemicelulose confere a flexibilidade da fibra favorecendo a ligação entre a celulose e a lignina. Esses grupos são compostos por alguns tipos de açúcares conforme mostrado na FIG.6, possuem cadeia ramificada de baixo peso molecular e são altamente hidrofílicos (RAZERA, 2006).

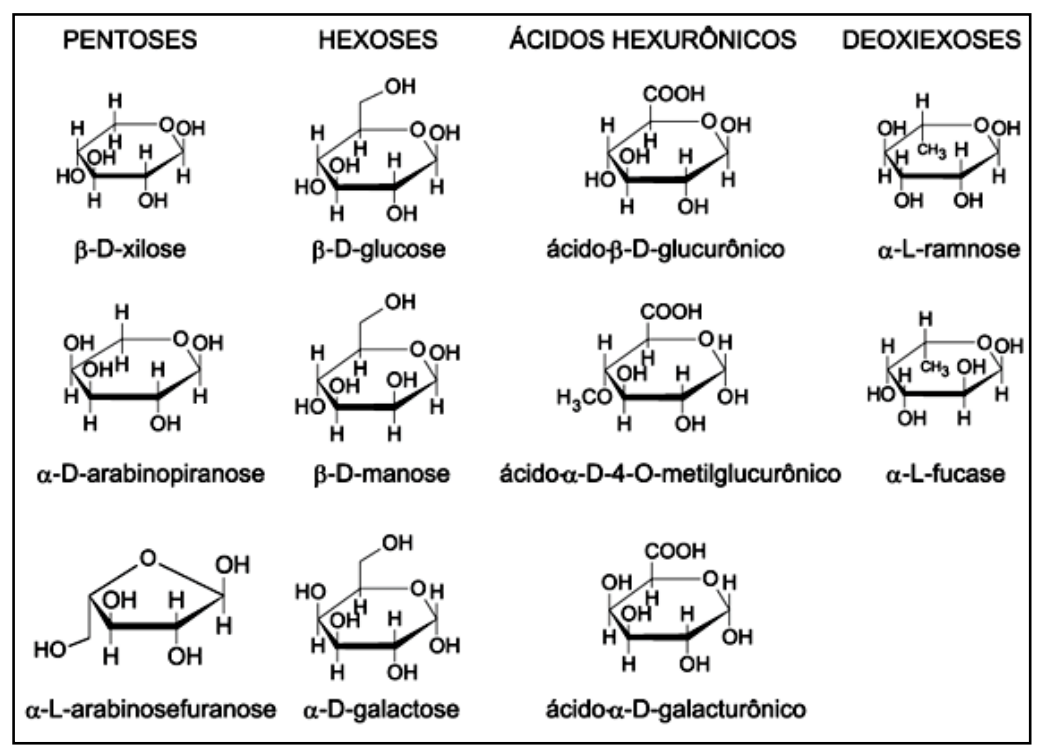

FIGURA 6 - Açúcares que compõem as unidades de hemicelulose Fonte: MORAIS et al., 2005

A lignina é um polímero natural amorfo e hidrofóbico de estrutura ramificada, conforme mostrado na FIG.7, que dependendo das características específicas de cada planta, pode apresentar diferentes formações, sendo assim classificada como um polifenol (SALIBA et al., 2001). 


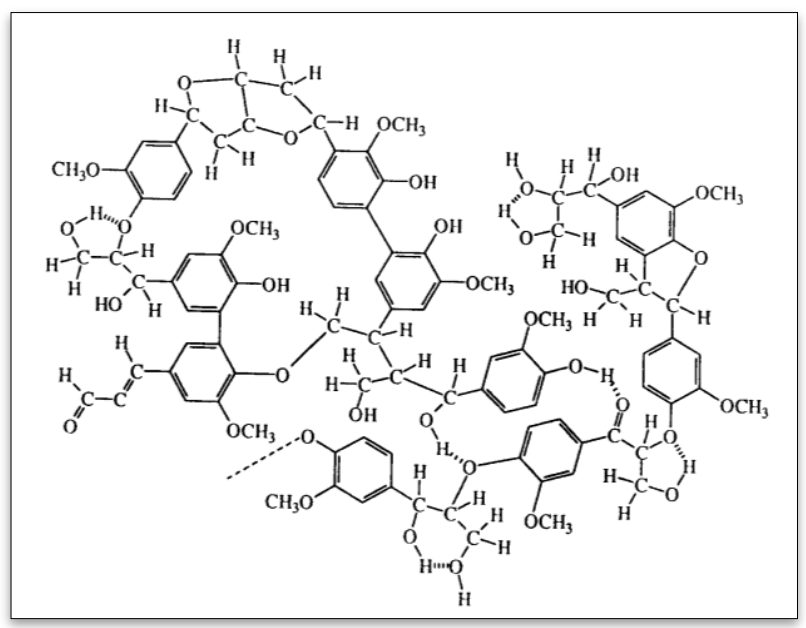

FIGURA 7 - Estrutura molecular da lignina

Fonte: HAIDER, 1964

\subsection{1 - Produção do coco verde: impactos ambientais e sócio-econômicos}

O Brasil é considerado o quarto maior produtor mundial de coco verde e possui cerca de 280 mil hectares cultivados de coqueiro em todo o território, especialmente na região litorânea do nordeste e norte, que detêm em torno de $75 \%$ de toda a produção nacional (IBGE, 2009).

A FIG.8 mostra a relação da área plantada e o aumento da produção de coco durante as duas últimas décadas. A cocoicultura emprega diretamente cerca de 500 mil pessoas, além dos empregos indiretos gerados ao longo da cadeia (CUENCA, 2007).

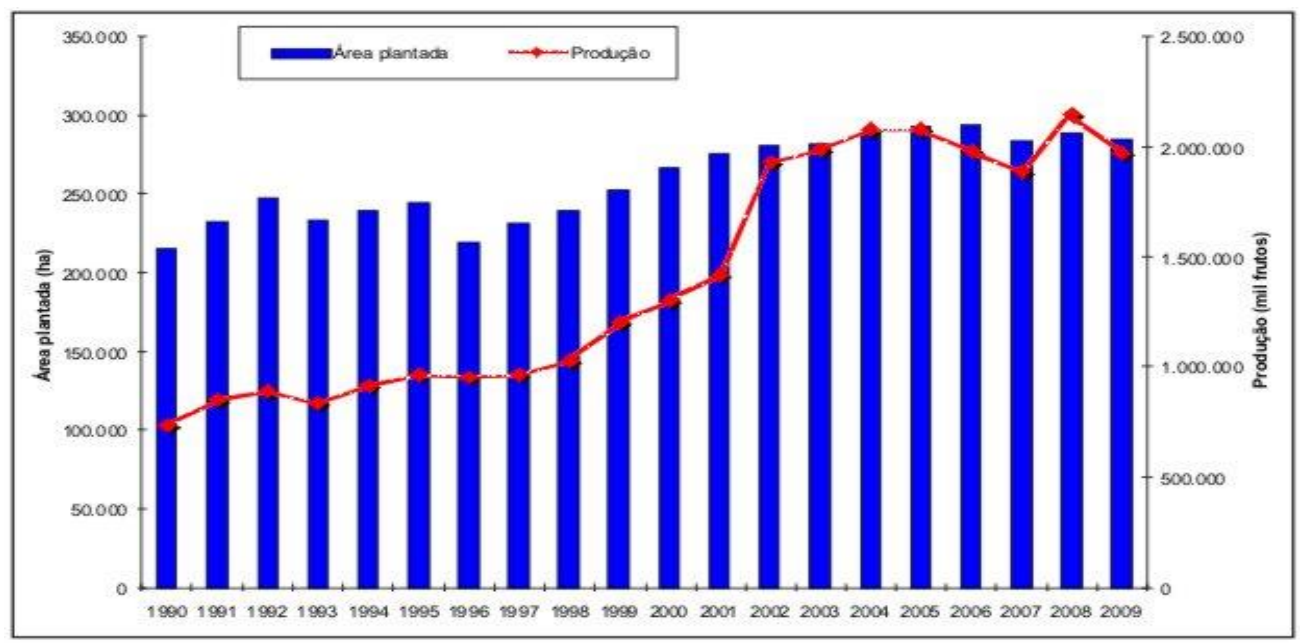

FIGURA 8 - Área plantada e produção de coco no Brasil (1990 a 2009) Fonte: IBGE, 2009 
A produção brasileira de coco é diversificada em três espécies: Gigante (70\%), Anão (20\%) e Híbrido (10\%) (MARTINS e JUNIOR, 2011) e destinada para vários segmentos, conforme é mostrada na FIG.9. Nos últimos anos, grande parte da produção tem sido comercializada para o consumo de água de coco, gerando, desta forma, um aumento de volume dos resíduos da casca, que representa cerca de $85 \%$ do peso bruto. Segundo a Embrapa, aproximadamente $70 \%$ do lixo gerado nas praias brasileiras é de casca de coco verde (CREA, 2010).

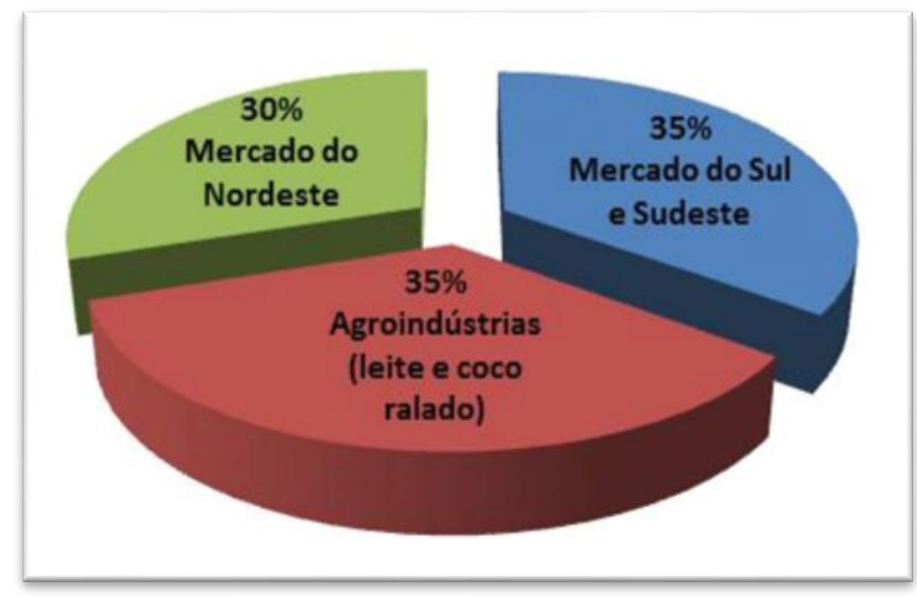

FIGURA 9 - Produção brasileira do coco

Fonte: Adaptação CUENCA, 2002

O resíduo da casca de coco verde quando disposto ao ar livre em lixões ou aterros sanitários gera uma poluição visual pelo volume que ocupa e, devido a sua constituição, a compactação é dificultada. A degradação é lenta gerando o acúmulo de água nas cascas, promovendo assim, a proliferação de vetores e causando sérios riscos à saúde humana, além de outros impactos ambientais (SILVEIRA, 2008).

Alguns estudos têm sido desenvolvidos com o intuito de processar a casca de coco verde e seca para utilizá-la em diversos segmentos, tais como: substrato agrícola, na confecção de calçados, encostos e bancos de veículos, mistura asfáltica e artesanatos em geral, fonte alternativa de energia, fabricação de adesivos e como fertilizante. Em países como a Índia e o Sri Lanka, o beneficiamento da fibra de coco tem sido considerado uma atividade estratégica do ponto de vista econômico (FONTONELE, 2005). 
No Brasil, existem cerca de 15 unidades de processamento de coco. A obtenção do pó e da fibra é feita por meio de uma máquina trituradora, conforme apresentada na FIG.10, em três etapas: a) trituração - esmagamento da parte fibrosa do fruto; b) prensagem - extração mecânica da umidade e dos sais solúveis; c) seleção - peneiramento da fibra, com rendimento de $30 \%$ e o restante para o tratamento térmico (EMBRAPA, 2012).

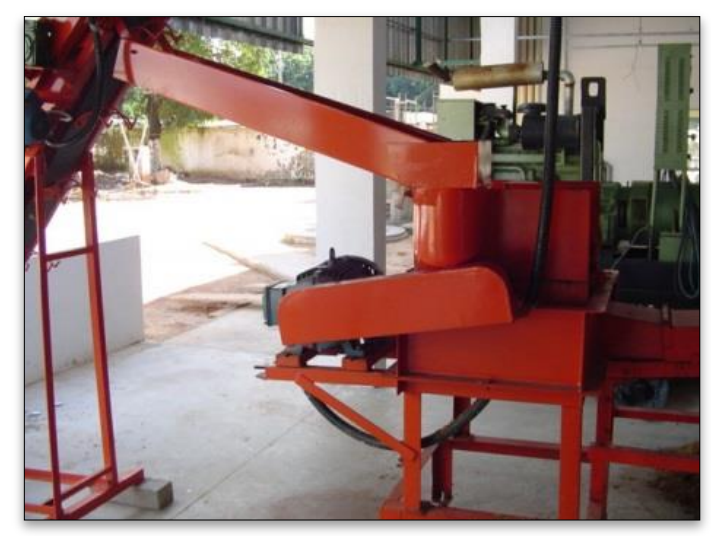

FIGURA 10 : Máquina trituradora da casca de coco Fonte: EMBRAPA, 2012.

\section{4 - Rejeitos radioativos}

Segundo a CNEN-NE 6.05, o rejeito radioativo é definido como "qualquer material resultante das atividades humanas, que contenha radionuclídeos em quantidades superiores aos limites de isenção especificados na Norma CNEN-NE 6.02: "Licenciamento de Instalações Radioativas" e para o qual a reutilização é imprópria ou não prevista." A gerência destes rejeitos deve ser considerada como o "conjunto de atividades administrativas e técnicas envolvidas na coleta, segregação, manuseio, tratamento, acondicionamento, transporte, armazenamento, controle e deposição de rejeitos radioativos." (CNEN, 1985), conforme ilustrado na FIG.11. É digno de nota que a norma CNEN-NE 6.02 foi revogada e substituída pela resolução CNEN-NN-3.01:2011 - DOU 01.09.2011 através da posição regulatória 3.01/001: "Diretrizes básicas de proteção radiológica" (CNEN, 2011). 


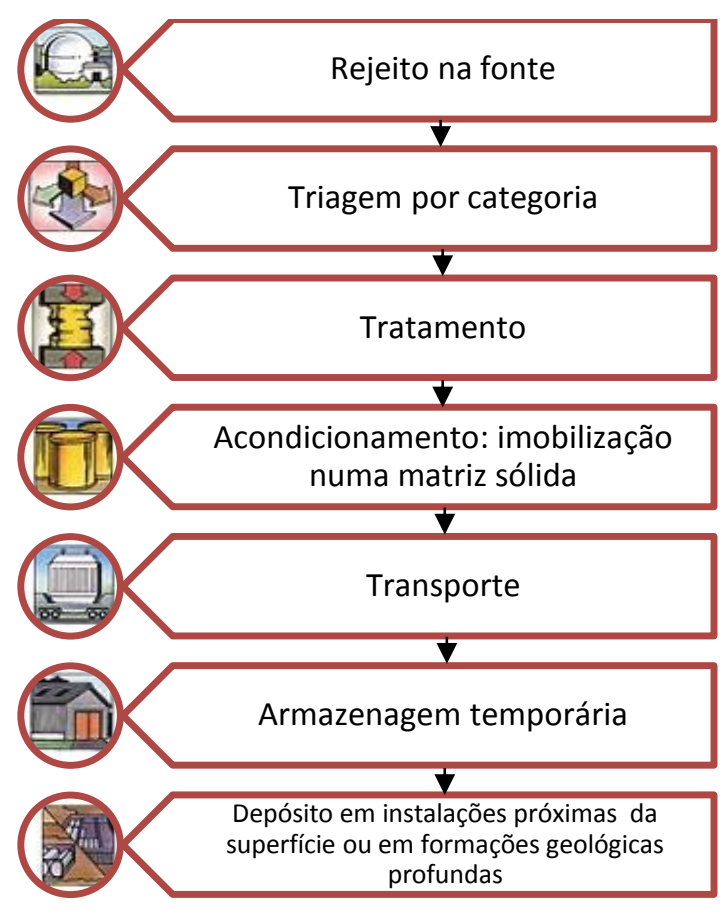

FIGURA 11: Esquema de gerenciamento de rejeitos radioativos Fonte: Adaptação de MARTINHO, 2012

Os rejeitos são classificados segundo o estado físico, natureza da radiação, concentração e taxa de exposição. Os rejeitos líquidos contendo emissores beta, gama e alfa são divididos em categorias de acordo com os níveis de concentração, conforme TAB.3 (CNEN, 1985).

TABELA 3 - Classificação de Rejeitos Líquidos

\section{Categoria Emissores Beta/ Gama Emissores Alfa}

\section{Concentração $\left(\mathrm{Bq} / \mathrm{m}^{3}\right)$}

$\begin{array}{lcc}\text { Baixo Nível de Radiação } & \leq 3,7 \times 10^{10} & 3,7 \times 10^{8} \leq 3,7 \times 10^{10} \\ \text { Médio Nível de Radiação } & >3,7 \times 10^{10} \leq 3,7 \times 10^{13} & >3,7 \times 10^{10} \leq 3,7 \times 10^{13} \\ \text { Alto Nível de Radiação } & >3,7 \times 10^{13} & >3,7 \times 10^{13}\end{array}$

Fonte: Adaptação CNEN, 1985

Consideram-se como baixa e média atividade, os rejeitos resultantes de materiais contaminados durante a operação das unidades radiativas e nucleares tais como: luvas, botas, roupas e instrumentos e também fontes usadas na medicina e indústria com uma meia vida radiativa limitada a 30 anos. Os rejeitos de alta atividade são gerados durante a fissão do urânio nos reatores nucleares e permanecem radioativos por um longo período de tempo. Estes 
rejeitos devem ser segredados, imobilizados e armazenados em repositórios a grande profundidade em terrenos geologicamente selecionados para serem isolados definitivamente do meio ambiente (ALMEIDA, 2010).

A Comissão Nacional de Energia Nuclear (CNEN) estabelece os níveis de concentração máxima permissíveis para a eliminação de rejeitos líquidos em rede de esgoto sanitário, conforme norma vigente.

Os rejeitos radiativos líquidos armazenados na Gerência de Rejeitos Radioativos (GRR) do Instituto de Pesquisas Energéticas e Nucleares (IPEN/CNEN-SP), cujo volume em 2009 era de cerca de 910 litros (DELLAMANO, 2010), são provenientes de diferentes setores geradores que realizam atividades de pesquisa e, principalmente dos processos do reator. Este rejeito é composto por diversos radionuclídeos, dentre eles o césio e o amerício, e estão armazenados em bombonas de polietileno e frascos de vidro, conforme FIG.12.

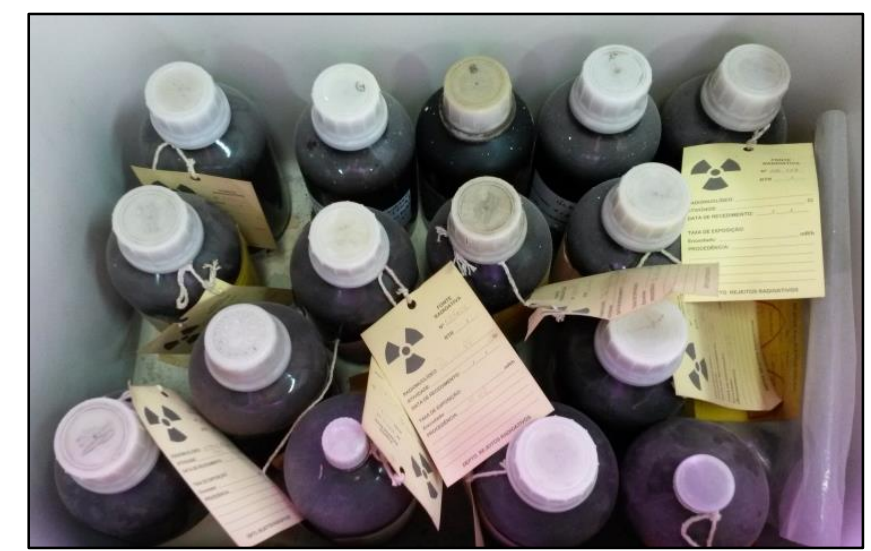

FIGURA 12 : Estocagem de rejeitos líquidos - IPEN

\section{5 - Biossorção}

A biossorção é definida como um processo no qual se utiliza biomassa, sem a atuação do seu metabolismo, para a retenção, remoção ou recuperação de metais pesados e/ou radionuclídeos de soluções aquosas diluídas (VOLESKY, 1994). Este processo envolve uma série de mecanismos como a complexação, quelação, adsorção na superfície da célula por forças físicas, troca iônica e precipitação (VOLESKY, 2004), que dependem do tipo da biomassa. 
ROTHSTEIN et al. (1948) apud VOLESKY (1990), apresentaram os primeiros estudos sobre o mecanismo de biossorção com estudos sobre a adsorção de urânio sobre a superfície de leveduras por meio de complexação. VOLESKY E TSEZOS pesquisaram sobre a biossorção do urânio e tório (VOLESKY, 2007) e impulsionaram um interesse maior nos estudos sobre remoção de materiais tóxicos.

Considerada como uma tecnologia emergente, a biossorção tem ocupado um papel importante em pesquisas científicas pois permite o tratamento de grandes volumes de rejeitos líquidos complexos com baixas concentrações (VEGLIÓ et al., 1997). Mesmo sendo promissora e comprovada em ensaios laboratoriais, ainda há desafios tecnológicos para a implantação em escalas industriais (VIJAYARAGHAVAN e YUN, 2008).

\section{6 - Remoção de metais pesados utilizando biomassa vegetal}

A eficiência da remoção de metais pesados está ligada a fatores que incluem: pH e a concentração do metal pesado na solução, tipo de adsorvente e o tempo de contato da solução com o adsorvente.

$\mathrm{Na}$ biossorção de metais pesados e radionuclídeos, os adsorventes podem ser de origem microbiana, tais como as leveduras (WANG e CHAN, 2006), bolores (KAPOOR, 1999) e bactérias (VIJAYARAGHAVAN e YUN, 2008), ou de origem vegetal (GARG, 2008). Esta última, além de apresentar uma boa capacidade de adsorção e estar de acordo com o conceito de química sustentável, tem se destacado pela possibilidade da utilização dos resíduos da indústria agrícola, o que torna o processo mais barato e, em alguns casos, sem custo. Os primeiros estudos da biossorção de radionuclídeos utilizando biomassa vegetal foram realizados com algas na remoção de íons de urânio em meados de 1980 (VOLESKY, 1999).

Há estudos, descritos na literatura, que relatam o uso dos mais diversos tipos de biomassa vegetal. A seguir são citados alguns deles e os respectivos metais removidos: casca de nozes para cádmio (ORHAN e 
BUYUKGUNGOR, 1993) e cobre (KIM et al., 2001), serragem para níquel (AJMAL et al., 1998), casca de amendoim para cádmio (BROWN et al., 2000) e cobre (JOHNSON, et al., 2002), resíduo de cenoura para cobre, zinco e cromo (NASERNEJAD et al., 2005), casca de arroz para cádmio (SINGH et al., 2005), mandioca para cádmio, cobre e zinco (JUNIOR et al., 2007), alface para ferro e arsênio (SILVA, 2008), bagaço de laranja para chumbo, cobre, níquel e zinco (MONTANHER, 2009), casca de banana para urânio (BONIOLO et al., 2010).

Para aumentar a eficiência da adsorção do metal, tem se observado, nos últimos anos, vários estudos que envolvem a modificação química do adsorvente de origem vegetal. $O$ tratamento com diferentes tipos de agentes modificadores como ácidos orgânicos e inorgânicos além de bases e agentes oxidantes, pode degradar parte da lignina, a hemicelulose e outros compostos orgânicos solúveis, aumentando a porosidade e a área superficial e assim promovendo uma melhor adsorção do metal em estudo (NGAH e HANAFIAH, 2008). É necessário considerar também a viabilidade desses tratamentos químicos em relação ao aumento do potencial de adsorção da biomassa e os possíveis impactos ambientais que podem ser gerados.

A modificação da biomassa de polpa de azeitonas feita com peróxido de hidrogênio $\left(\mathrm{H}_{2} \mathrm{O}_{2}\right)$ e ácido fosfórico $\left(\mathrm{H}_{3} \mathrm{PO}_{4}\right)$ foi utilizada por MARTíN-LARA et al. (2008), para oxidar grupos hidroxil a carboxil e incorporar grupos fosfato aumentando a eficiência na retenção de íons cobre (II) e cádmio (II).

MEMON et al (2008), compararam a eficiência de adsorção de íons Cd (II) em cascas de banana in natura e modificada por um processo de esterificação com metanol e ácido clorídrico. Os melhores resultados foram obtidos com o uso da biomassa in natura, o que demonstra que os grupos carboxílicos e íons carboxilados apresentam maior afinidade por cátions metálicos do que grupos ésteres. Agentes alcalinos como $\mathrm{NaOH}, \mathrm{Ca}(\mathrm{OH})_{2}$ e $\mathrm{KOH}$ são usados principalmente para converter grupos ésteres em carboxílicos por meio de reações de saponificação ou para a desprotonação de sítios ativos, aumentando, desta forma, a porcentagem de remoção (NASIR et al, 2007). 


\section{7 - Remoção de metais pesados utilizando fibra de coco}

O coco verde tem sido usado como biomassa na remoção de metais pesados devido ao alto teor de matéria orgânica, principalmente lignina e celulose, que são biopolímeros que conferem resistência e flexibilidade ao fruto (GABALLAH e KILBERTUS, 1994).

Recentemente MONTEIRO (2009) realizou uma série de estudos de biossorção utilizando a fibra de coco na remoção de urânio, tório, chumbo, zinco e níquel. A fibra de coco atingiu o equilíbrio de adsorção em apenas 5 minutos de contato e a remoção foi de cerca de $90 \%$ para o urânio, de $80 \%$ para o tório e de $60 \%$ para o chumbo, sendo menos eficiente para o zinco e o níquel, com remoção de $40 \%$ e $25 \%$, respectivamente.

Segundo PINO (2005), a fibra de coco também pode ser usada para adsorver cádmio e cromo (III e VI) que, nos estudos realizados, apresentaram uma taxa de remoção de cerca de $99 \%, 90 \%$ e $86 \%$ respectivamente. Para o arsênio (V), o estudo indicou uma baixa afinidade com a biomassa.

SOUZA et al. (2007), utilizaram o pó da casca de coco tratada com 0,1 mol. $L^{-1}$ de $\mathrm{NaOH}$ para remover chumbo em cerca de $99,5 \%$, níquel $(86 \%)$, cádmio $(97,5 \%)$, zinco $(90 \%)$ e cobre $(97,9 \%)$ presentes nos efluentes aquosos. O equilíbrio multielementar foi atingido em 5 minutos. Os estudos também foram realizados em coluna de leito fixo demonstrando uma porcentagem maior de remoção para todos os metais.

PARAB et al. (2006) estudaram a remoção separada e em conjunto dos íons $\mathrm{Co}(\mathrm{II}), \mathrm{Cr}$ (III) e Ni(II) com fibra de coco bruta. A quantidade máxima de adsorção foi de $12,82 \mathrm{mg} \cdot \mathrm{g}^{-1}, 11,56 \mathrm{mg} \cdot \mathrm{g}^{-1}$, e $15,95 \mathrm{mg} \cdot \mathrm{g}^{-1}$, respectivamente. SHUKLA (2006), verificou o potencial de remoção dos íons Ni (II), Zn (II) e Fe (II) utilizando a fibra de coco bruta e tratada com peróxido de hidrogênio, obtendo os melhores resultados de adsorção com a fibra de coco tratada. A quantidade removida foi cerca de $3 \mathrm{mg} \cdot \mathrm{g}^{-1}, 6,5 \mathrm{mg} \cdot \mathrm{g}^{-1} \mathrm{e} 7 \mathrm{mg} \cdot \mathrm{g}^{-1}$, respectivamente, em 120 minutos de tempo de contato. 
O carvão ativado, obtido da carbonização da fibra de coco, também já foi estudado por KADIRVELU et al. (2001) na adsorção de Ni(II), com capacidade de remoção de $62,5 \mathrm{mg} \cdot \mathrm{g}^{-1}$ para 40 minutos de tempo de contato e Cd (II), cerca de $80 \mathrm{mg} \cdot \mathrm{g}^{-1}$ de remoção após 60 minutos de tempo de contato (KADIRVELU e NAMASIVAYAM, 2003).

\section{8 - Métodos de Remoção de ${ }^{137}$ Cs em soluções aquosas}

Na literatura há descrição do uso de diversas tecnologias que propõem o tratamento de rejeitos radioativos líquidos, a troca iônica têm sido um dos mais promissores pois permite o uso de materiais inorgânicos e adsorventes (DANILIN, 2007). Para a remoção de césio, já foram aplicados diversos tipos de materiais, conforme é mostrado na TAB.4.

TABELA 4 - Diferentes métodos de remoção para o ${ }^{137} \mathrm{Cs}$

\begin{tabular}{lccc}
\hline \multicolumn{1}{c}{ Material } & $\begin{array}{c}\text { Quantidade } \\
\text { removida/ } \\
\text { taxa de remoção }\end{array}$ & $\begin{array}{c}\text { Tempo de } \\
\text { contato }\end{array}$ & Referência \\
\hline Magnetita & $0,4 \mu \mathrm{mol} / \mathrm{m}^{2}$ & $3 \mathrm{~d}$ & EBNER et al. 2001 \\
\hline $\begin{array}{l}\text { Compostos } \\
\text { de sílica-magnetita }\end{array}$ & $1,5 \mu \mathrm{mol} / \mathrm{m}^{2}$ & $3 \mathrm{~d}$ & EBNER et al. 2001 \\
\hline $\begin{array}{l}\text { Colunas de leito fixo } \\
\text { de zeólita }\end{array}$ & $70 \mathrm{mg} \cdot \mathrm{g}^{-1}$ & $\begin{array}{c}90 \mathrm{e} \\
120 \mathrm{~min} .\end{array}$ & EL-KAMASH, 2008 \\
\hline $\begin{array}{l}\text { Silicotitanato } \\
\text { cristalino (CST) }\end{array}$ & $70,4 \mathrm{mg} \cdot \mathrm{g}^{-1}$ & $24 \mathrm{~h}$ & TODD et al. 2005 \\
\hline $\begin{array}{l}\text { Molibdofosfato de } \\
\text { amônio -poliacrilo- } \\
\text { nitrila (AMP-PAN) }\end{array}$ & $85 \mathrm{mg} \cdot \mathrm{g}^{-1}$ & $24 \mathrm{~h}$ & TODD et al. 2005 \\
\hline $\begin{array}{l}\text { AMP granulado com } \\
\text { polímero de alginato } \\
\text { de cálcio em gel }\end{array}$ & $96 \%$ & $3 \mathrm{~h}$ & MIMURA et al. 2001 \\
\hline $\begin{array}{l}\text { PAN modificada com } \\
\text { hexacianoferrato de } \\
\text { potássio, cobre e } \\
\text { níquel (KCNF) }\end{array}$ & $97 \%$ & $2 \mathrm{~h}$ & NILCHI et al. 2007 \\
\hline $\begin{array}{l}\text { AMP-PAN } \\
\text { AMP-PAN }\end{array}$ & $32 \mathrm{~g} \cdot \mathrm{kg}^{-1}$ & $48 \mathrm{~h}$ & TRANTER et al. 2002 \\
\hline
\end{tabular}




\section{9 - Métodos de Remoção de ${ }^{241} \mathrm{Am}$ em soluções aquosas}

Para o amerício, há estudos de adsorção de soluções aquosas que relatam o uso de diversas biomassas vegetais e materiais inorgânicos também, conforme é mostrado na TAB.5.

TABELA 5 - Diferentes métodos de remoção para o ${ }^{241} \mathrm{Am}$

\begin{tabular}{lccl}
\hline \multicolumn{1}{c}{ Material } & $\begin{array}{c}\text { Quantidade } \\
\text { removida }\end{array}$ & $\begin{array}{c}\text { Tempo de } \\
\text { contato }\end{array}$ & Referência \\
\hline $\begin{array}{l}\text { Carvão vegetal de } \\
\text { madeira }\end{array}$ & $80 \%$ & $* * 30 \mathrm{~d}$ & MIRÓ et al. 2008 \\
\hline $\begin{array}{l}\text { Saccharomyces } \\
\text { cerevisiae }\end{array}$ & $90 \%$ & $16 \mathrm{~h}$ & LIU et al. 2008 \\
\hline $\begin{array}{l}\text { Rhizopus arrhizus } \\
\text { Rhizopus arrhizus }\end{array}$ & $\begin{array}{c}* \\
\text { Rh.900 }\end{array}$ & $3 \mathrm{~h}$ & DHAMI et al. 2002 \\
\hline $\begin{array}{l}\text { Rhizopus arrhizus } \\
\text { com alginato de } \\
\text { cálcio/CaCl } 2\end{array}$ & $86 \%$ & $2 \mathrm{~h}$ & LIAO et al. 2008 \\
\hline $\begin{array}{l}\text { Rhizopus arrhizus } \\
\text { com formaldeido } \\
\text { /HCl }\end{array}$ & $99 \%$ & $3 \mathrm{~h}$ & TRIPATHI et al. 2011 \\
\hline $\begin{array}{l}\text { Oxalato de tório em } \\
\text { matriz de gel sílica } \\
\text { em meio ácido }\end{array}$ & $* 77.500$ & $3 \mathrm{~h}$ & TRIPATHI et al. 2011 \\
$\begin{array}{l}\text { Membrana } \\
\text { surfactante líquida } \\
\text { (LSM) }\end{array}$ & $93 \%$ & 30 min & KEDARI et al. 2010 \\
$\begin{array}{l}{ }^{*} \text { Estes valores são referentes ao Kd (coeficiente de distribuição) } \\
* * \text { Tempo de contato antes da medição }\end{array}$ &
\end{tabular}

\subsection{0 - Fundamentos sobre o processo de adsorção}

A adsorção é um fenômeno físico-químico que ocorre na superfície do adsorvente e é observado em uma das etapas do processo de biossorção em que ocorre a interação da biomassa que contém o íon do líquido. A afinidade do adsorvente pelas espécies permitirá, por diferentes mecanismos, a captura e dissolução dos íons até que o equilíbrio seja estabelecido (VOLESKY, 2004).

Este processo pode ocorrer de duas formas, conforme é mostrado na TAB.6: adsorção física - observam-se interações fracas de Van der Waals entre o 
sorvente e o íon; e a adsorção química - quando há a formação seletiva de ligações químicas mais fortes que depende das substâncias envolvidas.

TABELA 6 - Diferenças entre os tipos de adsorção

\begin{tabular}{|c|c|}
\hline Adsorção física & Adsorção química \\
\hline Baixo calor de adsorção & Alto calor de adsorção \\
\hline Não é específica & Altamente específica \\
\hline $\begin{array}{l}\text { Não há dissociação das espécies } \\
\text { adsorvidas }\end{array}$ & Pode ocorrer dissociação \\
\hline Ocorre em baixas temperaturas & Ocorre em altas temperaturas \\
\hline $\begin{array}{l}\text { Processo rápido e reversível, não } \\
\text { depende de ativação }\end{array}$ & $\begin{array}{l}\text { Depende de ativação e pode ser lenta } \\
\text { e irreversível }\end{array}$ \\
\hline $\begin{array}{l}\text { Não há transferência de elétrons, } \\
\text { mas pode ocorrer uma polarização }\end{array}$ & $\begin{array}{l}\text { Há transferência de elétrons e } \\
\text { formação de ligações químicas }\end{array}$ \\
\hline
\end{tabular}

\subsection{1 - Isotermas de adsorção}

A isoterma de adsorção é uma expressão matemática que relaciona o equilíbrio entre a quantidade do material adsorvido e a concentração desse material na solução (VOLESKY, 2004).

Graficamente, as isotermas podem ser representadas pelas formas côncava, convexa, e linear, conforme ilustradas na FIG.13. A forma côncava é considerada desfavorável porque para grandes concentrações de íons na solução há uma menor quantidade de íons no material adsorvente. A forma convexa é considerada favorável, indicando que a capacidade de adsorção aumenta com a concentração. A forma linear demonstra que o aumento de íons no material adsorvente é proporcional ao aumento da concentração de íons na solução (SANHUEZA, 2013). 


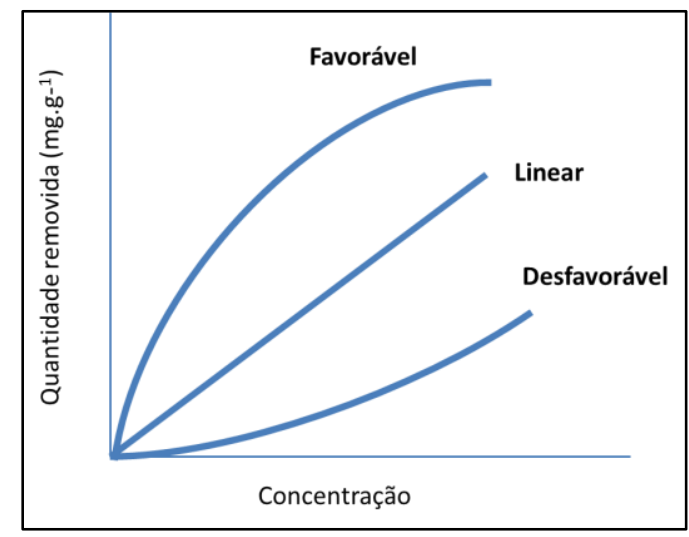

FIGURA 13 - Formas de isotermas

Os modelos de isotermas de adsorção de Langmuir e Freundlich são os mais utilizados nos estudos de biossorção (WEBER Jr. 1974). As representações estão a seguir:

\section{Modelo de Langmuir:}

$$
Q_{\text {eq }}=\frac{Q K_{L} C_{e q}}{1+K_{L} C_{e q}}
$$

Forma linearizada:

$$
\frac{C_{e q}}{Q_{e q}}=\frac{C_{e q}}{Q}+\frac{1}{\left(Q K_{L}\right)}
$$

Sendo:

$\mathrm{Q}_{\text {eq }}$ - quantidade de soluto adsorvido no adsorvente (mg.g ${ }^{-1}$ )

$\mathrm{C}_{\text {eq }}$ - concentração de adsorvato $\left(\mathrm{mg} \cdot \mathrm{L}^{-1}\right)$ na solução

$\mathrm{Q}$ - capacidade máxima de adsorção $\left(\mathrm{mg} \cdot \mathrm{g}^{-1}\right)$

$\mathrm{K}_{\mathrm{L}}$ - constante de adsorção de Langmuir (L.mg $\left.{ }^{-1}\right)$

O modelo de Langmuir utiliza o conceito do equilíbrio de adsorção na qual há igualdade entre as velocidades de adsorção e dessorção. Além disso, considera que o fenômeno ocorre em monocamada e em superfície homogênea com um número fixo de posições de adsorção, ou seja, cada sítio pode acomodar somente uma molécula adsorvida (RUTHVEN, 1984). 
O processo de adsorção pode ser determinado por meio da equação 3 . O valor de $\mathrm{RL}$ é o parâmetro de equilíbrio, prevê a forma da isoterma.

$$
R L=\frac{1}{\left(1+K_{L} C_{i}\right)}
$$

Se o valor de RL for maior que 1 o processo é desfavorável, se for igual a 1 é linear; e igual a 0 é irreversível. Portanto, o processo só é favorável se for menor que 1 e maior que 0 (PERGHER, 2005).

\section{Modelo de Freundlich}

$$
Q_{e q}=K_{F} C_{e q}^{1 / n}
$$

Forma linearizada

$$
\log Q_{e q}=\frac{1}{n} \cdot \log C_{e q}+\log K_{F}
$$

Sendo:

$\mathrm{K}_{\mathrm{F}}$ - constante de adsorção de Freundlich $\left(\mathrm{L} \cdot \mathrm{g}^{-1}\right)$

$1 / \mathrm{n}$ - fator de heterogeneidade

$\mathrm{C}_{\mathrm{eq}}$ - concentração de adsorvente $\left(\mathrm{mg} \cdot \mathrm{L}^{-1}\right)$ na solução

$\mathrm{Q}_{\mathrm{eq}}$ - capacidade máxima de adsorção $\left(\mathrm{mg} \cdot \mathrm{g}^{-1}\right)$

O valor de $\mathrm{n}$ é calculado pelo coeficiente angular da reta e deve ser maior do que 1 , indicando um processo de adsorção favorável. $\mathrm{O}$ valor de $\mathrm{K}_{\mathrm{F}}$ é obtido pelo coeficiente linear (ORTIZ, 2000).

Este modelo empírico proposto por Freundlich pode ser aplicado em sistemas não ideais com superfícies heterogêneas e adsorção em multicamadas, caracterizado pela distribuição exponencial (RUTHVEN, 1984). 


\subsection{2 - Cinética de adsorção e parâmetros termodinâmicos}

O estudo sobre a cinética de adsorção permite identificar a ordem de reação do sistema e contribui para o entendimento dos mecanismos de adsorção, que dependem, de características físicas e químicas do adsorvente e do adsorvato e, da interação que há entre eles. Este processo pode ser representado por uma sequência de passos, conforme apresentado na FIG.14. O transporte do adsorvato da fase aquosa para o filme que envolve o adsorvente não é considerado como limitante pois a agitação evita um gradiente de concentração na solução e a retenção nos sítios ativos é vista como um mecanismo instantâneo. A difusão externa, associada à velocidade inicial do processo, e a difusão intrapartícula, que pode ocorrer de forma mais lenta devido à natureza do adsorvente, são consideradas as etapas controladoras do processo de adsorção (MONTANHER et al. 2007).

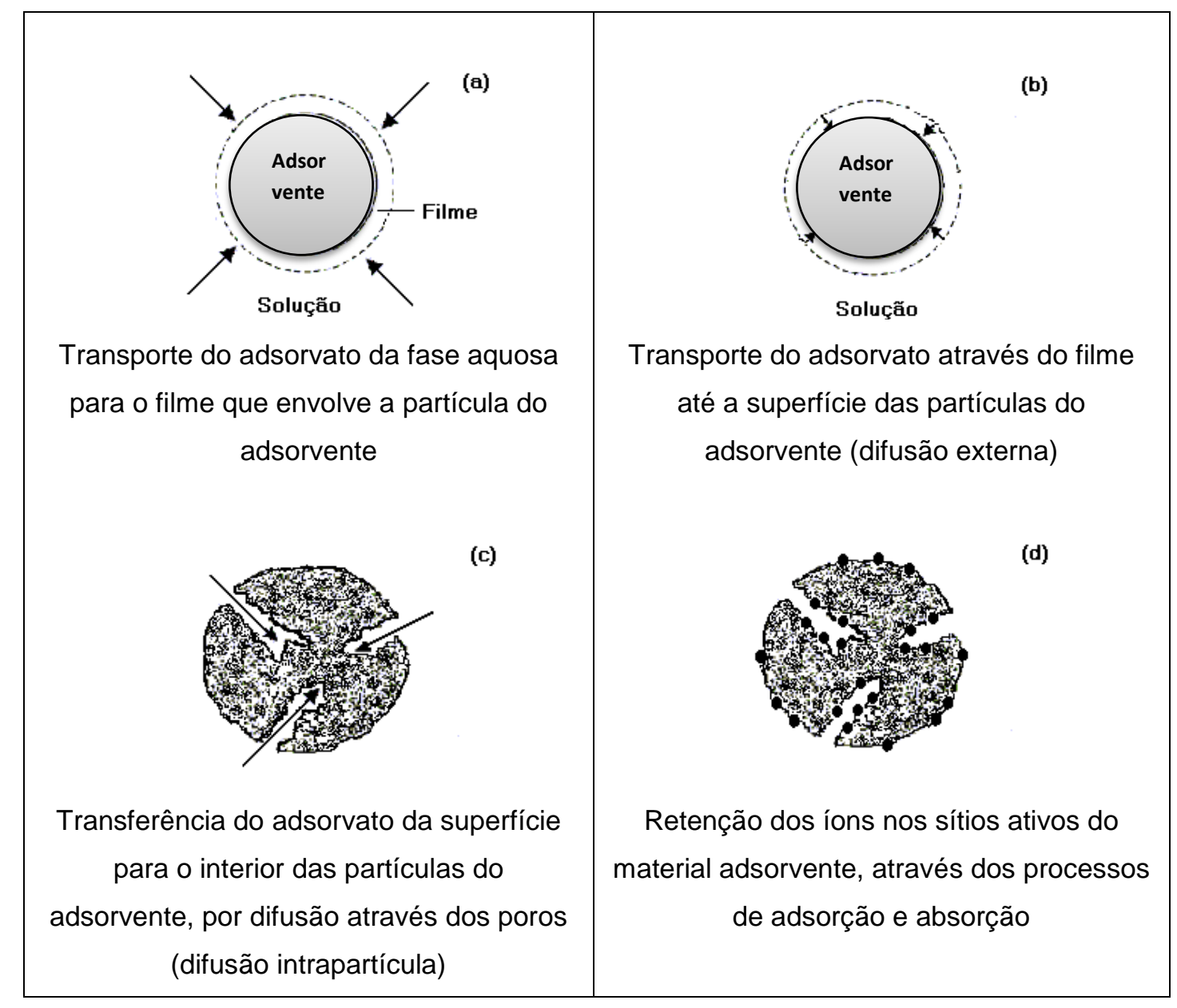

FIGURA 14: Processo de adsorção

Fonte: Adaptação - MONTANHER et al. 2007 
Os modelos de Lagergren de pseudo-primeira e de pseudo-segunda ordem são os mais utilizados para determinar a taxa de sorção de um sorvato em uma solução.(GOTTIPATI e MISHRA, 2010) As equações 6 e 7 representam os modelos:

\section{Modelo de pseudo-primeira ordem}

$$
\ln \left(Q_{e q}-Q_{t}\right)=\ln Q_{e q}-K_{1} t
$$

Sendo:

$\mathrm{K}_{1}$ - constante de velocidade da reação $\left(1 . \mathrm{min}^{-1}\right)$

$\mathrm{Q}_{\mathrm{eq}}$ - quantidade adsorvida no equilíbrio $\left(\mathrm{mg} \cdot \mathrm{g}^{-1}\right)$

$\mathrm{Q}_{\mathrm{t}}$ - quantidade do adsorvato em qualquer tempo $\mathrm{t}\left(\mathrm{mg} \cdot \mathrm{g}^{-1}\right)$

$\mathrm{t}$ - tempo de contato (min.)

\section{Modelo de pseudo-segunda ordem}

$$
\frac{t}{Q_{t}}=\frac{1}{K_{2} Q^{2}}+\frac{1}{Q} t
$$

Sendo:

$\mathrm{K}_{2}$ - constante de velocidade da reação $\left(\mathrm{g} \cdot \mathrm{mg}^{-1} \cdot \mathrm{min}^{-1}\right)$

$\mathrm{Q}$ - quantidade teórica de remoção ( $\left.\mathrm{mg} \cdot \mathrm{g}^{-1}\right)$

$\mathrm{Q}_{\mathrm{t}}$ - quantidade do adsorvato em qualquer tempo $\mathrm{t}\left(\mathrm{mg} \cdot \mathrm{g}^{-1}\right)$

$\mathrm{t}$ - tempo de contato (min.)

Este modelo cinético prediz o comportamento da adsorção durante todo o intervalo de tempo estudado. Os valores de $Q$ e $K_{2}$ são obtidos, respectivamente, pelo coeficiente angular e linear, por meio da linearização do gráfico $t / Q_{t}$ em função de $t$.

Outro parâmetro estudado no processo de adsorção é a energia livre de Gibbs $(\Delta G)$ que demonstra que, se a temperatura e a pressão permanecerem constantes, é possível predizer se um processo é espontâneo somente em termos 
das propriedades termodinâmicas do sistema. As reações são espontâneas quando o valor de $\Delta \mathrm{G}$ é negativo. (ATKINS, 2006).

$$
\Delta G=-R T \ln \left(K_{L}\right)
$$

Sendo:

$\mathrm{R}=$ constante universal dos gases perfeitos $8.314 \mathrm{~J} \cdot \mathrm{K}^{-1} \cdot \mathrm{mol}^{-1}$

$\mathrm{T}=$ temperatura absoluta em kelvin $(\mathrm{K})$

$\mathrm{K}_{\mathrm{L}}=$ constante de Langmuir $\left(\mathrm{L} . \mathrm{mol}^{-1}\right)$

O valor da energia livre de Gibbs permite identificar o tipo de processo de adsorção. Valores de $\Delta \mathrm{G}$ maiores que $|20| \mathrm{kJ}$ indicam adsorção química, valores inferiores, indicam a adsorção física.

\subsection{3 - Coeficiente de distribuição $\left(K_{d}\right)$}

O coeficiente de distribuição é um importante parâmetro para estimar o potencial de adsorção e é uma massa ponderada do coeficiente de partição entre a fase líquida sobrenadante da fase sólida (YANTASSE et al, 2007; FRYXELL et al, 2005), como é apresentado na equação 9. Portanto, o $K_{d}$ representa a concentração de cátions adsorvidos no adsorvente em relação à concentração remanescente em solução (PARK et al, 2010).

$$
K_{d}=\frac{\left(C_{i}-C_{f}\right)}{C_{f}} x \frac{V}{M}
$$

Sendo:

$\mathrm{C}_{\mathrm{i}}$ e $\mathrm{C}_{\mathrm{f}}-$ concentrações inicial e final da solução

$\mathrm{V}$ - volume da solução (L)

$\mathrm{M}$ - massa do sorvente $(\mathrm{kg})$

Quanto maior o valor de $\mathrm{K}_{\mathrm{d}}$, mais eficaz o material adsorvente é na remoção das espécies metálicas da solução. 


\section{4) METODOLOGIA}

\section{1 - Materiais}

Os experimentos foram realizados nas instalações da Gerência de Rejeitos Radioativos (GRR), com exceção das análises de espectrometria de infravermelho que foram realizadas no Instituto de Química (IQ-USP), as análises de microscopia de varredura eletrônica, realizadas no Centro Tecnológico da Marinha (CTM-SP) e as análises de difratometria de raios- $X$, realizadas no Centro de Química e Meio Ambiente (CQMA-IPEN).

\subsection{1- Reagentes}

Todos os reagentes são comerciais e foram utilizados conforme descrito: peróxido de hidrogênio $50 \%$ da Sigma Aldrich para a ativação da biomassa vegetal; ácido nítrico $65 \%$ ácido clorídrico da Alphatec para preparação das amostras para análise e ajuste de pH; cloreto de césio estável, da Fluka, para preparação da solução estoque para os experimentos de biossorção e da marca Merckmillipore para a preparação dos padrões de análise de espectrometria de emissão óptica por plasma acoplado indutivamente (ICP-OES); hidróxido de sódio da marca Vetec para ativação da biomassa e ajuste de pH; cloreto de amerício 241 (3 MBq. $\mathrm{g}^{-1}$ ) proveniente do Instituto de Radioproteção e Dosemetria (IRD), certificado 17L13, para os experimentos de biossorção.

\subsection{2- Equipamentos}

As análises de ${ }^{133} \mathrm{Cs}$ foram realizadas em um espectrômetro de emissão óptica por plasma acoplado indutivamente (ICP-OES) da marca Perkin Elmer modelo Optima 7000DV. As análises de ${ }^{241} \mathrm{Am}$ foram realizadas em um espectrômetro de radiação gama da marca Canberra, modelo GX2518A.

Os espectros de infravermelho com transformada de Fourier (FT-IR) foram obtidos em um equipamento da marca Bomem, modelo MB100. A 
espectroscopia no infravermelho é uma técnica de análise química que fornece evidências da presença de vários grupos funcionais na estrutura orgânica devido à interação das moléculas ou átomos com a radiação eletromagnética em um processo de vibração molecular. (PAVIA, 2010)

A estrutura morfológica da fibra de coco foi obtida em microscópio de varredura eletrônica (MEV) da marca FEI, modelo INSPECT S50, acoplado a espectrômetro de energia dispersiva (EDS). A análise consiste na formação de imagens eletrônicas por meio da incidência de um feixe de elétrons na amostra sob condições de vácuo. As imagens podem ter um aumento em até $2 \times 10^{5}$.

A difratometria de raios- $X$ utilizada para a caracterização da estrutura cristalina e amorfa da fibra de coco foi realizada em equipamento da marca Rigaku, modelo MiniFlex II Desktop X-Ray Diffractometer. A difratometria de raios$X$ é uma das principais técnicas utilizadas para a caracterização estrutural de materiais cristalinos e semicristalinos e seus arranjos moleculares. Os raios- $X$ são gerados quando uma partícula carregada de alta energia cinética é rapidamente desacelerada. O método mais utilizado para gerar a emissão de raios- $X$ é permitir que elétrons de alta energia colidam com um alvo metálico, aumentando a diferença de potencial entre os terminais do tubo e consequentemente sua intensidade e as faixas de comprimento de onda, produzindo, desta forma, um espectro característico do elemento alvo.

Para a preparação da biomassa foram utilizados um agitador e uma manta aquecedora da marca Fisatom, peneiras de granulometria da marca Granutest, balança analítica da marca Micronal, modelo B4000, lâmpada germicida UV, microprocessador da marca Chopper e estufa Fanem modelo 315 SE. Para os ensaios de biossorção foi utilizada uma mesa agitadora da marca Nova Técnica.

\section{2 - Método de preparação da biomassa}

A fibra de coco (Cocos nucifera L.) da marca West Garden foi adquirida no comércio local. A biomassa foi lavada com água destilada e seca em estufa a 
$80^{\circ} \mathrm{C}$ por 24 horas, esterilizada em luz UV por 2 horas, triturada em microprocessador e em seguida separada por meio de peneiras granulométricas entre as seguintes malhas mesh: $35-50(0,500 \mathrm{~mm}$ a 0,297 mm) e 50-80 (0,297 $\mathrm{mm}$ a $0,177 \mathrm{~mm})$.

\subsection{1 - Ativação com peróxido de hidrogênio em meio alcalino.}

A ativação da fibra de coco foi realizada segundo o método descrito por SHUKLA et al. (2009). Para cada $10 \mathrm{~g}$ de biomassa foi adicionada uma solução contendo $200 \mathrm{ml}$ de água destilada, $1,5 \mathrm{~g}$ de peróxido de hidrogênio (50\%) e 0,1 g de hidróxido de sódio em pastilhas. A mistura foi submetida à agitação constante em pH próximo de 11,5 por $2 \mathrm{~h}$ a $85^{\circ} \mathrm{C}$. Após este tempo de contato, a biomassa foi filtrada a vácuo e lavada três vezes com $50 \mathrm{ml}$ de água destilada quente e três vezes com $50 \mathrm{ml}$ de água destilada fria com posterior secagem em estufa por 24 h a $80^{\circ} \mathrm{C}$.

Após a lavagem, o pH da água restante foi medido, sendo descartada após atingir o $\mathrm{pH}$ neutro.

\subsection{2 - Preparação das soluções}

As soluções de ${ }^{241} \mathrm{Am}$ foram preparadas a partir da diluição, com água deionizada, da solução estoque de $3 \mathrm{MBq} \cdot \mathrm{g}^{-1}$ de $\mathrm{AmCl}_{3}$. As soluções de $\mathrm{CsCl}$ estável utilizadas nos experimentos foram preparadas a partir da solução estoque de $133 \mathrm{mg} \cdot \mathrm{L}^{-1}\left(1 \mathrm{~mol} \cdot \mathrm{L}^{-1}\right)$.

$\mathrm{O} \mathrm{pH}$ das soluções foi ajustado com ácido clorídrico $\left(0,1 \mathrm{~mol} / \mathrm{L}^{-1}\right) \mathrm{e}$ hidróxido de sódio $\left(0,4\right.$ mol. $\left.\mathrm{L}^{-1}\right)$ quando necessário.

\section{3 - Processo de biossorção}

Para os experimentos de biossorção foram realizados estudos de comparação entre a biomassa bruta e ativada. Para os experimentos foram 
utilizados frascos de $20 \mathrm{ml}$ de polietileno ou vidro. A biomassa foi colocada em com $5 \mathrm{ml}$ da solução do íon do metal em estudo, sob agitação constante à temperatura ambiente e em triplicata, conforme ilustrado na FIG.15. Após o contato, as soluções foram filtradas em papel de filtro quantitativo e a quantidade de íons remanescentes na solução foi analisada por métodos espectroscópicos.

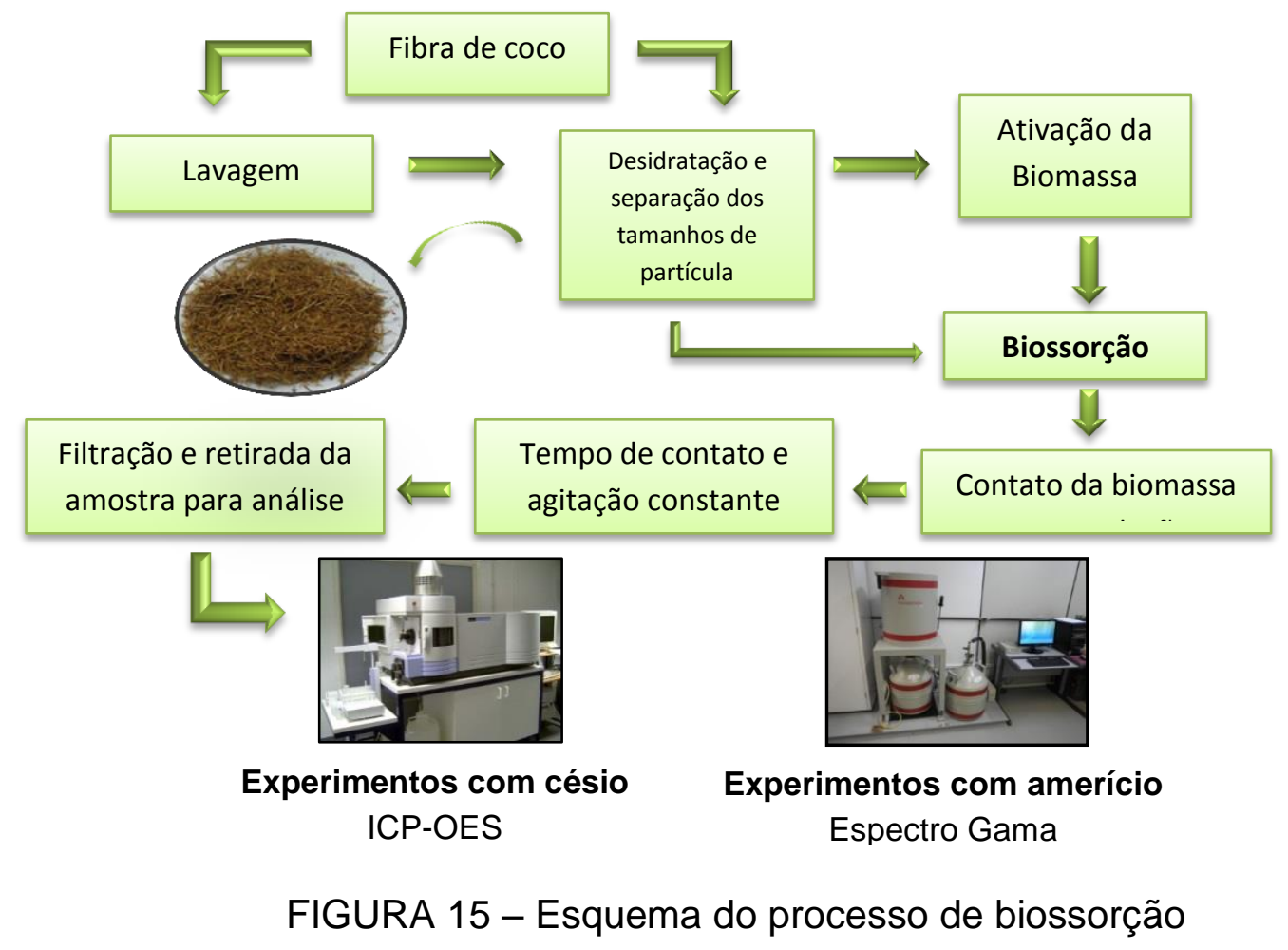

Os rejeitos da fibra de coco gerados durante os experimentos foram segregados para posterior compactação.

A quantidade de cátions em $\mathrm{mg}$ biossorvidos pela biomassa em $\mathrm{g} \mathrm{e}$ a eficiência de biossorção foram calculadas utilizando-se as equações 10 e 11 , respectivamente:

$$
\begin{aligned}
& Q_{e q}=\left(\frac{C_{i}-C_{f}}{M}\right) V \\
& E(\%)=\left(1-\frac{C_{f}}{C_{i}}\right) x 100
\end{aligned}
$$


Sendo:

$\mathbf{Q}_{\mathrm{eq}}$ - quantidade de cátion biossorvido $\left(\mathrm{mg} \cdot \mathrm{g}^{-1}\right)$

$\mathbf{C}_{\mathbf{i}}$ - concentração inicial do cátion $\left(\mathrm{mg}^{-\mathrm{L}^{-1}}\right)$

$\mathbf{C}_{\mathrm{f}}$ - concentração final ou de equilíbrio do cátion $\left(\mathrm{mg} \cdot \mathrm{L}^{-1}\right)$

M - massa da biomassa (g)

V - volume da solução (L)

E - eficiência de biossorção (\%).

\subsection{1 - Biossorção do ${ }^{133} \mathrm{Cs}$}

Foram realizados os estudos da influência dos seguintes parâmetros na biossorção do ${ }^{133} \mathrm{Cs}$ : $\mathrm{pH}$ e concentração da solução, tempo de contato e tamanho de partícula da biomassa das fibras de coco bruta e ativada.

Os estudos da influência do $\mathrm{pH}$ foram realizados com uma solução de $13 \mathrm{mg} \cdot \mathrm{L}^{-1}$ em meio ácido $(3,5)$, neutro $(7,0)$ e alcalino $(9,5)$ em 45 minutos de contato e $0,1 \mathrm{~g}$ de biomassa de malha mesh entre 35 e 50.

Os tempos de contato da biomassa com a solução de césio de 13 $\mathrm{mg} \cdot \mathrm{L}^{-1}$ com pH alcalino foram analisados em 10, 20, 30, 60 e 120 minutos e 0,1 g de biomassa de biomassa de malha mesh entre 35 e 50.

A influência do tamanho da partícula da biomassa, utilizando-se as peneiras com malha mesh entre 35-50 e 50-80, foi analisada usando-se uma solução de $13 \mathrm{mg} \cdot \mathrm{L}^{-1}$ em meio alcalino com os tempos de contato de 10, 20, 45 e 60 minutos e com $0,1 \mathrm{~g}$ de biomassa.

Para os estudos da influência da concentração e das isotermas, a solução estoque de césio de $133 \mathrm{mg} \cdot \mathrm{L}^{-1}$ foi diluída nas concentrações de 10, 20, 25, 30, 35 e 40 mg. $\mathrm{L}^{-1}$ em pH 9,5 com tempo de contato de 45 minutos e $0,1 \mathrm{~g}$ de biomassa de malha mesh entre 35 e 50 . 


\subsection{2 - Biossorção do ${ }^{241} \mathrm{Am}$}

Na remoção do amerício também foi realizada a comparação entre as formas bruta e ativada da fibra. Os experimentos da variação do $\mathrm{pH}$ e do tamanho das partículas da biomassa foram realizados com uma solução com concentração de $200 \mathrm{~Bq} \cdot \mathrm{g}^{-1}$, com tempo de contato de 30 minutos e $0,1 \mathrm{~g}$ de biomassa.

Os experimentos de variação do $\mathrm{pH}$ foram realizados em soluções de 3 , 5 e 6. A influência do tamanho das partículas foi realizada utilizando-se peneiras com malhas mesh entre $35-50$ e $50-80$ em pH 5 .

Os tempos de contato de biossorção foram fixados em 5, 10, 20, 30, 45 e 60 minutos com uma solução com concentração de $200 \mathrm{~Bq} \cdot \mathrm{g}^{-1}$ e $0,1 \mathrm{~g}$ de biomassa. As isotermas de adsorção e a influência da concentração foram estudadas utilizando-se soluções com 50, 150, 200, 300, 400 e 600 Bq.g ${ }^{-1}$ em pH 5,30 minutos de tempo de contato e $0,3 \mathrm{~g}$ de biomassa.

\subsection{3 - Cálculos de cinética, parâmetros termodinâmicos e de equilíbrio}

As isotermas do modelo de Langmuir foram obtidas por meio da equação 2 e representadas no gráfico linear de $\mathrm{C}_{\mathrm{eq}} / \mathrm{Q}_{\mathrm{eq}}$ em função de $\mathrm{C}_{\mathrm{eq}}$. A partir do gráfico foi possível obter os valores de $\mathrm{K}_{\mathrm{L}}$, utilizado para calcular a energia livre de Gibbs, e Q $\left(\mathrm{mg}^{-1} \mathrm{~g}^{-1}\right)$ que indica a capacidade máxima de adsorção.

Para verificar o modelo de isoterma de Freundlich utilizou-se a equação 5. Por meio das equações obtidas nos gráficos lineares de In $Q_{\text {eq }}$ em função de In $C_{\text {eq }}$ foi possível determinar a constante $K_{F}$ e o fator de heterogeneidade $(1 / n)$.

Os resultados foram analisados e tratados por modelos de cinética de pseudo-primeira ordem e pseudo-segunda ordem de Lagergren, conforme equações apresentadas na subseção 3.10.2. Para cada experimento realizado foram calculados os valores de concentração inicial e final, obtendo-se a quantidade de remoção, conforme descrito na seção 4.3. Os parâmetros termodinâmicos foram obtidos por meio da constante de Langmuir. 


\subsection{4 - Análise do ${ }^{133} \mathrm{Cs}$}

Para as análises das concentrações de césio utilizadas nos experimentos e da concentração remanescente em solução, após os ensaios de biossorção, foi utilizado o ICP-OES nos comprimentos de onda de $455,5 \mathrm{~cm}^{-1} \mathrm{e}$ $459,3 \mathrm{~cm}^{-1}$. As FIG.16 e 17 representam as curvas de calibração obtidas com as concentrações de $1,5,10,20,40$ e $60 \mathrm{mg} \cdot \mathrm{L}^{-1}$.

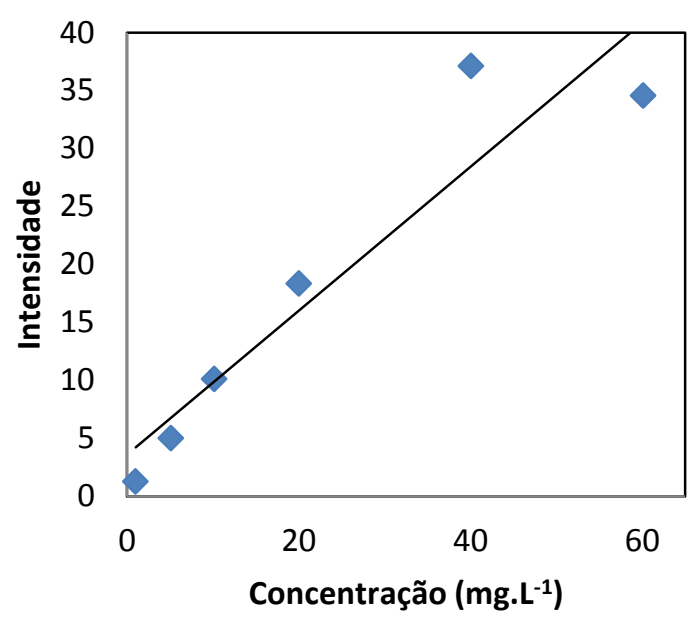

FIGURA 16 - Curva de calibração para o número de onda de $455,5 \mathrm{~cm}^{-1}$. Coeficiente de correlação: $R^{2}: 0,9485$

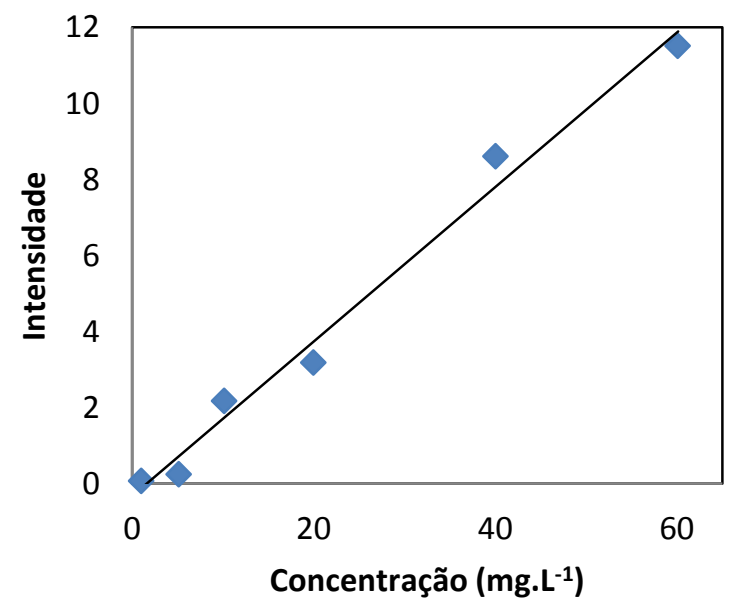

FIGURA 17 - Curva de calibração para o número de onda de 459,3 $\mathrm{cm}^{-1}$ Coeficiente de correlação: $R^{2}: 0,9942$ 


\section{5) RESULTADOS E DISCUSSÕES}

\section{1 - Fibra de coco}

\subsection{1 - Caracterização por Microscopia de Varredura Eletrônica (MEV) acoplado a espectrômetro de energia dispersiva (EDS)}

As características da estrutura fibrosa e morfológica da biomassa foram obtidas por microscopia de varredura eletrônica. As micrografias demonstram a porosidade e a estrutura rígida das fibras de coco bruta e ativada, conforme FIG.18.

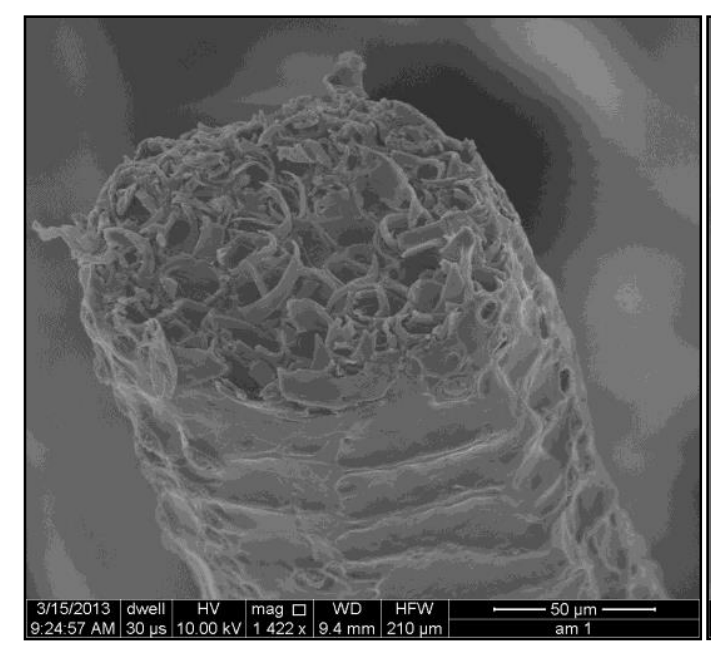

(a)

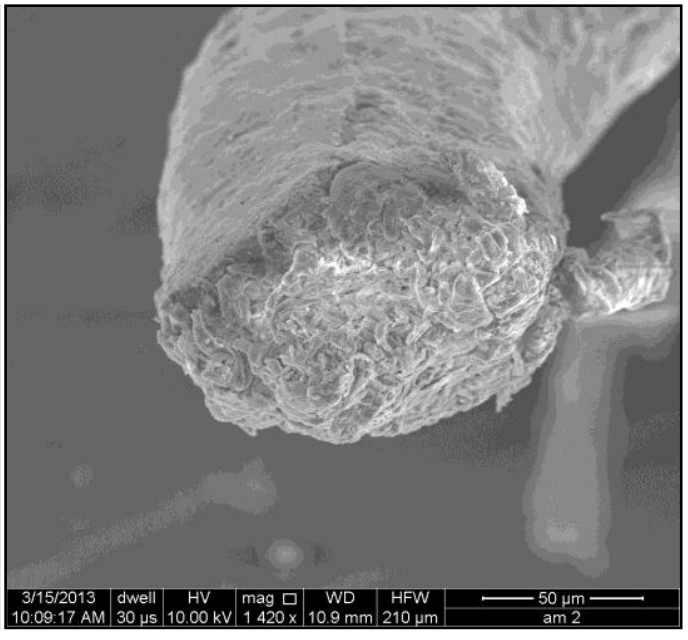

(b)

FIGURA 18 - (a) Imagens de MEV da fibra de coco ativada com ampliação de 1422 vezes e (b) fibra de coco bruta com ampliação de 1400 vezes

É possível verificar que a fibra de coco tratada quimicamente apresenta maior porosidade em relação à bruta devido ao efeito oxidativo do peróxido de hidrogênio que atua degradando parte da lignina da fibra.

Além de carbono, hidrogênio e oxigênio, há outros elementos que constituem a fibra, como potássio, ferro e silício, conforme é mostrado por EDS na FIG.19. Os picos referentes ao ouro $(\mathrm{Au})$ são devido ao revestimento feito na amostra, que possui baixa condutividade. 


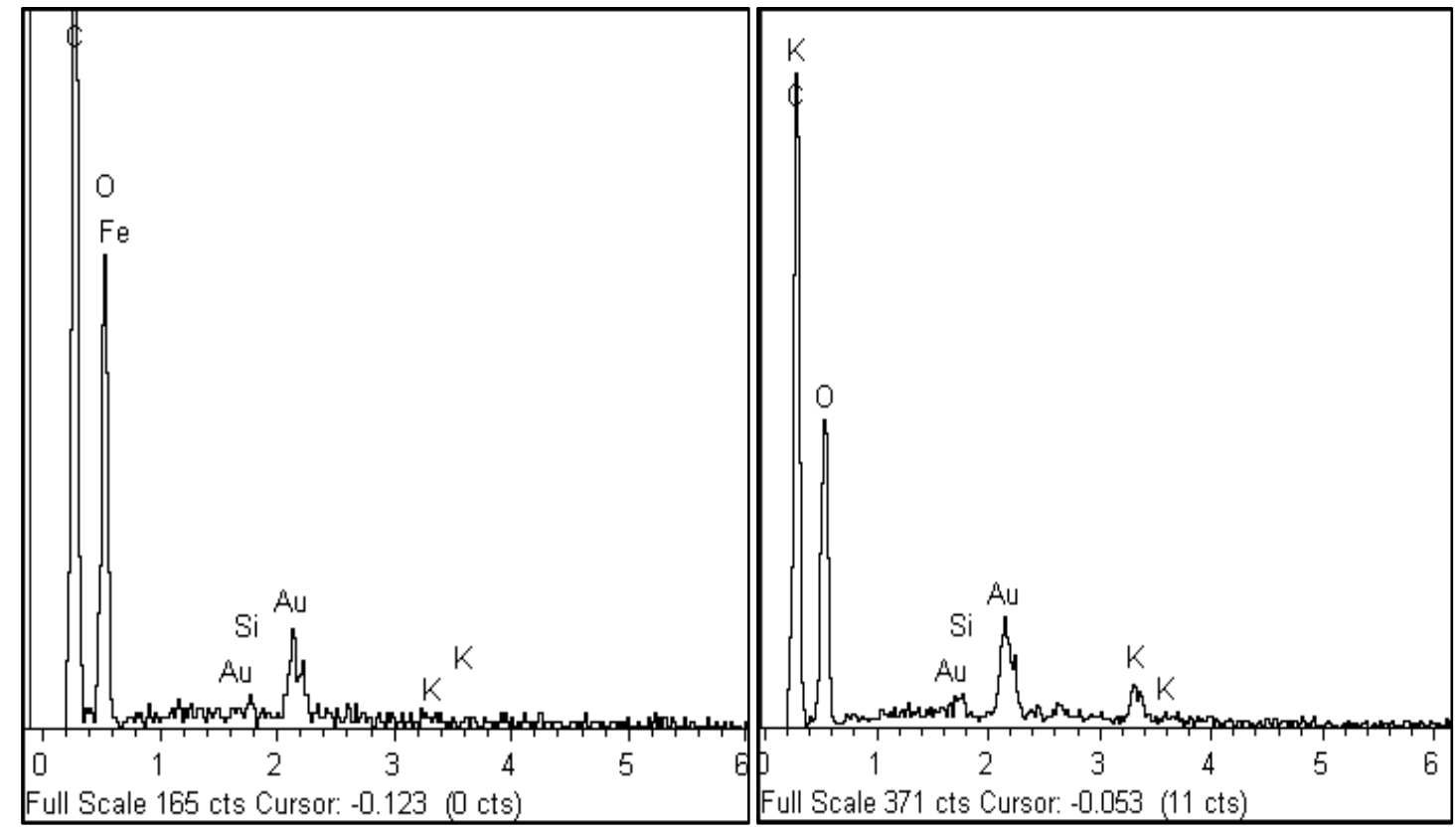

FIGURA 19 - Espectros de EDS das fibras de coco bruta e ativada respectivamente

\subsection{2 - Caracterização por difratometria de raios-X (DRX)}

Segundo CHEN et al, (2007), os espectros de difração de raios-X das fibras naturais são muito semelhantes. $O$ pico correspondente à celulose está presente em $24,7^{\circ}$ e o da região cristalina em $22^{\circ}$, conforme relatado por TOMCZAK (2010). A FIG.20 mostra o difratograma obtido da fibra de coco bruta.

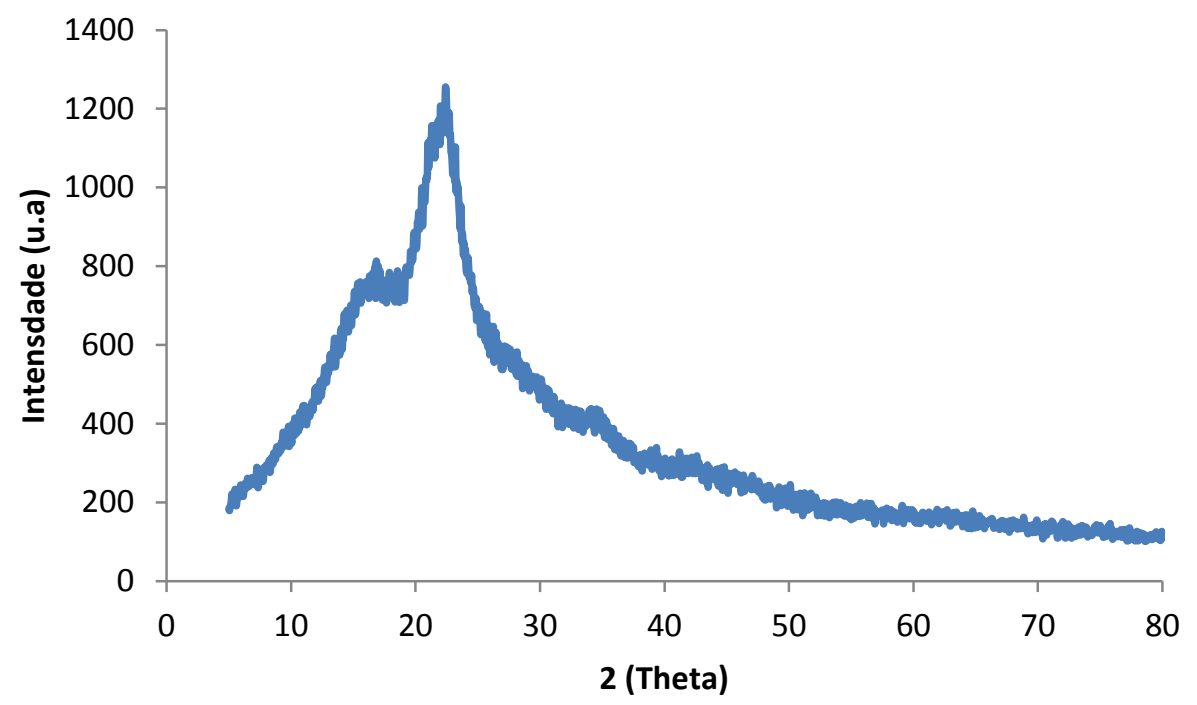

FIGURA 20- Difratograma de raios-X da fibra de coco bruta 
As fibras de coco bruta e ativada apresentaram difratogramas semelhantes. De acordo com FENGEL E WEGNER (1989), observam-se picos agudos atribuídos ao espalhamento das regiões cristalinas e o espalhamento mais difuso das regiões amorfas. Segundo TANOBE (2007), há uma transição de um arranjo ordenado das cadeias de celulose para um estado mais amorfo. Os picos máximos são produzidos por flexões das regiões cristalinas e correspondem aos picos centrados nos ângulos de difração de Bragg de $16^{\circ}, 19^{\circ} ; 22,14^{\circ}$ e $34,73^{\circ}$ para a fibra de coco.

\subsection{3 - Caracterização por infravermelho com transformada de Fourier} (FT-IR)

Os espectros de absorção na região de infravermelho das biomassas bruta e ativada são apresentados nas FIG.21 e 22.



FIGURA 21 - Espectro de absorção do infravermelho para a fibra de coco bruta

As bandas de absorção do espectro do infravermelho (FT-IR) demonstram os grupos característicos dos principais constituintes da fibra de coco: $-\mathrm{OH}\left(3400-3200 \mathrm{~cm}^{-1}\right),-\mathrm{C}=\mathrm{O}\left(1776-1715 \mathrm{~cm}^{-1}\right)$ de ácido carboxílico, $-\mathrm{C}=\mathrm{O}$ $\left(1620 \mathrm{~cm}^{-1}\right)$ de cetona da hemicelulose, -C-O-C- $\left(1270 \mathrm{~cm}^{-1}\right)$ e $-\mathrm{C}-\mathrm{OH}$ (aproximadamente $1050 \mathrm{~cm}^{-1}$ ). A banda mais intensa atribuída para - $\mathrm{OH}$ e $-\mathrm{C}-\mathrm{O}-$ 
C- é encontrada na celulose, enquanto que a hemicelulose apresenta fortes bandas $-\mathrm{C}=\mathrm{O}$. As bandas em $1100 \mathrm{~cm}^{-1}$, da vibração de $-\mathrm{C}-\mathrm{O}-\mathrm{C}-$ e de $-\mathrm{C}-\mathrm{OH}$ a $1060-1050 \mathrm{~cm}^{-1}$ são referentes à cadeia da celulose. Há outras bandas devido ao grupo $-\mathrm{OH}$ do álcool da celulose que aparecem em 1360 e $1320 \mathrm{~cm}^{-1}$ (YANG, 2007 e MOTHÉ, 2009).

A diferença que ocorre na fibra de coco após o tratamento químico é evidenciada nas regiões $500 \mathrm{~cm}^{-1}$ a $2000 \mathrm{~cm}^{-1}$. A quebra das cadeias de celulose resultante da oxidação leva a formação de ácidos carboxílicos e, da mesma forma, a oxidação da lignina também leva a formação de ácidos dicarboxílicos solúveis em água (SHUKLA, 2009). Um aumento na intensidade da banda característica da carbonila de $-\mathrm{COOH}$ é observada em $1739,19 \mathrm{~cm}^{-1}$, e a diminuição da intensidade da banda em $1060 \mathrm{~cm}^{-1}$ sugere a hidrólise do éster.

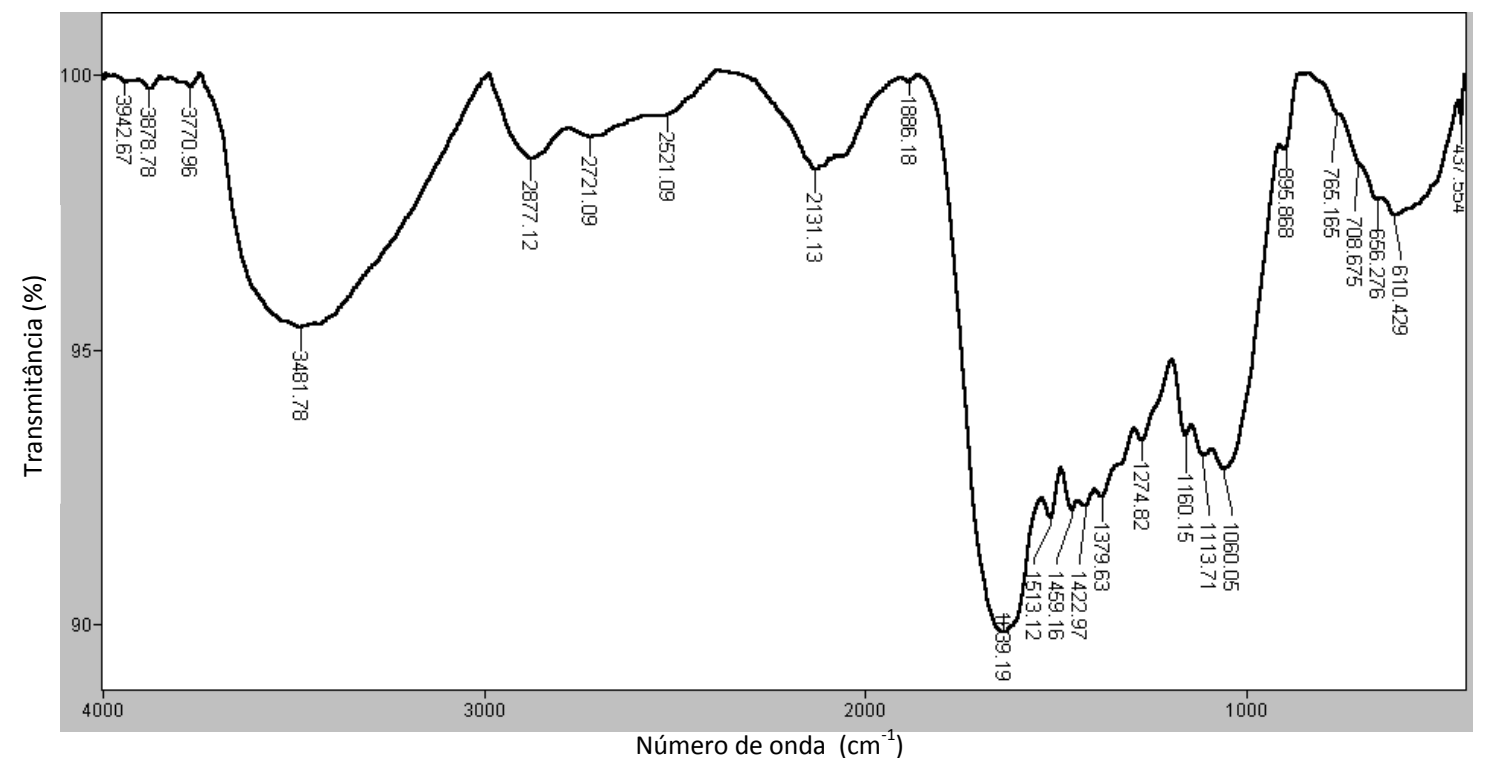

FIGURA 22 - Espectro de absorção do infravermelho para a fibra de coco ativada

\section{2 - Estudos de biossorção do ${ }^{133} \mathrm{Cs}$}

\subsection{1 - Influência do pH na adsorção}

A especiação dos íons na solução e a carga dos sítios ativos na superfície da biomassa são influenciadas pelo pH, por esse motivo o estudo dessa variável é importante no processo de biossorção de íons metálicos (PINO, 
2005). A TAB.7 apresenta a quantidade removida de césio em diferentes valores de $\mathrm{pH}$, tanto nas fibras na forma bruta quanto na ativada.

TABELA 7 - Estudo de remoção de césio para diferentes valores de pH

\begin{tabular}{ccc}
\hline \multicolumn{3}{c}{ Remoção de césio $-Q_{\text {eq }}\left(\mathbf{m g}_{\cdot} \mathbf{g}^{-1}\right)$} \\
\hline pH & Biomassa bruta & Biomassa ativada \\
$\mathbf{3 . 5}$ & 0 & 0,06 \\
$\mathbf{7 . 0}$ & 0,33 & 0,29 \\
$\mathbf{9 . 5}$ & 0,39 & 0,50 \\
\hline
\end{tabular}

Os resultados demonstram que houve uma melhor adsorção tanto para a biomassa bruta quanto para a ativada em pH 9,5. O pKa do ácido carboxílico é 5 , ou seja, neste $\mathrm{pH}$ há um equilíbrio entre a quantidade de ácido carboxílico e a formação de íons carboxilatos. Acima deste $\mathrm{pH}$ há o deslocamento do equilíbrio para a formação de íons carboxilatos.

Nota-se que há um acréscimo na eficiência de remoção para a biomassa ativada em meio básico, cerca de $82 \%$ de remoção, enquanto que para a biomassa bruta é de cerca de $64 \%$.

Como foi apresentado no item 5.1.3, a oxidação da biomassa converte os grupos hidroxila da celulose em grupos carboxila, criando assim uma fraca troca iônica-catiônica (SHUKLA, 2009).

Segundo AKAR e TUNALI (2006) e KAPOOR (1999), esta variação na eficiência de remoção pode ser explicada pela presença de centros ativos nos compostos constituintes da fibra de coco, tais como: grupos carboxila, amina e hidroxilas. Esses grupos são mais suscetíveis de serem protonados em valores de $\mathrm{pH}$ mais baixos, impedindo a adsorção de cátions metálicos nestes sítios de ligação. No entanto, em valores de $\mathrm{pH}$ mais elevados ocorre a desprotonação levando a formação de ânion ou elétrons desaparelhados, tornando a superfície carregada negativamente, favorecendo a captação de cátions metálicos por complexação e troca iônica, aumentando a adsorção de $\mathrm{Cs}^{+}$(MISHRA e TIWARI, 2002; SHARMA e FORSTER, 1994). 


\subsection{2 - Influência do tempo de contato}

Os tempos de contato adotados nos experimentos foram estabelecidos de acordo com estudos já realizados de biossorção com fibra de coco para remoção de diversos íons metálicos. (MONTEIRO, 2009; SOUZA, 2007; PINO, 2005; MONTANHER, 2009).

A FIG.23 mostra que a adsorção dos íons de $\mathrm{Cs}^{+}$na biomassa da fibra de coco atinge o equilíbrio a partir de 30 minutos, sendo relativamente rápida quando comparada a outros tipos de adsorvente como o PAN modificado relatado por NILCHI et al. (2007), que atinge o equilíbrio de adsorção em 2 horas de tempo contato. Para a biomassa bruta, a quantidade removida foi de $0,46 \mathrm{mg} \cdot \mathrm{g}^{-1}$, cerca de $70 \%$ e de $0,51 \mathrm{mg}^{-1} \mathrm{~g}^{-1}$ para a biomassa ativada, cerca de $75 \%$, em 30 minutos.

Os valores obtidos em 5 minutos de contato não foram representativos e em 120 minutos de contato observa-se que a biomassa ativada mantém a capacidade de remoção enquanto que a bruta apresenta uma pequena diminuição na remoção de $\mathrm{Cs}^{+}$.

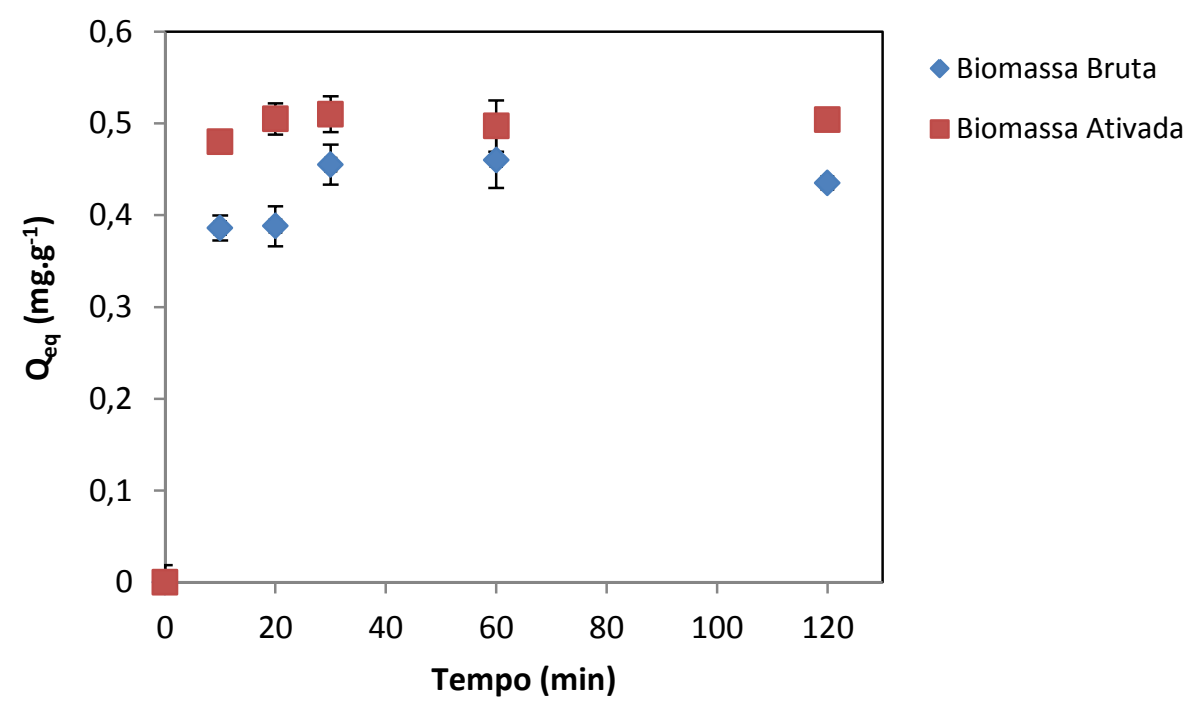

FIGURA 23 - Influência do tempo de contato na adsorção de íons $\mathrm{Cs}^{+}$ 


\subsection{3 - Influência do tamanho da partícula da biomassa}

A influência do tamanho da partícula da biomassa foi verificada para duas granulometrias entre 35-50 e 50-80 mesh. Este parâmetro é muito importante nos processos de biossorção porque tem influência nos custos e procedimentos operacionais.

Os experimentos de remoção dos íons de $\mathrm{Cs}^{+}$foram realizados conforme descrito na subseção 4.3.1. Observa-se na FIG.24, que as biomassas ativadas para ambas as granulometrias apresentam capacidades de remoção semelhante até 45 minutos de tempo de contato, e após este período, a biomassa em granulometria entre 35-50 mesh mantém uma eficiência de remoção maior, enquanto que a de 50-80 mesh perde eficiência, provavelmente devido à saturação da partícula menor. Para a biomassa bruta, nota-se que o tamanho de partícula maior proporcionou um aumento na capacidade de remoção, devido à maior área de contato.

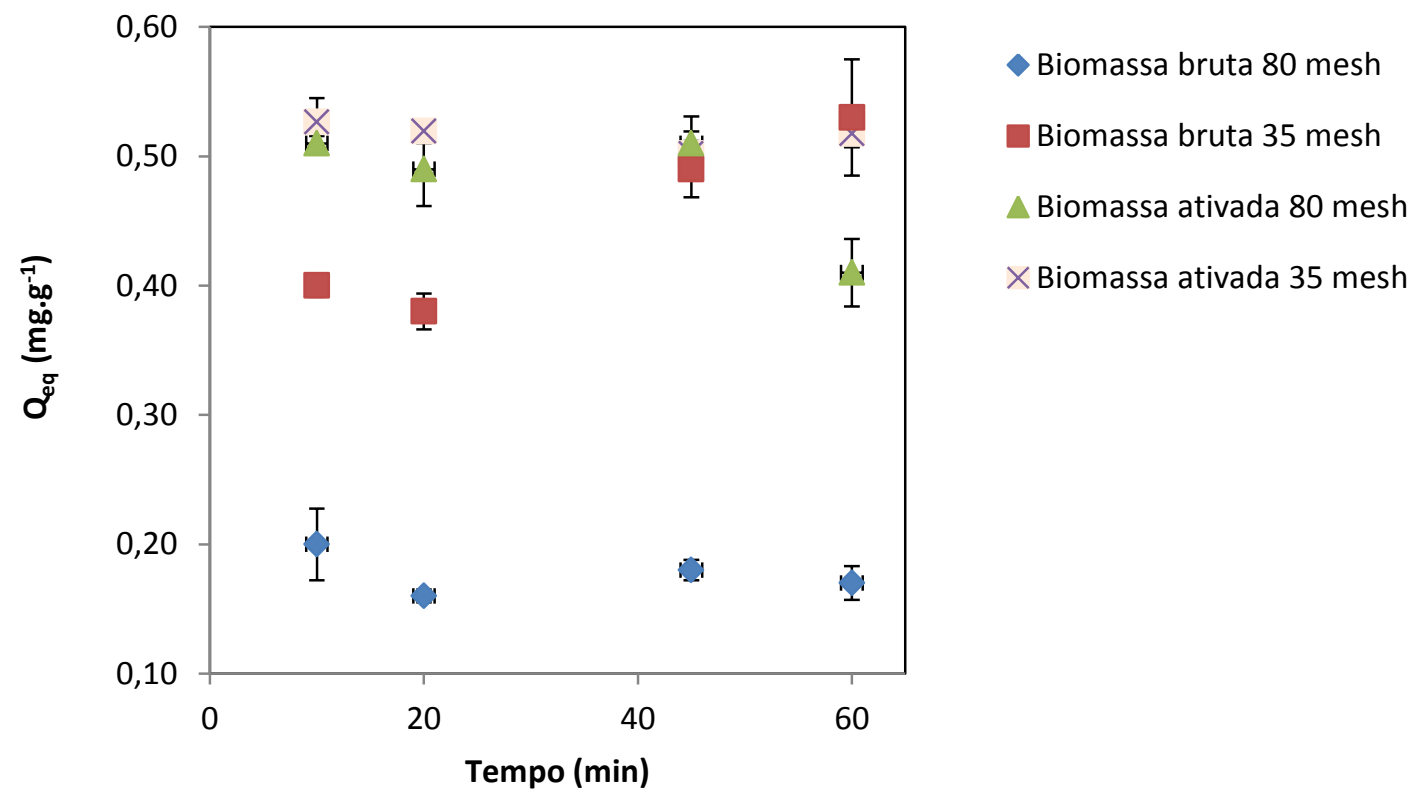

FIGURA 24 - Influência do tamanho da partícula na adsorção de íons $\mathrm{Cs}^{+}$ 


\subsection{4 - Influência da concentração da solução}

A FIG.25 representa a capacidade de biossorção da fibra de coco em concentrações entre 10 e $40 \mathrm{mg} \cdot \mathrm{L}^{-1}$ de $\mathrm{Cs}^{+}$.

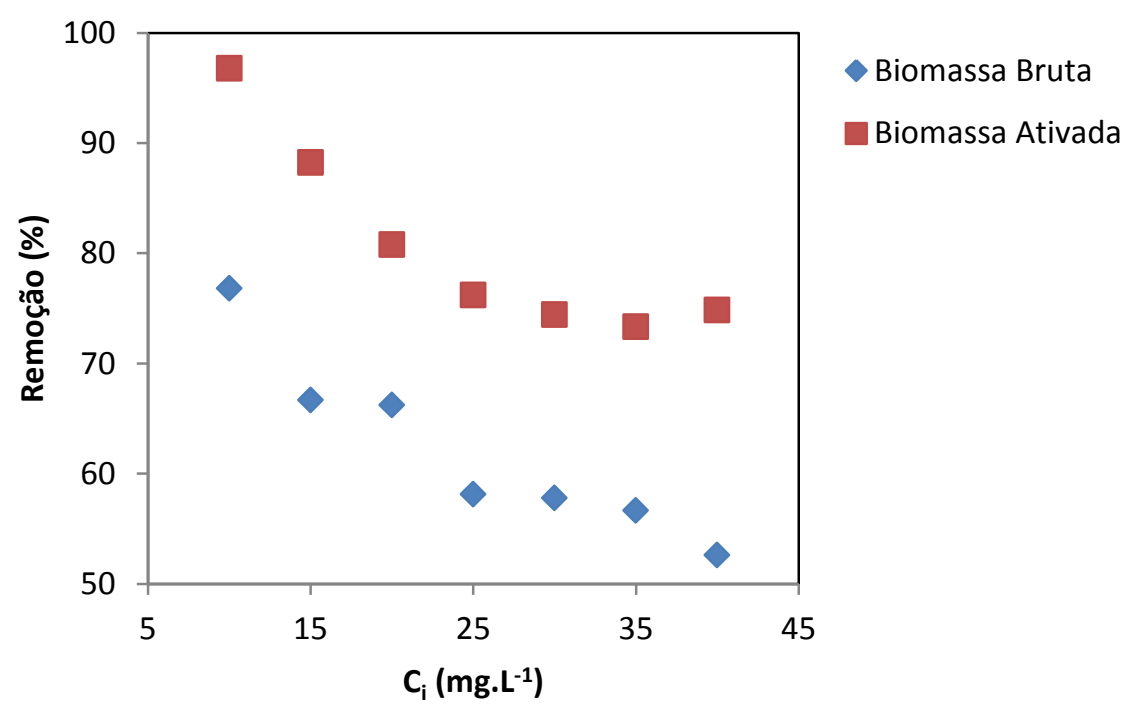

(a)

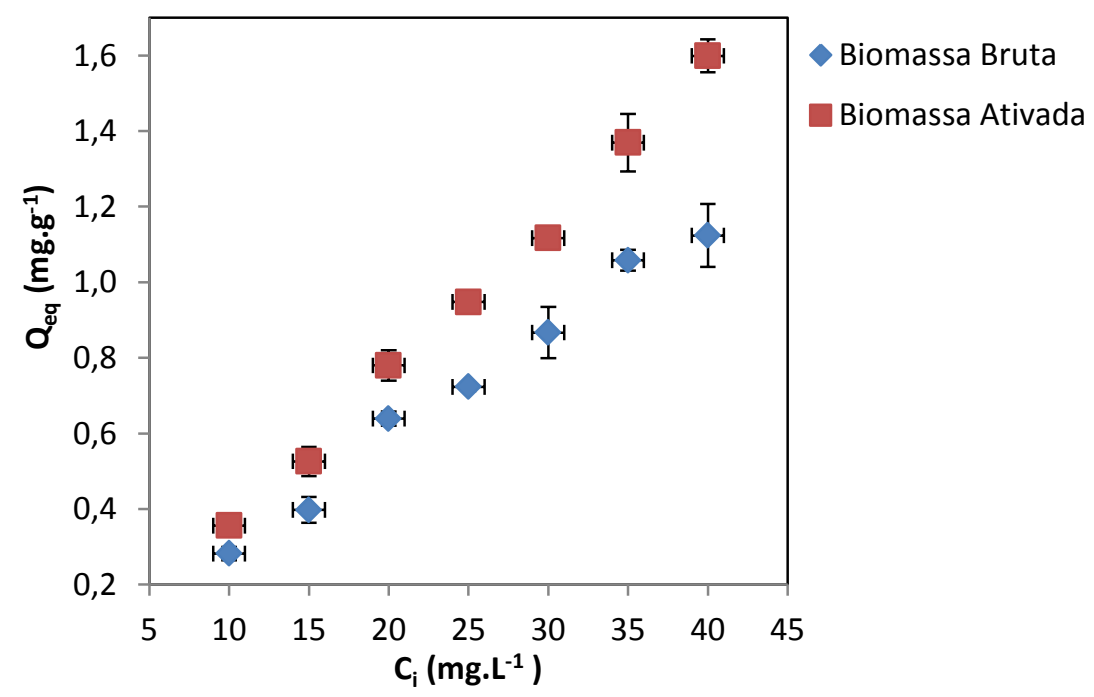

(b)

FIGURA 25 - (a) Porcentagem de remoção em função da concentração inicial (b) Influência da concentração da solução na adsorção de íons $\mathrm{Cs}^{+}$

Para a solução com concentração de $40 \mathrm{mg} \cdot \mathrm{L}^{-1}$ a porcentagem removida, utilizando-se a biomassa ativada, foi de aproximadamente $75 \%$, conforme mostrado na FIG. 25a. Por outro lado a capacidade de remoção 
aumenta proporcionalmente com a concentração da solução, conforme mostrado na FIG.25b.

\subsection{5 - Isotermas de adsorção}

A partir dos resultados da concentração da solução apresentados no item 5.2.4, estudou-se o equilíbrio de biossorção por meio de modelos de isotermas de adsorção, que relacionam a concentração do adsorvente na fase líquida e a quantidade adsorvida. A FIG.26 apresenta as isotermas de equilíbrio de adsorção dos íons $\mathrm{Cs}^{+}$pelas biomassas bruta e ativada.

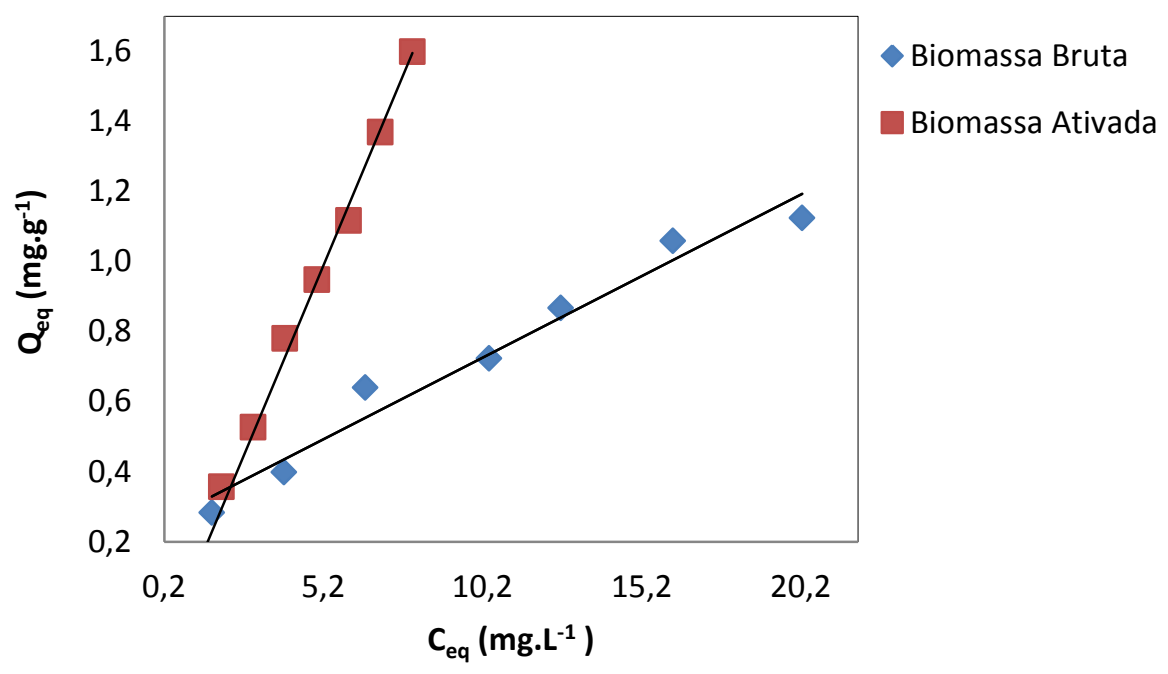

FIGURA 26 - Isoterma de equilíbrio de adsorção das biomassas bruta e ativada para o íon $\mathrm{Cs}^{+}$

Analisando a FIG.26 é possível verificar que as isotermas de adsorção para o íon $\mathrm{Cs}^{+}$apresentam um comportamento linear.

As isotermas de adsorção foram analisadas utilizando-se as equações 2 e 5 que são as formas linearizadas das equações de Langmuir e Freundlich respectivamente e estão representadas nas FIG.27 e 28. 


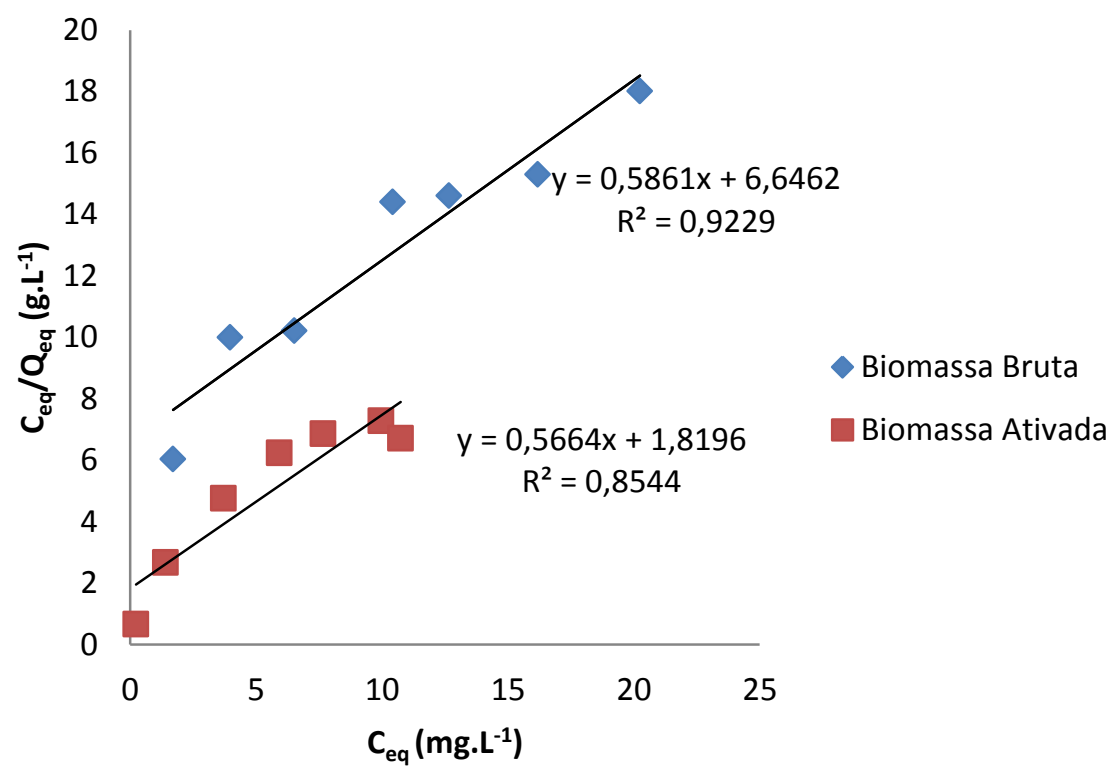

FIGURA 27- Representação da isoterma de Langmuir para a fibra de colco bruta e ativada na adsorção de íons $\mathrm{Cs}^{+}$

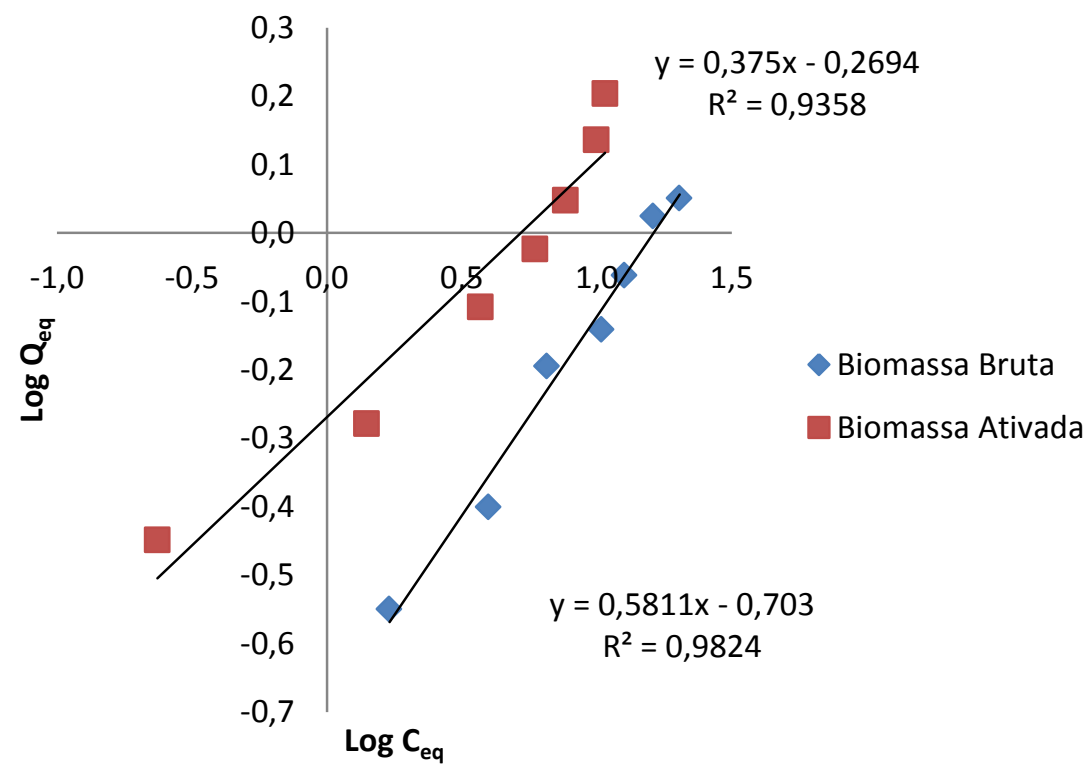

FIGURA 28 - Representação da isoterma de Freundlich para a fibra de coco bruta e ativada na adsorção de íons $\mathrm{Cs}^{+}$

Os parâmetros obtidos a partir das isotermas são apresentados na TAB.8. Analisando os resultados pode-se concluir que tanto para a biomassa bruta quanto para a ativada o modelo de Freundlich é o que melhor se ajusta na adsorção de $\mathrm{Cs}^{+}$. 
TABELA 8: Parâmetros das isotermas para o processo de adsorção do $\mathrm{Cs}^{+}$ utilizando-se fibra de coco

\begin{tabular}{|c|c|c|c|c|c|c|}
\hline \multicolumn{7}{|c|}{ Biomassa Bruta } \\
\hline \multicolumn{7}{|c|}{ Parâmetros } \\
\hline Íon & & ngmuir & & Fre & dlich & \\
\hline & $\mathrm{K}_{\mathrm{L}}\left(\mathrm{L} \cdot \mathrm{mg}^{-1}\right)$ & $\mathrm{Q}\left(\mathrm{mg} \cdot \mathrm{g}^{-1}\right)$ & $\mathrm{R}^{2}$ & $\mathrm{~K}_{\mathrm{F}}\left(\mathrm{L} \cdot \mathrm{g}^{-1}\right)$ & $1 / n$ & $\mathrm{R}^{2}$ \\
\hline $\mathrm{Cs}^{+}$ & 0,09 & 1,71 & 0,923 & 0,20 & 0,58 & 0,982 \\
\hline
\end{tabular}

\section{Biomassa Ativada}

\begin{tabular}{cccc|ccc} 
Íon & \multicolumn{3}{c}{ Langmuir } & \multicolumn{3}{c}{ Freundlich } \\
\hline \multirow{2}{*}{$\mathbf{C s}^{+}$} & 0,31 & $\mathrm{~K}\left(\mathrm{mg} \cdot \mathrm{g}^{-1}\right)$ & $\mathrm{R}^{2}$ & $\mathrm{~K}_{\mathrm{F}}\left(\mathrm{L} \cdot \mathrm{g}^{-1}\right)$ & $1 / \mathrm{n}$ & $\mathrm{R}^{2}$ \\
\cline { 2 - 7 } & 0,37 & 0,854 & 0,54 & 0,38 & 0,935 \\
\hline
\end{tabular}

O valor de n para a biomassa bruta é 1,72 e para a biomassa ativada é 2.63, indicando que os processos são favoráveis, conforme descrito na subseção 3.10.1.

\subsection{6 - Estudos da cinética química}

Para determinar a quantidade adsorvida no equilíbrio $\left(Q_{e q}\right)$, relacionou-se o tempo $(\min )$ e a quantidade de íons removida $\left(\mathrm{mg} \cdot \mathrm{g}^{-1}\right)$. Os gráficos que relacionam In $\left(Q_{e q}-Q_{t}\right)$ em função do tempo e representam o modelo de pseudo-primeira ordem, são representados pelas FIG.29 e 30 para a biomassa bruta e ativada respectivamente.

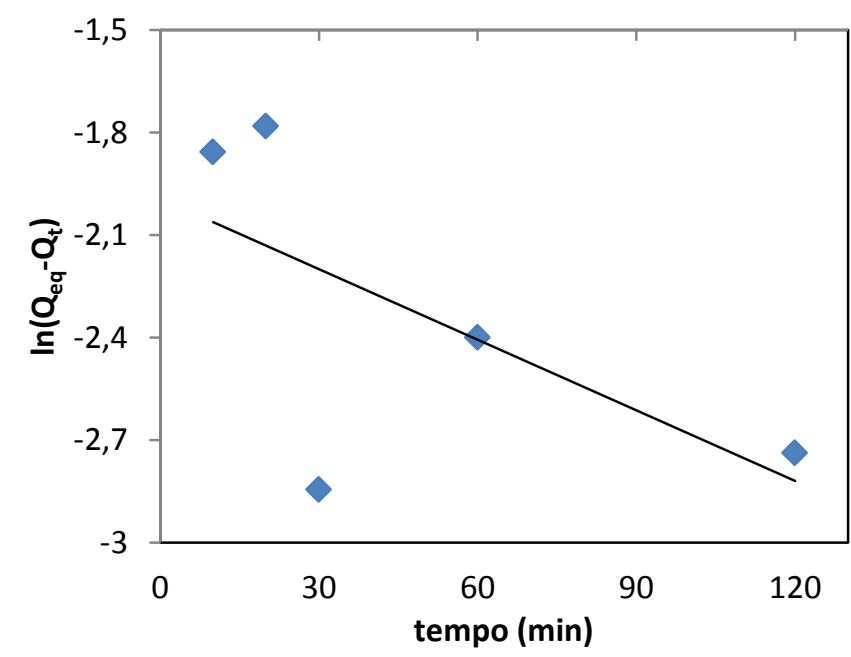

FIGURA 29 - Representação do modelo de pseudo-primeira ordem para a adsorção de $\mathrm{Cs}^{+}$em fibra de coco bruta 


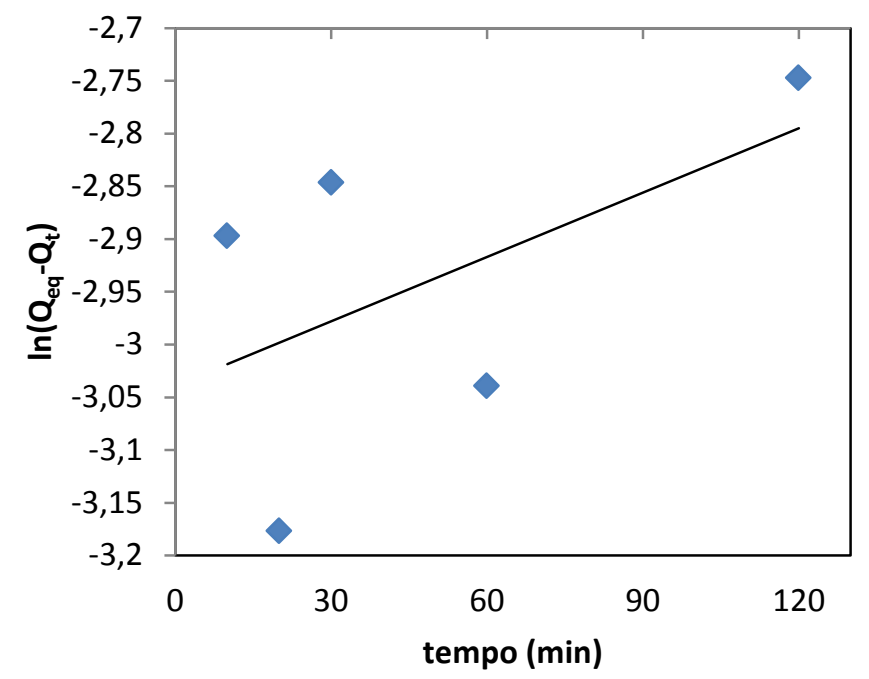

FIGURA 30 - Representação do modelo de pseudo-primeira ordem para a adsorção de $\mathrm{Cs}^{+}$em fibra de coco ativada

Os gráficos que mostram a relação entre o tempo/quantidade removida em função do tempo mostram o comportamento de uma equação de pseudosegunda ordem. As FIG.31 e 32 representam o modelo para a adsorção do Cs+

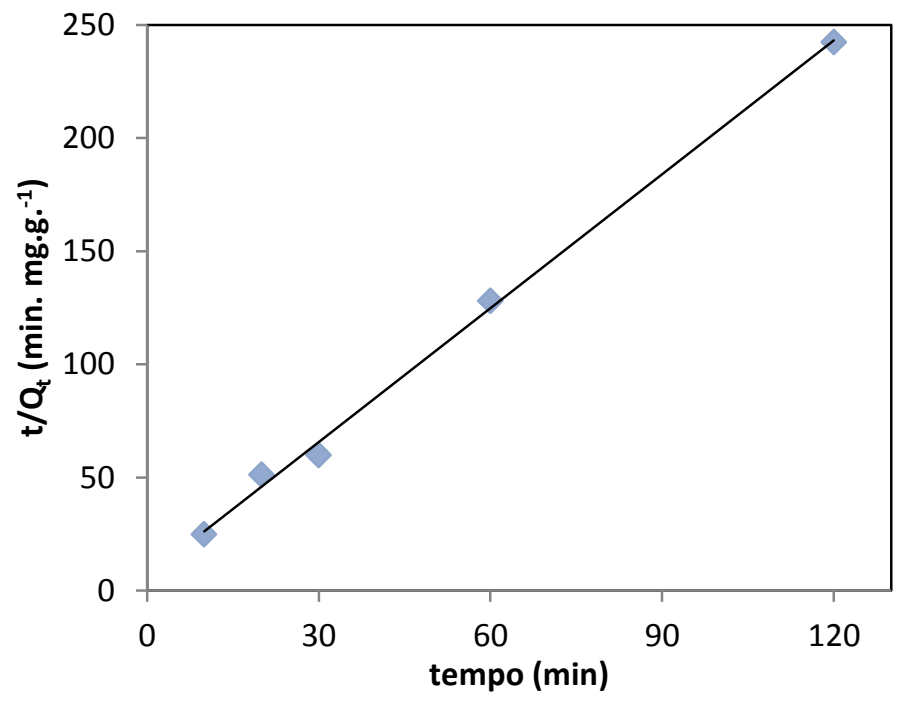

FIGURA 31 - Representação do modelo de pseudo-segunda ordem para a adsorção de $\mathrm{Cs}^{+}$em fibra de coco bruta 


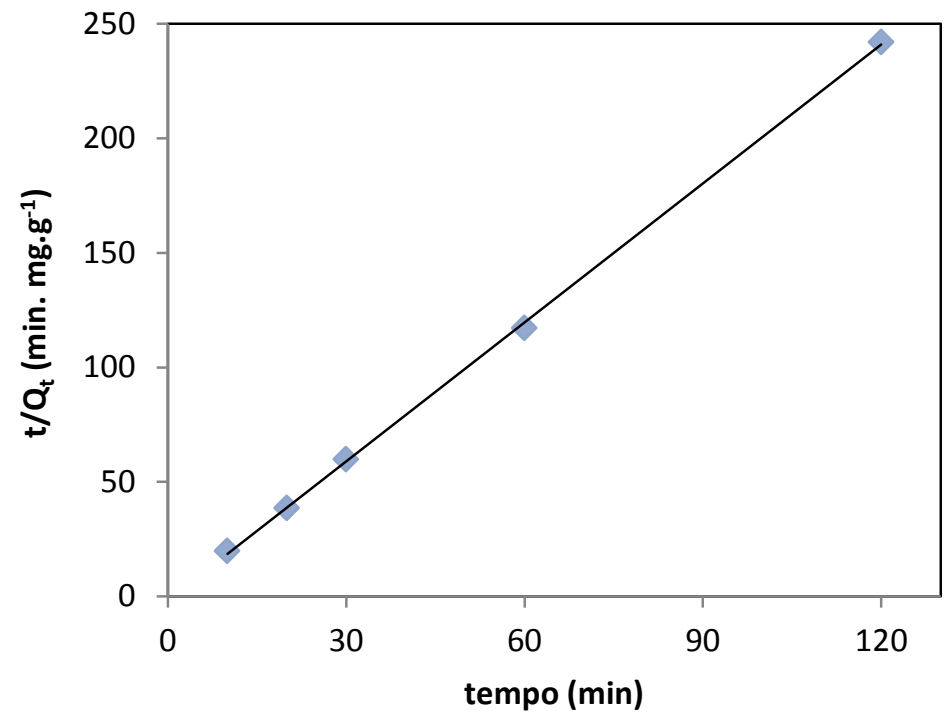

FIGURA 32 - Representação do modelo de pseudo-segunda ordem para a adsorção de $\mathrm{Cs}^{+}$em fibra de coco ativada

O modelo de pseudo-segunda ordem, que prediz o comportamento de adsorção durante todo o tempo do processo, indica que a adsorção é de natureza química.

A TAB.9 apresenta os dados obtidos por meio dos gráficos e dos estudos cinéticos e suas respectivas constantes.

TABELA 9: Parâmetros da cinética de adsorção na fibra de coco

\begin{tabular}{|c|c|c|c|c|c|c|c|}
\hline \multirow{2}{*}{ Íon } & \multicolumn{7}{|c|}{ Biomassa Bruta } \\
\hline & \multicolumn{3}{|c|}{ Pseudo-primeira } & Parâmetros & Pseudo-s & aunda & \\
\hline & $\begin{array}{c}\mathrm{K}_{1} \\
\left(1 \cdot \mathrm{min}^{-1}\right)\end{array}$ & $\begin{array}{c}Q_{\text {eq }} \\
\left(\mathrm{mg}^{-1}\right)\end{array}$ & $\mathrm{R}^{2}$ & $\begin{array}{c}\mathrm{K}_{2} \\
{\left[\mathrm{~g}\left(\mathrm{mg}^{-1} \cdot \mathrm{min}^{-1}\right)\right]}\end{array}$ & $\begin{array}{c}\mathrm{Q}_{\mathrm{t}} \\
\left(\mathrm{mg} \cdot \mathrm{g}^{-1}\right)\end{array}$ & $\begin{array}{c}\mathrm{Q} \\
\left(\mathrm{mg} \cdot \mathrm{g}^{-1}\right)\end{array}$ & $\mathrm{R}^{2}$ \\
\hline $\mathrm{Cs}^{+}$ & 0,016 & 0,138 & 0,386 & 0,594 & 0,495 & 0,507 & 0,997 \\
\hline & \multicolumn{7}{|c|}{ Biomassa Ativada } \\
\hline Íon & \multicolumn{3}{|c|}{ Pseudo-primeira } & \multicolumn{4}{|c|}{ Pseudo-segunda } \\
\hline & $\begin{array}{c}\mathrm{K}_{1} \\
\left(1 \cdot \mathrm{min}^{-1}\right)\end{array}$ & $\begin{array}{c}\mathrm{Q}_{\mathrm{eq}} \\
\left(\mathrm{mg}^{-1} \mathrm{~g}^{-1}\right)\end{array}$ & $\mathrm{R}^{2}$ & $\begin{array}{c}\mathrm{K}_{2} \\
{\left[\mathrm{~g}\left(\mathrm{mg}^{-1} \cdot \mathrm{min}^{-1}\right)\right]}\end{array}$ & $\begin{array}{c}\mathrm{Q}_{\mathrm{t}} \\
\left(\mathrm{mg} \cdot \mathrm{g}^{-1}\right)\end{array}$ & $\begin{array}{c}\mathrm{Q} \\
\left(\mathrm{mg} \cdot \mathrm{g}^{-1}\right)\end{array}$ & $\mathrm{R}^{2}$ \\
\hline $\mathrm{Cs}^{+}$ & $-0,006$ & 0,058 & 0,008 & 2,70 & 0,495 & 0,494 & 0,999 \\
\hline
\end{tabular}

Conforme apresentado na tabela, os coeficientes de correlação obtidos por meio dos gráficos, indicam que o processo de adsorção do $\mathrm{Cs}^{+}$pode ser 
explicado pelo modelo de pseudo-segunda ordem. Os valores da capacidade máxima de adsorção $(Q)$ tanto da biomassa bruta, quanto da ativada, estão muito próximos dos valores obtidos nos experimentos realizados.

\subsection{7 - Caracterização da biomassa após contato com o césio}

A análise por MEV da fibra bruta após o contato com a solução de césio é apresentada a seguir na FIG.33.

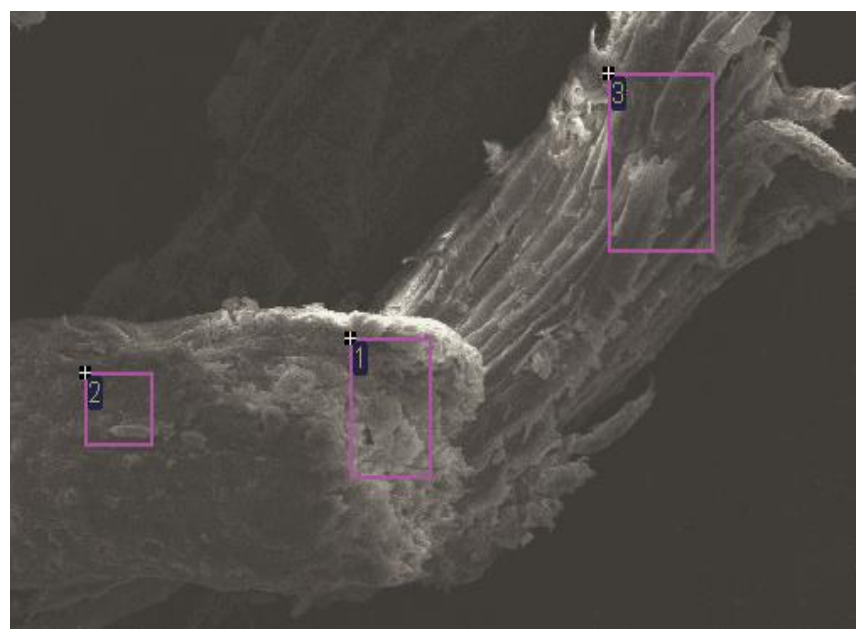

FIGURA 33 - Imagem por MEV da fibra de coco bruta após a biossorção do césio com ampliação de 1028 vezes

As regiões marcadas como 1, 2 e 3 foram analisadas por EDS. A presença de césio na biomassa após o experimento foi confirmada pela presença de picos em 4,2 e 4,8 keV na região 3, conforme mostrado na FIG.34.
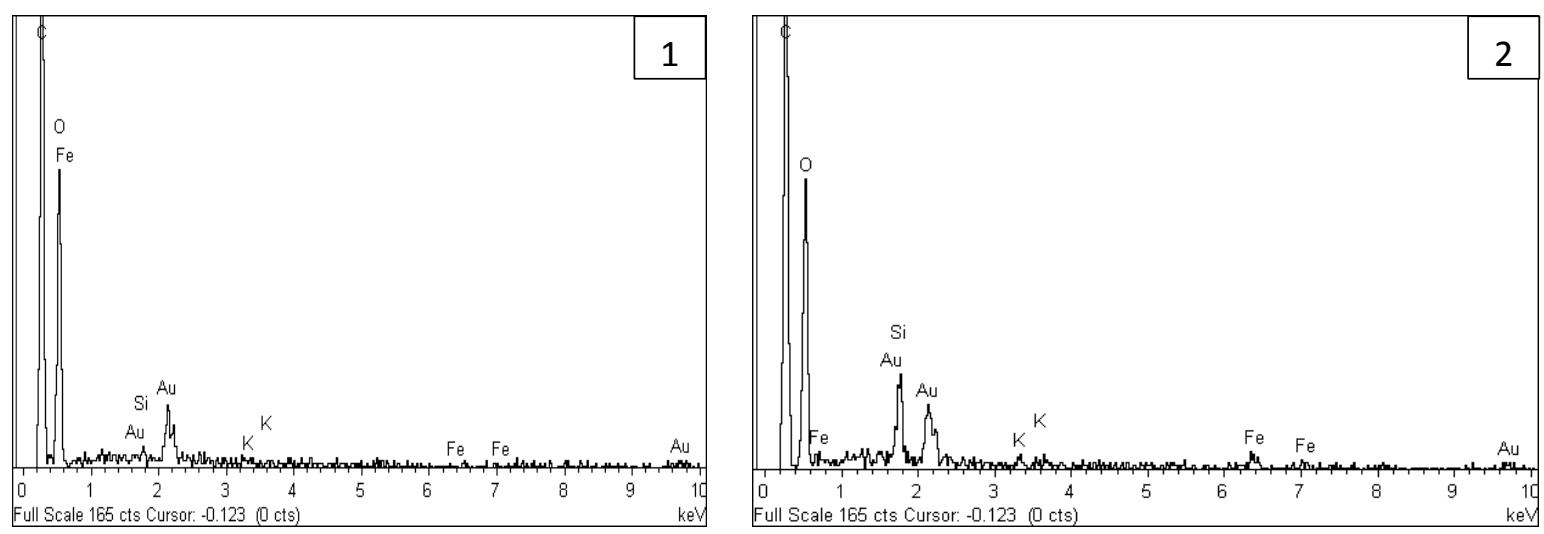


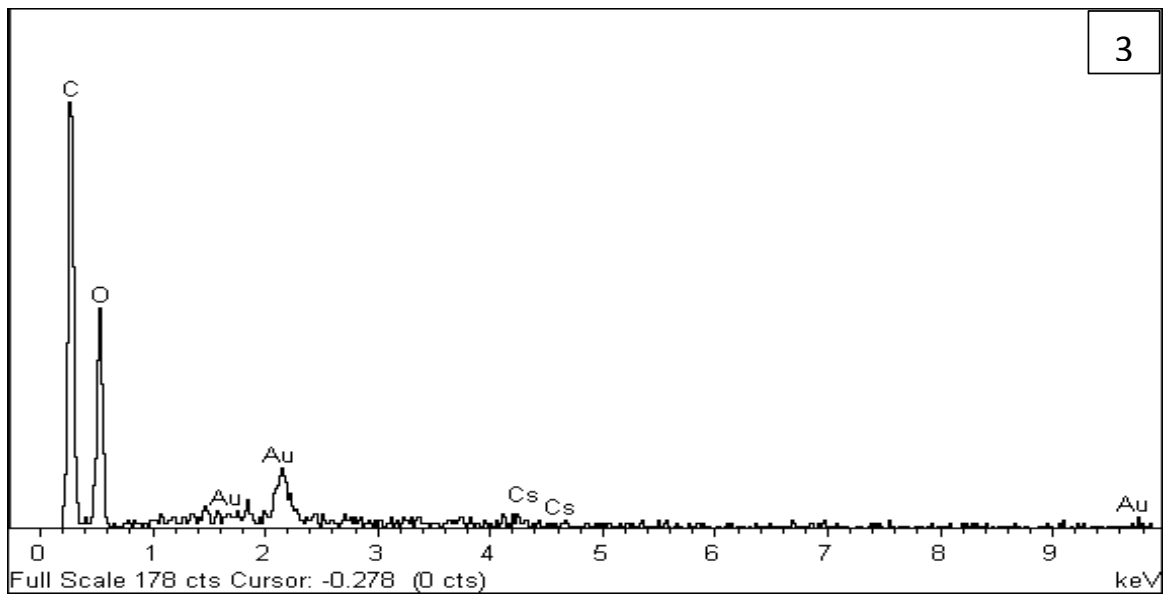

FIGURA 34 - Espectro de EDS nas regiões 1 e 2 e na região 3

Na FIG.35 o difratograma apresenta uma comparação da fibra de coco bruta antes e após o contato com o césio. Presume-se que os picos ligeiramente superiores na região entre os ângulos 15 e 20 podem ter sido alterados devido à adsorção dos íons de césio na região cristalina da fibra.

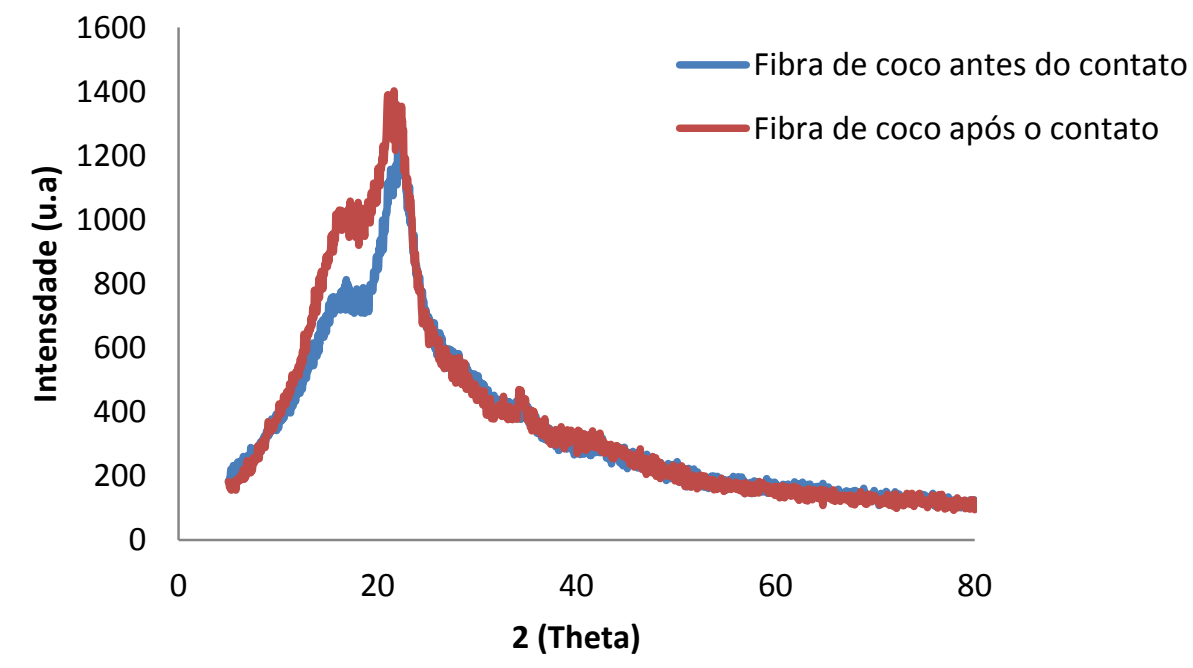

FIGURA 35 - Difratograma de raios-X da fibra de coco bruta antes e após contato com césio

A comparação entre os espectros de infravermelho da fibra de coco ativada antes e após contato com o césio é apresentada nas FIG.36 e 37. 


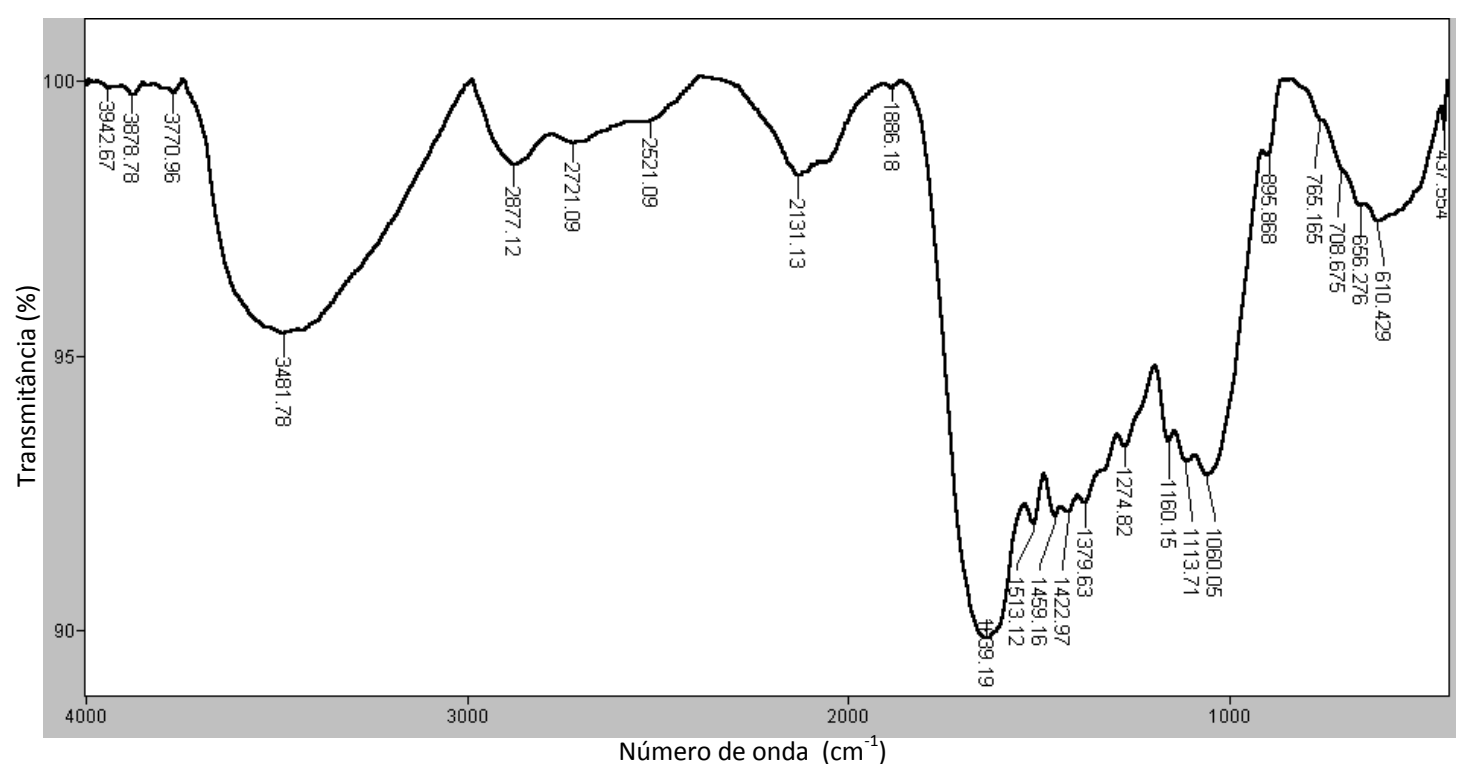

FIGURA 36 - Espectro de absorção do infravermelho para a fibra de coco ativada antes do contato com o césio

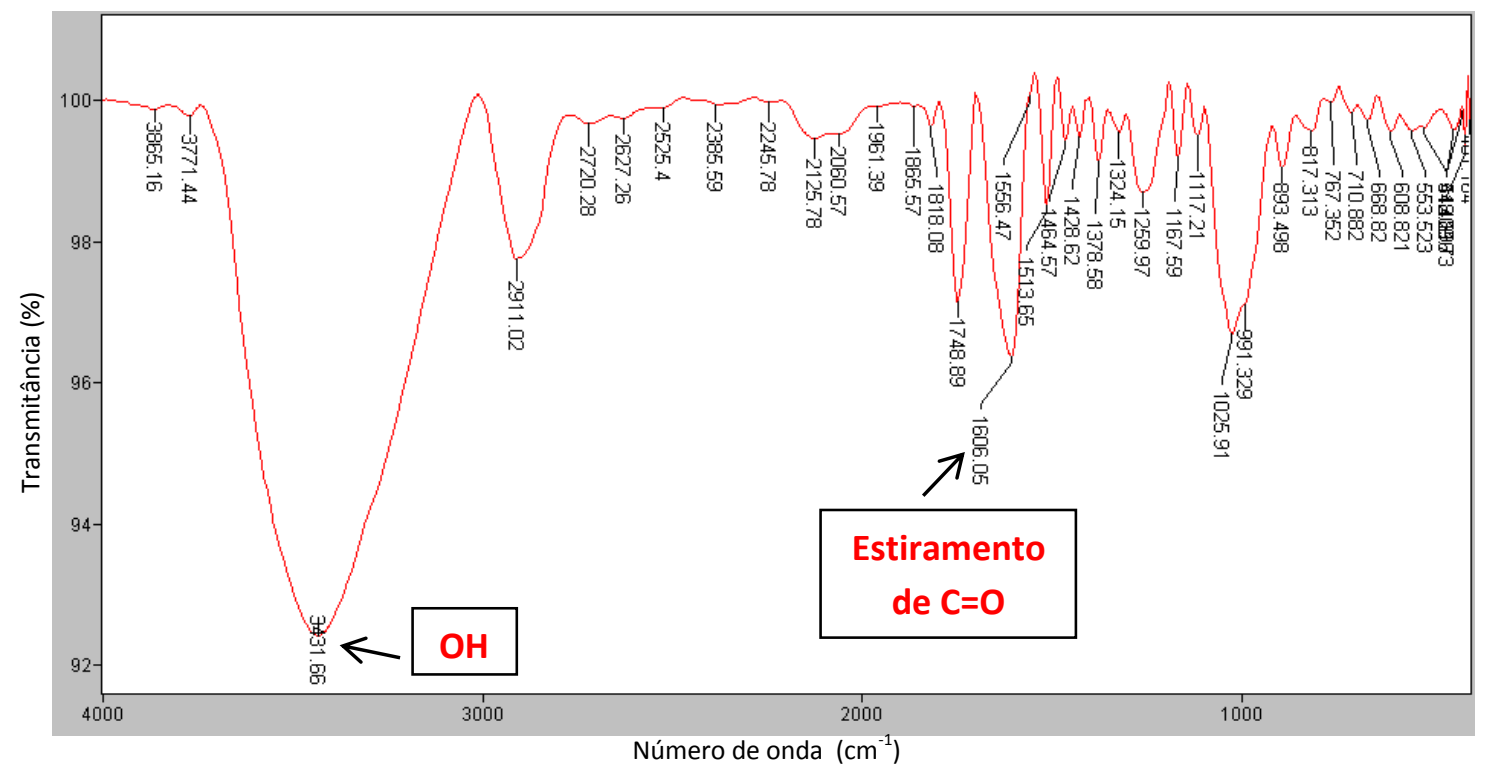

FIGURA 37 - Espectro de absorção na região do infravermelho para a fibra de coco ativada após o contato com o césio

É possível observar a interação entre $\mathrm{O} \mathrm{Cs}^{+} \mathrm{e}$ a fibra de coco pelos deslocamentos ocorridos nas bandas abaixo de $1500 \mathrm{~cm}^{-1}$ da carbonila de ácido carboxílico e da amida. 


\section{3 - Estudos de biossorção do ${ }^{241} \mathrm{Am}$}

\subsection{1 - Influência do pH na adsorção}

Os valores obtidos dos experimentos realizados com o amerício são apresentados na TAB.10. É possível perceber que houve pouca diferença na remoção tanto para a biomassa bruta quanto para a ativada.

TABELA 10 - Estudo de remoção de amerício em diferentes valores de pH

\begin{tabular}{ccc}
\hline \multicolumn{3}{c}{ Porcentagem de Remoção de Amerício (\%) } \\
\hline $\mathbf{p H}$ & Biomassa bruta & Biomassa ativada \\
$\mathbf{3}$ & 92,2 & 94,9 \\
$\mathbf{5}$ & 92.6 & 95,8 \\
$\mathbf{6}$ & 92,0 & 97,8 \\
\hline
\end{tabular}

Estudos da especiação de radionuclídeos em solução realizado por ROMANCHUK et al (2013), mostraram que a formação dos íons de $\mathrm{Am}^{3+}$ ocorre nas faixas de $\mathrm{pH}$ entre 3 e 8 , conforme é mostrado no FIG.38. Em pH 5 há uma maior quantidade de $\mathrm{Am}^{3+}$ livre em solução e o início da formação de $\mathrm{AmOH}^{2+}$. Nesta faixa de $\mathrm{pH}$ provavelmente ocorre uma competição de $\mathrm{H}^{+}$. Quando o $\mathrm{pH}$ da solução é 6 , estas duas espécies se apresentam na mesma quantidade. Com o aumento do $\mathrm{pH}$, a quantidade de $\mathrm{Am}^{3+}$ diminui e há formação de outros complexos.

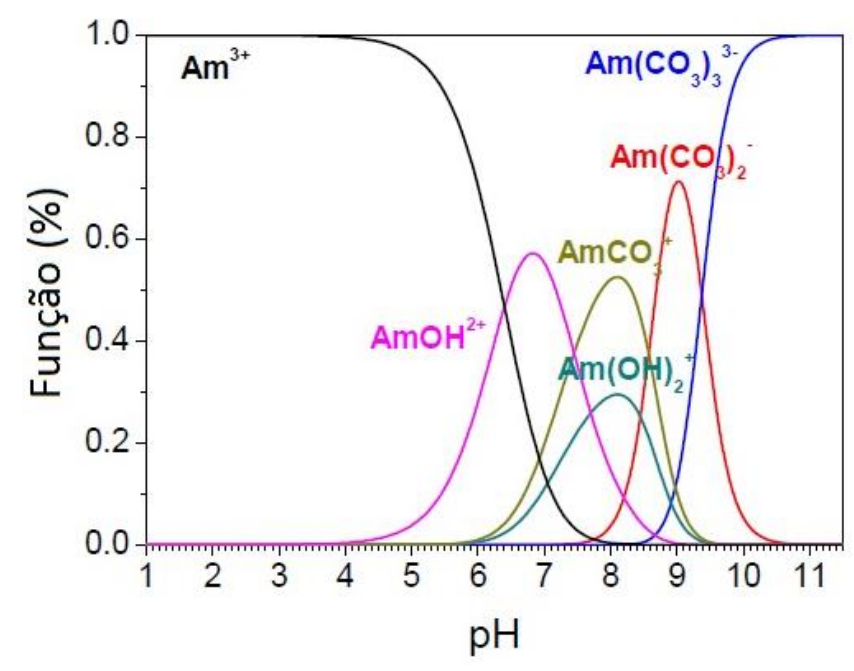

FIGURA 38 - Diagrama de especiação do amerício em solução Fonte: ROMANCHUK et al, 2013 
Comparando-se os resultados obtidos com a biossorção do césio, a biomassa ativada possue pouca influência no processo de biossorção do amerício. Em pH 3 e 5 há o deslocamento do equilíbrio da solução para a formação de ácido carboxílico, diminuindo os sítios de ligação e em pH 6 há a formação do complexo de $\mathrm{Am}(\mathrm{OH})_{2}{ }^{+}$, diminuindo a espécie Am3+ disponível para remoção.

\subsection{2 - Influência do tempo de contato}

Os estudos de adsorção dos íons de $\mathrm{Am}^{3+}$, apresentados na FIG.39, mostraram que em 10 minutos de contato há uma remoção de cerca de $93 \%$ e quantidade removida de $9,5 \mathrm{~g} \cdot \mathrm{mg}^{-1} \mathrm{em} 30$ minutos o equilíbrio é atingido.

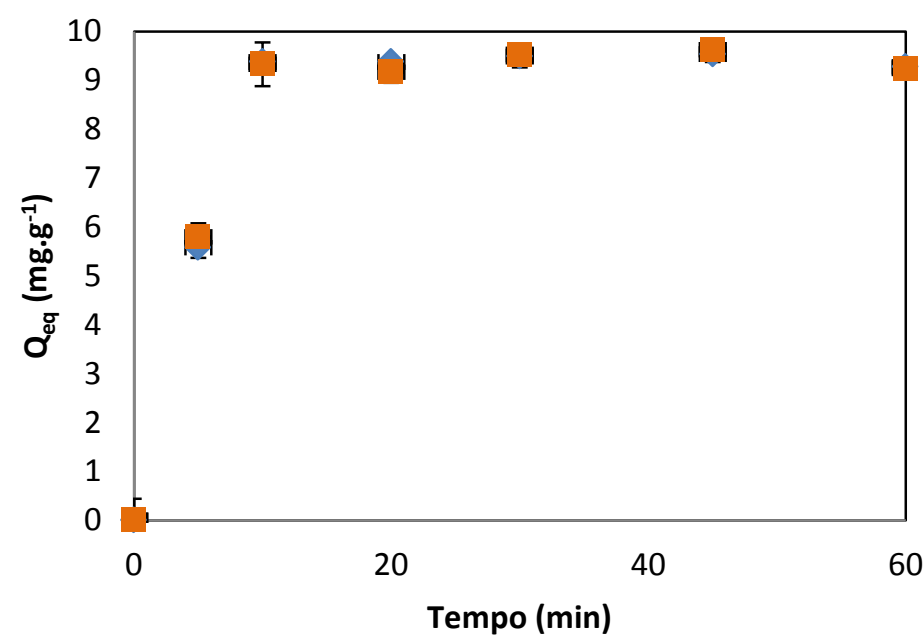

- Biomassa Bruta

Biomassa Ativada

(a)

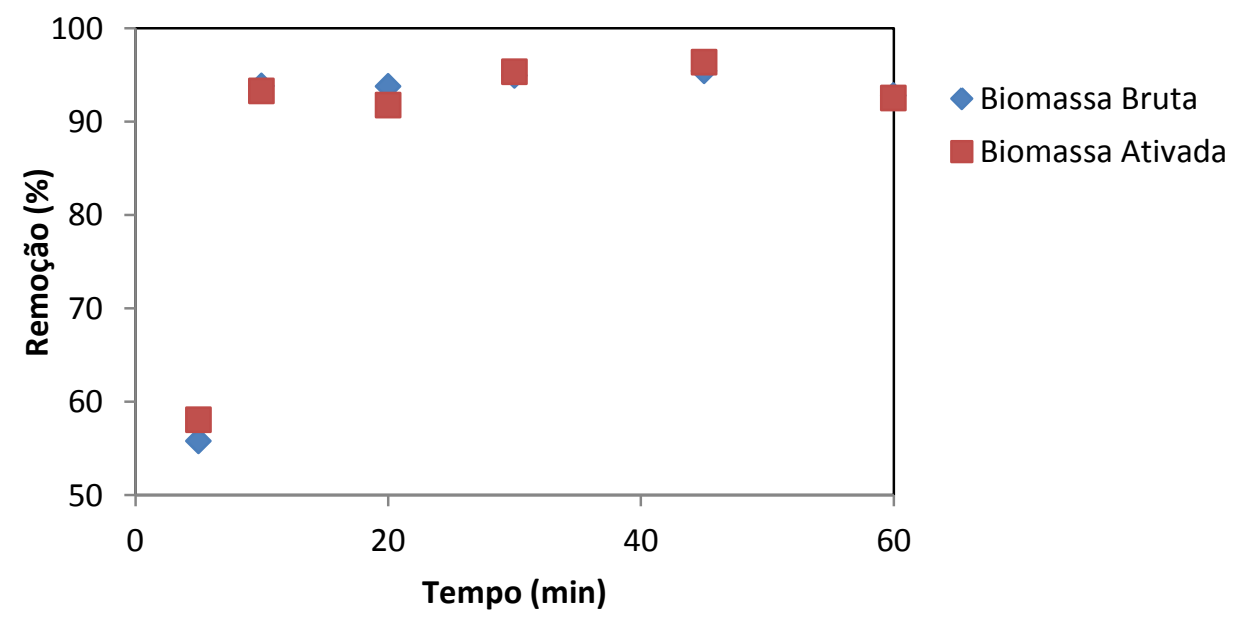

(b)

FIGURA 39 - (a) Influência do tempo de contato na adsorção de íons $\mathrm{Am}^{3+}$, (b)

Porcentagem de remoção em função do tempo de contato 


\subsection{3 - Influência do tamanho da partícula da biomassa}

Os resultados dos ensaios de adsorção do $\mathrm{Am}^{3+}$ foram semelhantes ao comportamento observado na remoção dos íons de $\mathrm{Cs}^{+}$, conforme é apresentado na TAB.11. Observou-se que, para a biomassa ativada, a porcentagem de remoção é um pouco superior em relação à biomassa bruta para ambos os tamanhos de partícula, mesmo assim, a saturação da partícula de 80 mesh ocorre mais rapidamente.

TABELA 11 - Remoção de $\mathrm{Am}^{3+}$ com fibra de coco em diferentes tamanhos

\begin{tabular}{ccc}
\hline \multicolumn{3}{c}{ Porcentagem de Remoção do Amerício (\%) } \\
\hline Tamanho partícula (mesh) & Biomassa bruta & Biomassa ativada \\
$\mathbf{3 5 - 5 0}$ & 84,4 & 96,2 \\
$\mathbf{5 0 - 8 0}$ & 50,4 & 95,3 \\
\hline
\end{tabular}

A superfície de contato do adsorvente e a interação com a fase líquida desempenham um importante papel no fenômeno da adsorção. $O$ fato de alguns metais apresentarem maior retenção em partículas menores é atribuído ao transporte de massa no interior das partículas do adsorvente e não apenas na superfície (JANSSON et al, 1996). Porém, as partículas maiores apresentam maior transferência de massa externa do que as partículas menores. (LEUSCH and VOLESKY, 1995).

Este fenômeno foi observado por OLIVEIRA et al. (2009), com bagaço de caju utilizando tamanhos de partícula semelhantes aos utilizados neste trabalho, para a remoção de íons de $\mathrm{Pb}^{2+}, \mathrm{Cu}^{2+}, \mathrm{Ni}^{2+}, \mathrm{Zn}^{2+}$ e $\mathrm{Cd}^{2+}$. Notou-se que para os dois primeiros íons, o tamanho de partícula pouco influencia na eficiência de remoção, já para o $\mathrm{Ni}^{2+}, \mathrm{Zn}^{2+}$ há um aumento no percentual de remoção com a diminuição do tamanho da partícula e para o $\mathrm{Cd}^{2+}$ o efeito é contrário. Este fato também foi observado por PINO (2005), para quem a diminuição do tamanho de partícula favoreceu o aumento da adsorção de $\mathrm{Cr}(\mathrm{VI})$ mas diminuiu a adsorção de $\mathrm{Cd} \mathrm{e} \operatorname{Cr}(I I I)$. 


\subsection{4 - Influência da concentração da solução}

As concentrações das soluções de amerício analisadas variaram de 50 a $600 \mathrm{~Bq} \cdot \mathrm{g}^{-1}$ e os resultados são apresentadas na FIG.40.

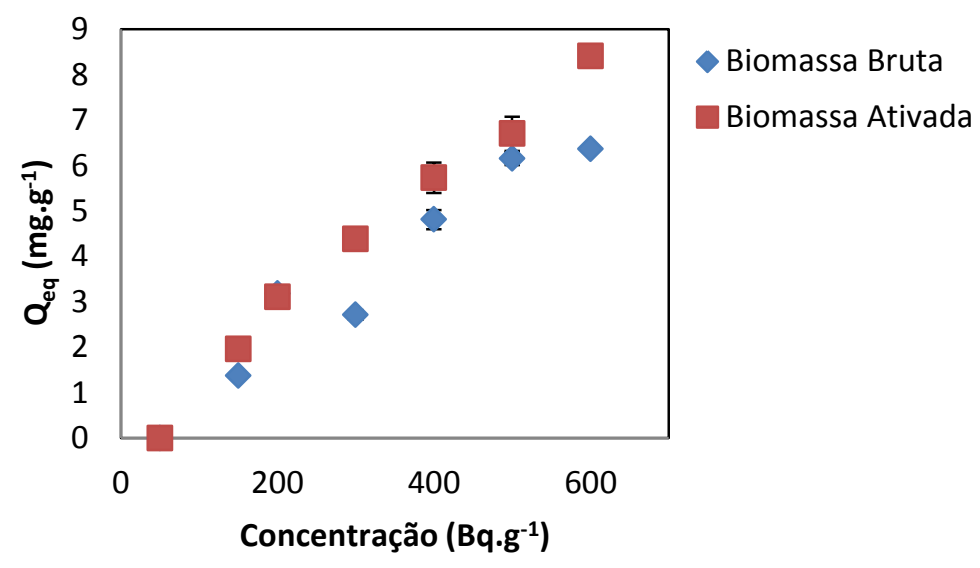

FIGURA 40 - Influência da concentração da solução na adsorção de íons $\mathrm{Am}^{3+}$

Para a solução de amerício com concentração de $600 \mathrm{~Bq} \cdot \mathrm{g}^{-1} \mathrm{com}$ a biomassa ativada, a capacidade de remoção foi de $8,41 \mathrm{mg} \cdot \mathrm{g}^{-1}$. É possível observar que o aumento da capacidade de remoção e o aumento da concentração da solução são proporcionais para a faixa estudada.

\subsection{5 - Isotermas de adsorção}

Os experimentos para obtenção das isotermas de adsorção do amerício foram realizados conforme descritos na subseção 4.3.2. A FIG.41 representa a isoterma de adsorção para o íon $\mathrm{Am}^{3+}$.

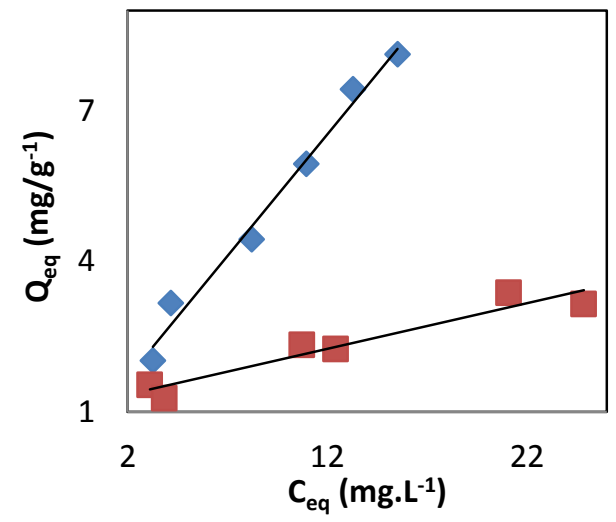

\section{- Biomassa Bruta}

Biomassa Ativada

FIGURA 41 - Isoterma de equilíbrio de adsorção da biomassa bruta e ativada para o íon $\mathrm{Am}^{3+}$ 
A relação entre a concentração final $\left(\mathrm{C}_{\mathrm{eq}}\right)$ e a quantidade removida $\left(Q_{\text {eq }}\right)$ para a adsorção do íon $\mathrm{Am}^{3+}$ apresenta um comportamento linear.

As FIG.42 e 43 representam a comparação entre as formas linearizadas das equações de Langmuir e Freundlich respectivamente.

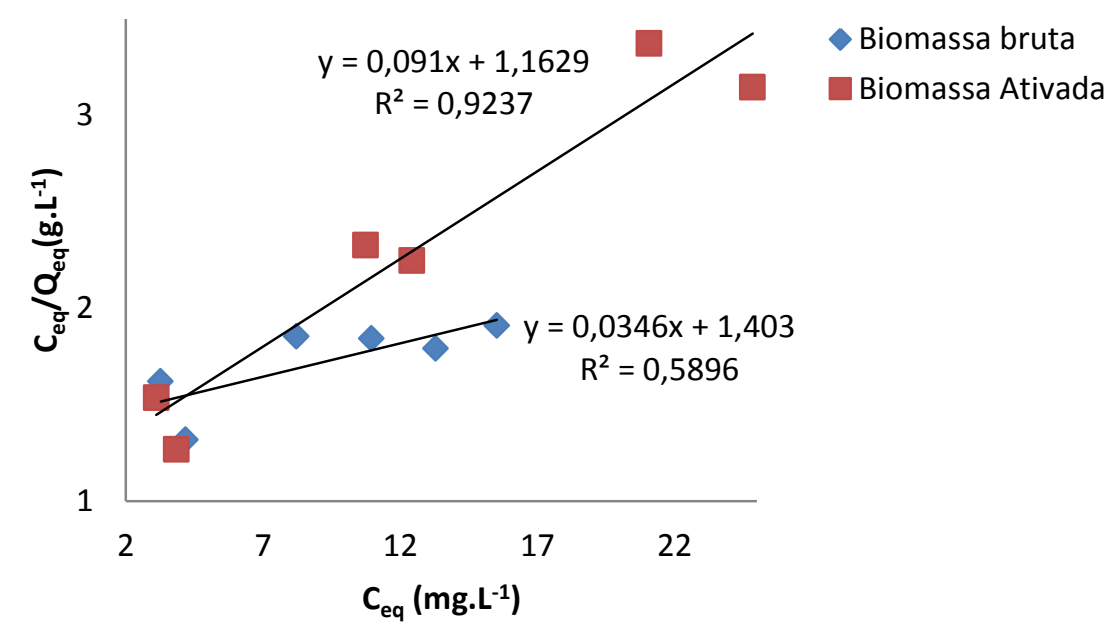

FIGURA 42 - Representação da isoterma de Langmuir na adsorção de íons $\mathrm{Am}^{3+}$ para a fibra de coco bruta e ativada

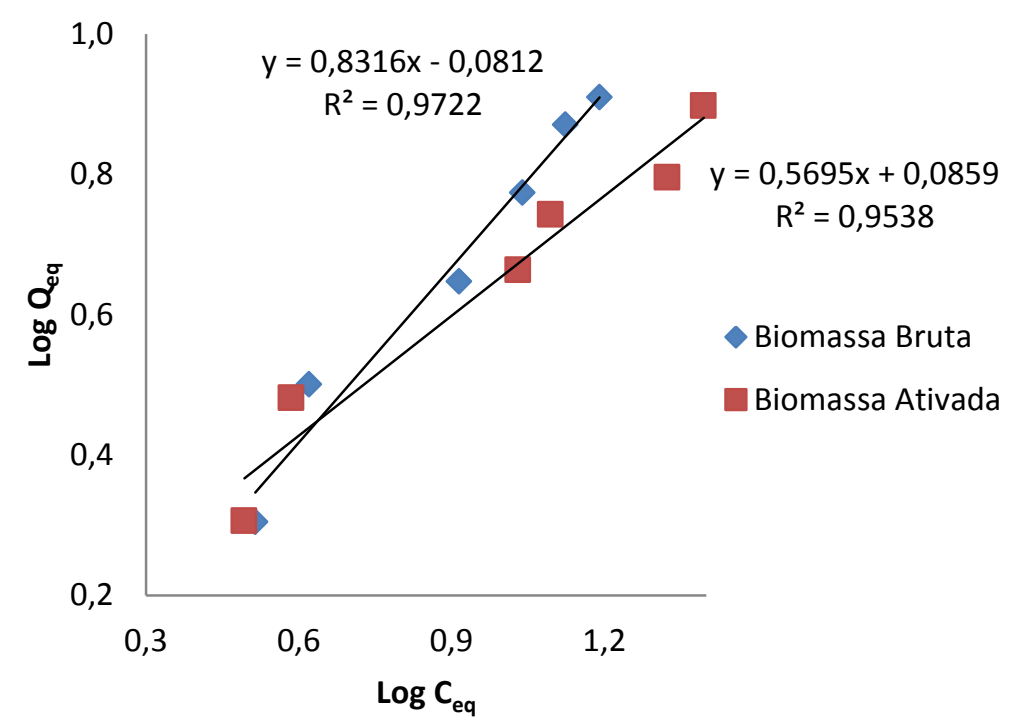

FIGURA 43 - Representação da isoterma de Freundlich na adsorção de íons $\mathrm{Am}^{3+}$ para a fibra de coco ativada e bruta

Os parâmetros obtidos no estudo das isotermas são apresentados na TAB.12. Os coeficientes de correlação indicam que tanto para a biomassa bruta e ativada o modelo de Freundlich é o que melhor se ajusta na adsorção de $\mathrm{Am}^{3+}$. 
TABELA 12: Parâmetros das isotermas para o processo de adsorção do $\mathrm{Am}^{3+}$ utilizando-se fibra de coco

\begin{tabular}{|c|c|c|c|c|c|c|}
\hline \multicolumn{7}{|c|}{ Biomassa Bruta } \\
\hline \multicolumn{7}{|c|}{ Parâmetros } \\
\hline Íon & \multicolumn{3}{|c|}{ Langmuir } & \multicolumn{3}{|c|}{ Freundlich } \\
\hline & $\mathrm{K}_{\mathrm{L}}\left(\mathrm{L} \cdot \mathrm{mg}^{-1}\right)$ & $Q\left(m g \cdot g^{-1}\right)$ & $\mathrm{R}^{2}$ & $\mathrm{~K}_{\mathrm{F}}\left(\mathrm{L} . \mathrm{g}^{-1}\right)$ & $1 / n$ & $\mathrm{R}^{2}$ \\
\hline $\mathrm{Am}^{3+}$ & 0,02 & 29,0 & 0,587 & 0,83 & 0,83 & 0,972 \\
\hline
\end{tabular}

\section{Biomassa Ativada}

\begin{tabular}{cccc|ccc} 
Íon & \multicolumn{3}{c}{ Langmuir } & \multicolumn{3}{c}{ Freundlich } \\
\hline & $\mathrm{K}_{\mathrm{L}}\left(\mathrm{L} \cdot \mathrm{mg}^{-1}\right)$ & $\mathrm{Q}\left(\mathrm{mg} \cdot \mathrm{g}^{-1}\right)$ & $\mathrm{R}^{2}$ & $\mathrm{~K}_{\mathrm{F}}\left(\mathrm{L} \cdot \mathrm{g}^{-1}\right)$ & $1 / \mathrm{n}$ & $\mathrm{R}^{2}$ \\
\hline $\mathrm{Am}^{3+}$ & 0,08 & 11,0 & 0,924 & 1,22 & 0,57 & 0,953 \\
\hline
\end{tabular}

Os valores de $n$ para a bioamassa bruta é 1,20 e para a biomassa ativada é de 1,75 indicando que os processos são favoráveis conforme descrito na subseção 3.10.1.

\subsection{6 - Estudos da cinética química}

Os gráficos referente ao modelo de pseudo-primeira ordem são apresentados nas FIG.44 e 45. O modelo de pseudo-segunda ordem é apresentado pelas FIG.46 e 47.

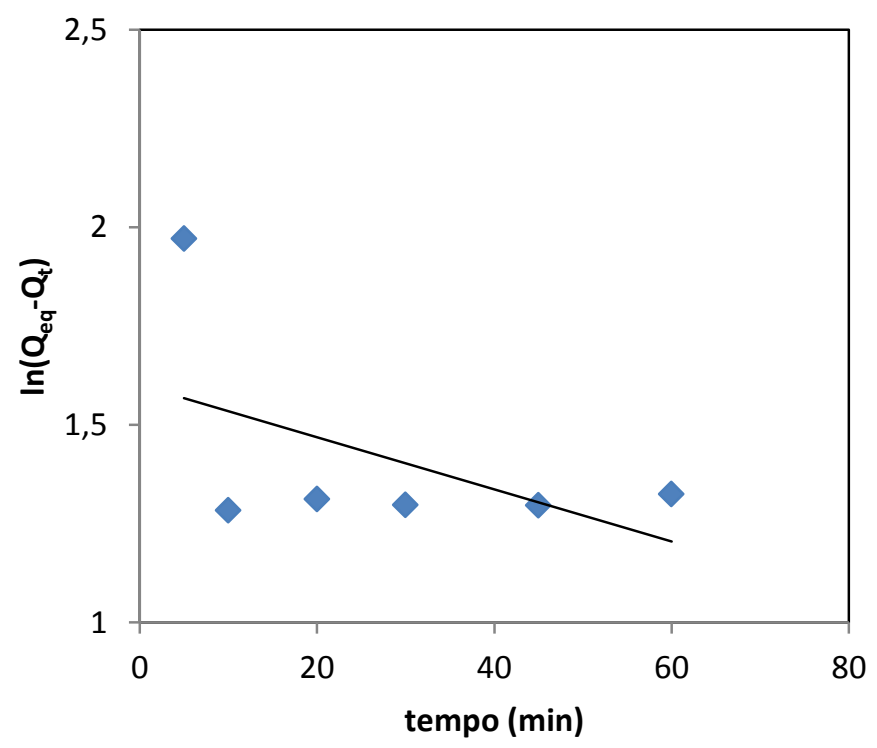

FIGURA 44 - Modelo linear de pseudo-primeira ordem para a adsorção de $\mathrm{Am}^{3+}$ em fibra de coco bruta 


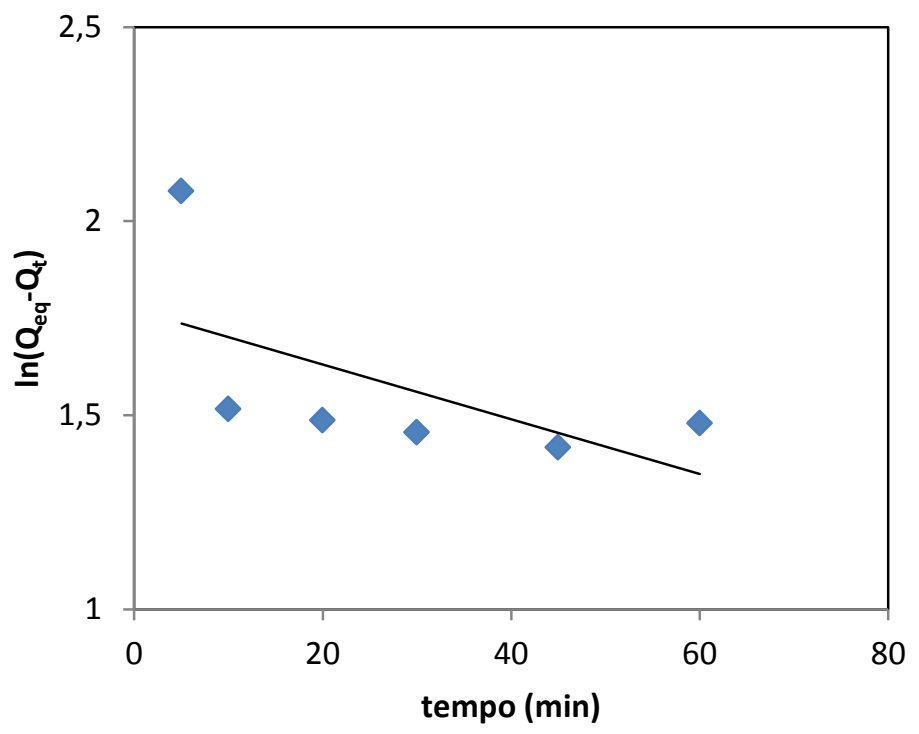

FIGURA 45 - Modelo linear de pseudo-primeira ordem para a adsorção de $\mathrm{Am}^{3+}$ em fibra de coco ativada

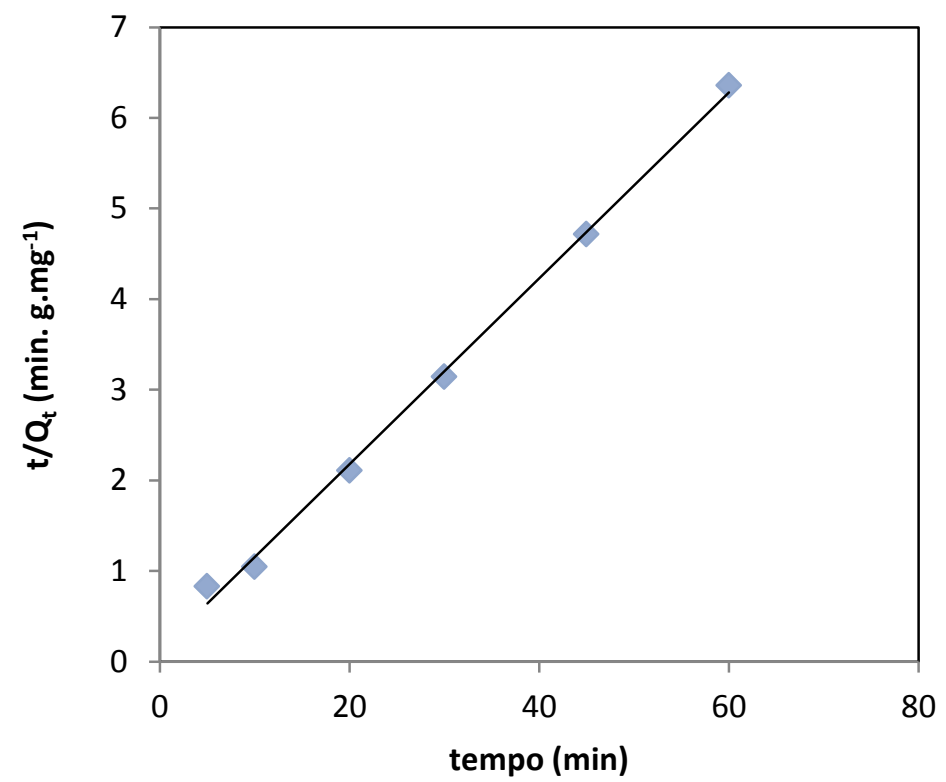

FIGURA 46 - Modelo linear de pseudo-segunda ordem para a adsorção de $\mathrm{Am}^{3+}$ em fibra de coco bruta 


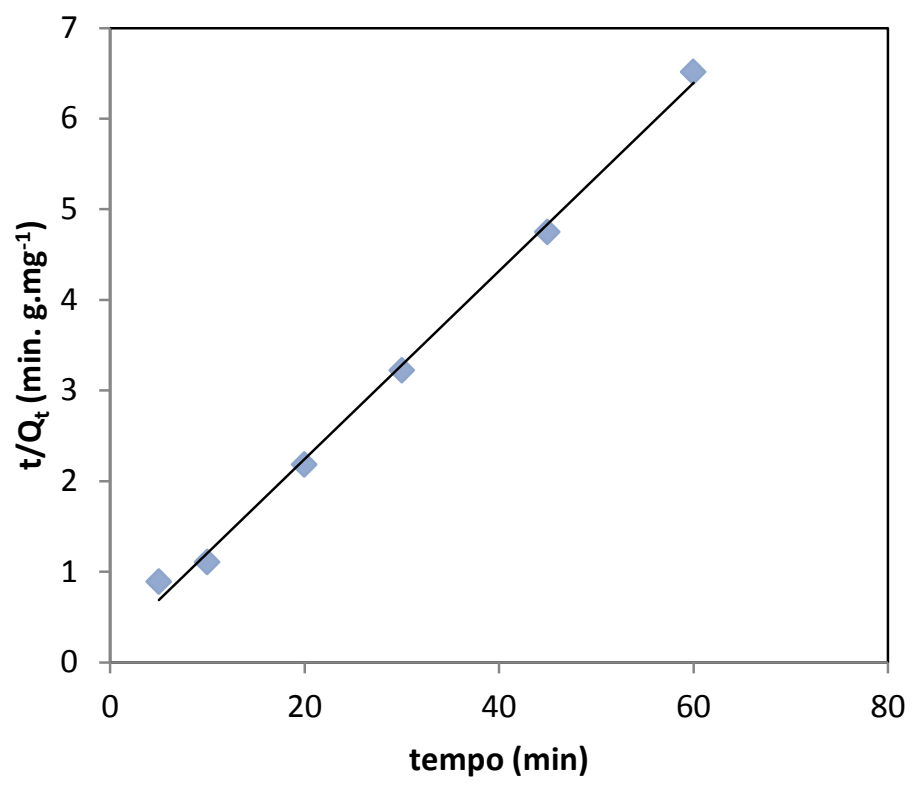

FIGURA 47 - Modelo linear de pseudo-segunda ordem para a adsorção de $\mathrm{Am}^{3+}$ em fibra de coco ativada

Assim como o processo de adsorção de césio, o modelo de pseudosegunda ordem também se ajusta ao processo de adsorção do amerício, o que demonstra que a adsorção é química.

A TAB.13 apresenta os dados obtidos por meio dos gráficos e dos estudos cinéticos e suas respectivas constantes.

TABELA 13: Parâmetros da cinética de adsorção na fibra de coco

\begin{tabular}{|c|c|c|c|c|c|c|c|}
\hline & \multicolumn{7}{|c|}{ Biomassa Bruta } \\
\hline \multirow{3}{*}{ Íon } & \multicolumn{7}{|c|}{ Parâmetros } \\
\hline & \multicolumn{3}{|c|}{ Pseudo-primeira } & \multicolumn{4}{|c|}{ Pseudo-segunda } \\
\hline & $\begin{array}{c}\mathrm{K}_{1} \\
\left(1 . \mathrm{min}^{-1}\right)\end{array}$ & $\begin{array}{c}Q_{e q} \\
\left(m g \cdot g^{-1}\right)\end{array}$ & $\mathrm{R}^{2}$ & $\begin{array}{c}\mathrm{K}_{2} \\
{\left[\mathrm{~g}\left(\mathrm{mg}^{-1} \cdot \mathrm{min}^{-1}\right)\right]}\end{array}$ & $\begin{array}{c}\mathrm{Q}_{\mathrm{t}} \\
\left(\mathrm{mg} \cdot \mathrm{g}^{-1}\right)\end{array}$ & $\begin{array}{c}\mathrm{Q} \\
\left(\mathrm{mg} \cdot \mathrm{g}^{-1}\right)\end{array}$ & $\mathrm{R}^{2}$ \\
\hline $\mathrm{Am}^{3+}$ & 0,015 & 4,956 & 0,260 & 0,082 & 9,540 & 9,756 & 0,997 \\
\hline & \multicolumn{7}{|c|}{ Biomassa Ativada } \\
\hline Íon & \multicolumn{4}{|c|}{ Pseudo-primeira } & \multicolumn{3}{|c|}{ Pseudo-segunda } \\
\hline & $\begin{array}{c}\mathrm{K}_{1} \\
\left(1 . \mathrm{min}^{-1}\right)\end{array}$ & $\begin{array}{c}\mathrm{Q}_{\mathrm{eq}} \\
\left(\mathrm{mg} \cdot \mathrm{g}^{-1}\right)\end{array}$ & $\mathrm{R}^{2}$ & $\begin{array}{c}\mathrm{K}_{2} \\
{\left[\mathrm{~g}\left(\mathrm{mg}^{-1} \cdot \mathrm{min}^{-1}\right)\right]}\end{array}$ & $\begin{array}{c}\mathrm{Q}_{\mathrm{t}} \\
\left(\mathrm{mg} \cdot \mathrm{g}^{-1}\right)\end{array}$ & $\begin{array}{c}Q \\
\left(m g \cdot g^{-1}\right)\end{array}$ & $\mathrm{R}^{2}$ \\
\hline $\mathrm{Am}^{3+}$ & 0,017 & 5,461 & 0,356 & 0,062 & 9,313 & 9,643 & 0,995 \\
\hline
\end{tabular}


Analisando os valores dos coeficientes de correlação foi possível verificar que o modelo de pseudo-segunda ordem é o mais adequado para o processo de biossorção do $\mathrm{Am}^{3+}$. Os valores de $\mathrm{Q}$ encontrados para a representação do modelo de pseudo-primeira ordem, cerca de $5 \mathrm{mg} \cdot \mathrm{g}^{-1}$, para as biomassas bruta e ativada não são coerentes com os valores encontrados experimentalmente que são aproximadamente $9,5 \mathrm{mg} \cdot \mathrm{g}^{-1}$.

\section{4 - Coeficiente de distribuição e energia livre de Gibbs}

O coeficiente de distribuição $(K d)$ foi calculado segundo a equação 9 a partir da solução de $40 \mathrm{mg} \cdot \mathrm{L}^{-1}$ para o césio e de $600 \mathrm{~Bq} \cdot \mathrm{g}^{-1}$ para o amerício. Os

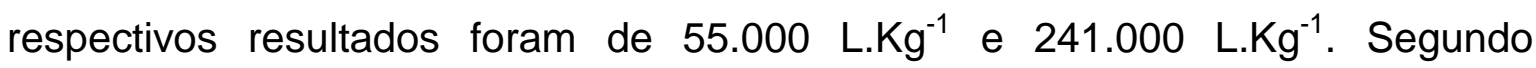
FRYXELL et al (2005), valores acima de $50000{\mathrm{~L} . \mathrm{Kg}^{-1}}^{-1}$ são considerados excelentes.

Por meio da equação 8 foi possível calcular a energia livre de Gibbs, com os valores de $\mathrm{K}_{\mathrm{L}}$ convertidos em L. $\mathrm{mol}^{-1}$. Os resultados são mostrados na TAB.14.

TABELA 14: Energia livre de Gibbs $\left(\mathrm{kJ} \cdot \mathrm{mol}^{-1}\right)$ para o processo de adsorção com fibra de coco

\begin{tabular}{lll}
\hline & $\mathbf{C s}^{+}$ & $\mathbf{A m}^{3+}$ \\
\hline Biomassa bruta & $-34,7$ & $-39,9$ \\
Biomassa ativada & $-31,7$ & $-36,4$ \\
\hline
\end{tabular}

Os valores negativos indicam que o processo de adsorção dos íons estudados nas biomassas de fibra de coco é espontâneo. 


\section{6) CONCLUSÕES}

Neste estudo foi possível avaliar a utilização da fibra de coco como adsorvente para o tratamento de rejeitos radioativos líquidos diluídos de baixa concentração contendo ${ }^{241} \mathrm{Am}$ e ${ }^{137} \mathrm{Cs}$.

Os resultados obtidos para $\circ{ }^{133} \mathrm{Cs}$ indicaram que a biomassa quimicamente modificada por peróxido de hidrogênio foi a mais eficiente na remoção devido ao aumento dos sítios ativos e à formação de carboxilatos pela oxidação em meio básico. Estes grupos são conhecidos pela sua alta seletividade por prótons, favorecendo, desta forma, a troca iônica entre o íon e a biomassa. Para a biossorção do ${ }^{241} \mathrm{Am}$, a ativação da biomassa apresentou pouca influência, indicando que o processo de adsorção ocorre mais na superfície do que no interior da fibra.

As melhores condições para a remoção de ${ }^{241} \mathrm{Am}$ foram de $94 \% \mathrm{com}$ uma solução de $\mathrm{pH}$ 5. Para o ${ }^{133} \mathrm{Cs}$ a melhor remoção foi de $75 \%$ em solução com pH 9,5. Para ambos os íons, a capacidade de remoção é diretamente proporcional ao aumento da concentração da solução para as faixas de concentração estudadas.

Os estudos cinéticos mostraram que o tempo de equilíbrio é atingido a partir de 30 minutos para ambos os íons e o modelo que melhor se ajusta aos processos de adsorção é o de pseudo-segunda ordem. O coeficiente de distribuição, ou seja, o potencial de adsorção, foi acima de $50.000{\mathrm{~L} . \mathrm{Kg}^{-1}}^{-1}$ para os dois íons, sendo considerado um valor muito bom. Os valores da energia livre de Gibbs comprovaram que o processo é espontâneo.

Os modelos de isotermas de Langmuir e Freundlich foram representativos para os estudos realizados, porém o coeficiente de correlação tanto para o ${ }^{241} \mathrm{Am}$ quanto para o ${ }^{133} \mathrm{Cs}$ indicam que o modelo de isoterma que melhor se ajusta é o de Freundlich para ambos os íons. Este modelo indica que a adsorção é heterogênea e ocorre em multicamadas. 


\section{REFERÊNCIAS BIBLIOGRÁFICAS}

AGENCY FOR TOXIC SUBSTANCES AND DISEASE REGISTRY- ATSDR; Toxicological Profile for americium, 2004. USA. Disponível em $<$ http://www.atsdr.cdc.gov/toxprofiles/tp156.pdf>. Acesso em 06 de março de 2013.

AJMAL, M.; KHAN, A.H.; AHMAD, S.; AHMAD, A.; "Role of sawdust in the removed of copper (II) from industrial wastes". Water Res, v. 32, p. 3085-3091, 1998.

AKAR, T., TUNALI, S.; "Biosorption characteristics of Aspergillus flavus biomass for removal of $\mathrm{Pb}(\mathrm{II})$ and $\mathrm{Cu}(\mathrm{II})$ ions from aqueous solutions", Bioresource Technol. v. 97, p 1780-1787, 2006.

ALMEIDA, I. P. S.; "Comunicação e interação com a sociedade dentro de um processo de construção de repositório de rejeitos - aspectos relevantes - Projeto CIS", CNEN - Rio de Janeiro, 2010. Disponível em <http://www.iaea.org /inis/collection/NCLCollectionStore/_Public/43/063/43063125.pdf>. Acesso em 20 de dezembro de 2013.

ANDRADE, A. M. DE ET AL; "Pirólise de resíduos do coco-da-baía (Cocos nucifera Linn) e análise do carvão vegetal". Rev. Árvore, v. 28, p. 707-714, 2004.

ANTUNES, P. D.; SAMPAIO, E. V. S. B.; JÚNIOR, A. L. G. F.; GALINDO, I. C. L.; SALCEDO, I. H.; "Distribuição de ${ }^{137} \mathrm{Cs}$ em três solos representativos do estado de Pernambuco", R. Bras. Ci. Solo, 34, p. 935-943, 2010.

ATKINS, P.; JONES, L.; "Princípios de Química - Questionando a vida moderna e o meio ambiente", 2006, Bookman, 3 ed.

BLEDZKI, A. K.; GASSAN, J.; "Composites reinforced with cellulose based fibres", Prog. Polym. Sci., v. 24, p. 221-274, 1999.

BONIOLO, M.R.; YAMAURA, M.; MONTEIRO, R. A.; "Biomassa residual para remoção de íons uranilo", Quim. Nova, v.33, p. 547-551, 2010.

BROWN, P.; JEFCOAT, I. A.; PARRISH, D.; GILL, S.; GRAHAM, E.; "Evaluation of the adsorptive capacity of peanut hull pellets for heavy metals in solution". Adv Environ. Res., v. 4, p. 19-29, 2000.

CHEN, Y; STIPANOVIC, A. J.; WINTER, W. T.; WILSON, D. B.; KIM, Y.; "Effect of digestion by pure cellulases on crystallinity and average chain length for bacterial and microcrystalline celluloses". Cellulose, v. 14, p. 283-293, 2007.

CLAIN, A. F.; AQUINO, J. O.; "Recuperação de ${ }^{241} A m$ de para-raios e detectores de fumaça", Quim. Nova, v. 22, p. 677-678, 1999.

COLLINS, K. E.; JARDIM, I. C. S.F.; COLLINS, C. H.; "O que é césio-137", Quim. Nova, v. 11, p.169-178, 1988. 
COMISSÃO NACIONAL DE ENERGIA NUCLEAR - CNEN; "História da Energia Nuclear". Disponível em <http://www.cnen.gov.br/ensino/apostilas/historia.pdf>. Acesso em 07 de janeiro de 2013.

COMISSÃO NACIONAL DE ENERGIA NUCLEAR - (CNEN); "Gerencia de Rejeitos Radioativos em Instalações Radiativas (CNEN-NE-6.05)", 1985

COMISSÃO NACIONAL DE ENERGIA NUCLEAR - (CNEN); "Diretrizes básicas de proteção radiológica (CNEN-NN-3.01:2011)", 2011

CONSELHO REGIONAL DE ENGENHARIA E AGRICULTURA-RJ- (CREA); "Aproveitamento da casca de coco verde", Janeiro de 2010 Disponível em: <http://www.natucoco.com.br/index.php/pt/multimidia/noticias/31aproveitamento-da-casca-do-coco-verde-lixo-transformado-em-riqueza> Acesso em 19 de agosto de 2013.

CORRADINI. E.; ROSA, M. F.; MACEDO, B. P; PALADIN, P. D.; MATTOSO, L. H. C.; "Composição química, propriedades mecânicas e térmicas da fibra de frutos de cultivares de coco verde" - Rev. Bras. Frutic, v. 31, p. 837-846, 2009

CUENCA, M. A. G; "A cultura do coqueiro - importância econômica da cocoicultura no Brasil", Embrapa Tabuleiros Costeiros, Sistemas de Produção, Nov, 2007; Disponível em <http://sistemasdeproducao.cnptia.embrapa.br/ FontesHTML/Coco/ACulturadoCoqueiro/importancia.htm.> Acesso em 22 de setembro de 2013.

CUENCA, M. A. G.; RESENDE, J. M.; SAGGIN JÚNIOR, O. J. et al.; "Mercado brasileiro do coco: situação atual e perspectivas". In: ARAGÃO, W. M. Coco: pós colheita. Brasília, DF: Embrapa, p. 11-18, 2002.

CRYSTAL, T.; "Polucita (Pólux)"; Disponível em: <http://www.crystal-treasure. com/product_info.php/language/es/info/p4544_2-Polluzit-Kristall.html> Acesso em 12 de janeiro de 2013.

DANILIN, L.D., DROZHZHIN, V.S.; "Inorganic sorbents based modified microspheres for the treatment of liquid radioactive waste", Radiochem. v. 49, p. 319-322, 2007

DELLAMANO, J. C.; "Gestão de Rejeitos Radioativos",2010, Disponível em <files.confime.webnode.com.br/200000027.../Palestra\%202.pdf>., Acesso em 12 de outubro de 2013.

DHAMI, P. S.; KANNAN, R.; NAIK, P. W.; GOPALAKRISHNAN, V; RAMANUJAM, A.; SALVI, N. A.; CHATTOPADHYAY, S.; "Biosorption of americium using biomasses of various Rhizopus species", Biotechnol Lett, v. 24 p. 885-889, 2002.

DULAMA, M.; DENEANU, N.; DULAMA, C.; PAVELESCU, M.; "Experimental studies concerning the semi permeable membrane separation efficiency for ${ }^{134} \mathrm{Cs}$, ${ }^{137} \mathrm{Cs},{ }^{57} \mathrm{Co},{ }^{58} \mathrm{Co},{ }^{60} \mathrm{Co},{ }^{54} \mathrm{Mn}$ in liquid radioactive waste. Treatment of secondary waste from POD decontamination procedure", Rev. Chime, v 59, p. 544-549, 2008. 
EBNER, A.D., RITTER, J.A., NAVRATIL, T.D., "Adsorption of cesium, strontium and cobalt ions on magnetite and a magnetite-silica composite", Ind. Eng. Chem. Res. v. 40, p 1615-1623, 2001.

EL-KAMASH, A.M.; "Evaluation of zeolite a for the sorptive removal of $\mathrm{Cs}^{+}$and $\mathrm{Sr}_{2}{ }^{+}$ions from aqueous using batch and fixed bed column operations, J. Hazard. Mater, v. 151, p. 432-445, 2008.

EMPRESA BRASILEIRA DE PESQUISA AGROPECUÁRIA - (EMBRAPA); "Beneficiamento da casa de coco verde", 2012. Disponível em: <http://www.ceinfo.cnpat.embrapa.br/arquivos/artigo_3830.pdf.> Acesso em 22 de setembro de 2013.

FENGEL, D.; WEGNER, G.; "Wood Chemistry, Ultrastructure, Reaction”. Walter de Gruyer, 2da. Ed. Unich. 1989.

FINSTON, H. L., KINSLEY M. T., "The radiochemistry of Cesium", Brookhaven National Laboratory Upton, NY, 1961.

FONTONELE, R. E. S.; "Cultura do coco no Brasil: caracterização do mercado atual e perspectivas futuras", XLIII CONGRESSO DA SOBER - 24 a 27 de Julho de 2005.

FRYXELL, G. E.; LIN, Y.; FISKUM, S.; BIRNBAUM, J. C.; WU, H.; "Actinide Sequestration Using Self-Assembled Monolayers on Mesoporous Supports", Environ. Sci. Technol, v. 39, p. 1324-1331, 2005

GABALLAH, I.; KILBERTUS, G.; "Elimination of $\boldsymbol{A s}, \boldsymbol{H g}$ and $\mathbf{Z n}$ from synthetic solutions and industrial effluents using modified barks", In: Misra, M. (ed.), Separation process: Heavy metals, ions and minerals", The minerals, Metals \& Materials Society, 1994.

GALLO, L. A.; "Carboidratos"; Disponível em <http://docentes.esalq.usp.br /luagallo/carboidratos.html> Acesso em 22 de setembro de 2013.

GARG, U.; KAUR, M. P.; JAWA, G. K.; SUD, D.; GARG, V. K.; "Removal of cadmium (II) from aqueous solution by adsorption on agricultural waste biomass" J. Hazard. Mater., v. 154, p. 1149-1157, 2008.

GASSER, M.S.; El-HEFNY, N.E.; DAOUD, J.A.; "Extraction of Co(II) from aqueous solution using emulsion liquid membrane”, J. Hazard. Mater, v. 151, p. 610-615, 2008.

GOTTIPATI, R.; MISHRA, S.; "Application of biowaste (waste generated in biodiesel plant) as an adsorbent for the removal of hazardous bye - methylene blue - from aqueous phase", Braz. J. Chem. Eng., v. 27, 2010.

HAIDER, K; LIM S.; FLAIG, W.; Holzforshung, 1964, Disponível em <http://www.subirimagenes.com/imagen-lignina-7257383.html> Acesso em 22 de setembro de 2013. 
HANDBOOK OF CHEMISTRY AND PHYSICS, 94th edn., CRC Press, p. 76-79, 2013.Disponível em <http://www.hbcpnetbase.com/> Acesso em 23 de dezembro de 2013.

HART, W. A. \& BEUMEL, O. F, Jr., WHALEY T. P., "The Chemistry of Lithium, Sodium, Potassium, Rubidium, Cesium and Francium", Pergamon Texts in Inorganic Chemistry, v. 13, Pergamon Press, 1975.

HIROMOTO, G.; DELLAMANO, J.C.; MARUMO, J.T.; ENDO, L.S.; VICENTE, R.; HIRAYAMA, T., "Introdução à gerência de rejeitos radioativos", Instituto de Pesquisas Energéticas, Departamento de Rejeitos Radioativos, 1999.

HYDE, K. E.; SEABORG, T. G; "The transuranium elements - Preprint of a contribution to Volume 39, Handbuch der Physik", 1956. Disponível em: $<$ http://escholarship.org/uc/item/56h2r51f\#page-1>, Acesso em 07 de dezembro de 2013.

INSTITUTO BRASILEIRO DE GEOGRAFIA E ESTATÍSTICA - (IBGE) "Estatística de Produção do coco, 2009". Disponível em <http://www.agencia.cnptia. embrapa.br/gestor/coco/arvore/CONT000fo7hz6ox02wyiv8065610d6ky3ary.html> Acesso em 22 de setembro de 2013.

JANSSON. C. M.; GUIBAL, E.; ROUSSY, J.; SURJOUS, R.; LE CLOIREC, P.; "Dynamic removal of uranium by chitosan: influence of operating parameters". Water Sci. Technol. v. 34, p. 169-177, 1996.

JOE, J. H.; "Health Effects of the Japanese Nuclear Accident", Mount Kisco, NY, Disponível em <http://www.hcli.com/health-effect-from-japanese-nuclearaccident/>, Acesso em 09 de dezembro de 2013.

JOHNSON, P. D.; WATSON, M. A.; BROWN, J.; JEFCOAT, I. A.; "Peanut hull pellets as a single use sorbent for the capture of $\mathrm{Cu}(\mathrm{II})$ from waste water", Waste Manage, v.22, p. 471-480, 2002.

JUNIOR, O. K.; GURGEL, L. V. A.; MELO, J. C. P.; BOTARO, V. R.; MELO, T. M. S.; GIL, R. P. F.; GIL, L. F.; "Adsorption of heavy metal ion from aqueous single metal solution by chemically modified sugarcane bagasse". Bioresource Technol, v. 98, p. 1291-1297, 2007.

KADIRVELU, K.; THAMARAISELVI, K.; NAMASIVAYAM, C.; "Adsorption of nickel (II) from aqueous solution onto activated carbon prepared from coir pith", Sep Purif Technol, v.24, p. 497-505, 2001

KADIRVELU, K.; NAMASIVAYAM, C.; "Activated carbon from coconut coir pith as metal adsorbent: adsorption of Cd(II) from aqueous solution", Sep Purif Technol v.7, p. 471-478, 2003

KAPOOR, A., VIRARAGHAVAN, T., CULLIMORE, D.R.; "Removal of heavy metals using the fungus Aspergillusniger", Biores. Techn, v.70, p. 95-104, 1999. 
KEDARI, C. S.; PANDIT, S. S.; PARIKH, K. J.; TRIPATHI, S. C.; "Removal of ${ }^{241} \mathrm{Am}$ from aqueous nitrate solutions by liquid surfactant membrane containing 2ethylhexyl phosphonic acid mono-2-ethylhexyl ester as ion carrier", Chemosphere, v. 80, p. 433-437, 2010.

KIM, J W.; SOHN, M. H.; KIM, D. S.; SOHN, S. M.; KNOW, Y. S.; "Production of granular activated carbon from waste walnut shell and its adsorption characteristics for $\mathrm{Cu}^{2+}$ ion", J Hazardous Mater, v. 85, p. 301-315, 2001.

LEUSCH, A.; VOLESKY, B.; "The influence of film diffusion on cadmium biosorption by marine biomass”, J. Biotechnol. v. 43, p. 1-10, 1995.

LIAO, J.; LIU, N.; YANG, Y.; LUO, S.; LUO, Q.; AN, Z.; DUAN, Y.; LIU, M.; ZHAO, P.; "Preliminary investigation on biosorption mechanism of ${ }^{241} \mathrm{Am}$ by Rhizopusarrhizus", J. Radional Nucl Chem, v. 277, p. 329-336, 2008.

LIU, N.; LIAO, J.; YANG, Y.; LUO, S; LUO, Q.; AN, Z; DUAN, Y. LIU, M.; ZHAO, $\mathrm{P}$.; "Biosorption of ${ }^{241} \mathrm{Am}$ by Saccharomyces cerevisiae: Preliminary investigation on mechanism", J. Radional Nucl Chem, v. 275, p. 173-180, 2008.

MALIK, A.; "Metal bioremediation through growing cells", Environ Int, v.30, p.261278, 2004.

MARTINS, R.C.; JÚNIOR, L. A. J.; "Evolução da produção de coco no Brasil e o comércio internacional: panorama 2010" - Embrapa, p. 28, 2011

MARTINHO, E.; "Residuos Radiactivos, Energia Nuclear - Bases", 2012. Disponível em <http://energianuclear-bases.blogspot.com.br/.> Acesso em 12 de outubro de 2013.

MARTÍN-LARA, M.A.; PAGNANELLI, F.; MAINELLI, S.; CALERO, M.; TORO, L.; "Chemical treatment of olive pomace: Effect on acid-basic properties and metal biosorption capacity", J Hazardous Mater, v. 156, p. 448-457, 2008.

MEMON, J. R.; MEMON, S.Q.; BHANGER, M. I.; MEMON, G.Z.; EL-TURKI,A.; ALLEN, G.C.; "Characterization of banana peel by scanning electronmicroscopy and FT-IR spectroscopy and its use for cadmium removal", Colloid Surface B: Biointerfaces, v. 66, p. 260-265, 2008.

MIMURA, H.;SAITO, M.;AKIBA, K.;ONODERA, Y.; "Selective uptake of cesium by ammonium molybdophosphate (AMP)-calcium alginate composites", J. Nucl.

Sci. Technol. v.38, p. 872-878, 2001.

MINFIND; "Rhodizite"; Disponível em http://www.minfind.com/mineral-114915.html Acesso em 12 de janeiro de 2013.

MIRÓ, C.; BAEZA, A.; SALAS, A.; VALLE, J. F. P.; VILLEGAS, J. P.; "Adsorption of ${ }^{241} \mathrm{Am}$ and ${ }^{226} \mathrm{Ra}$ from natural water by wood charcoal", Appl Radiat Isotopes, v. 66, p. $95-102,2008$. 
MISHRA, S. P.; TIWARI, D.; "Biosorptive behavior of some dead biomasses in the removal of Sr (85+89) from aqueous solutions". J. Radioanal. Nucl. Chem. v. 251, p. 47-53, 2002

MÖLLER, S.V., "Aplicações industriais das radiações ionizantes radioatividade", Universidade Federal do Rio Grande do Sul, Disponível em <http://www.segurancaetrabalho.com.br/download/radioatividade.pdf >,Acesso em 20 de novembro de 2013.

MONTANHER, S.F., "Avaliação do potencial de adsorção de $U$, $T h, P b, Z n$ e Ni pelas fibras de coco", 2009 Tese (Doutorado) - Universidade Estadual de Maringá

MONTANHER, S.F.; OLIVEIRA, E.A.; ROLLEMBERG, M.C.; "Utilization of Agroresidues in the metal ions removal from aqueous solutions" In: LEWINSKY, A.A. (Ed). Hazardous Materials and Wastewater: Treatment, Removal and Analysis. Nova York: Nova Science Publishers, 2007.

MONTEIRO, R.A., "Avaliação do potencial de adsorção de $U$, $T h, P b, Z n$ e $\mathbf{N i}$ pelas fibras de coco", 2009, Dissertação (Mestrado) Instituto de Pesquisas Energéticas e Nucleares

MORAIS, S. A. L.; NASCIMENTO, E. A.; MELO, D. C; "Análise da madeira de Pinus oocarpa parte I - estudo dos constituintes macromoleculares e extrativos voláteis". Rev. Árvore, v. 29, p. 461-470, 2005.

MORSS, L. R.; EDELSTEIN, N. M. FUGER, J.; "The chemistry of the actinide and transactinide elements". Chapter Americium, v. .2 - Wolfgang $\mathrm{H}$. Runde and Wallace W. Schulz. 3ed, Springer, 2006.

MOTHÉ, C. G.; MIRANDA, I. C.; "Characterization of sugarcane and coconut fiber by thermal analysis and FTIR", J Therm Anal Calorim, v. 97, p. 661-665, 2009

NGAH, W. S. W.; HANAFIAH, M.A.K. M.; "Removal of heavy metal ions from wastewater by chemically modified plant wastes as adsorbents: A review", Biores. Techn., v. 99, p. 3935-3948, 2008.

NASERNEJAD, B.; ZADEH, T. E.; POUR, B. B.; BYGI, M. E.; ZAMANI, A.; "Comparison for biosorption modeling of heavy metals ( $\mathrm{Cr}$ (III), $\mathrm{Cu}$ (II), Zn (II)) adsorption from wastewater by carrot residues", Process Biochem, v. 40, p.13191322, 2005

NASIR, M.H.; NADEEM, R.; AKHTAR, K.; HANIF, M.A.; KHALID A.M.; "Efficacy of modified distillation sludge of rose (Rosa centifolia) petals for lead(II)and zinc(II) removal from aqueous solutions", J Hazardous Mater v. 147, p. 1006-1014, 2007.

NILCHI, A.; ATASHI, H.;JAVID, A. H.;SABERI, R.; "Preparation of PAN-based adsorbers for separation of cesium and cobalt from radioactive wastes", Appl. Radiat. Isot. v.65, p. 482-487, 2007. 
NORONHA, D. M.; PIUS, I. C.; MUKERJEE, S. K.; "Preparation of thorium oxalate-silica sorbent and its application for the sorption of americium from aqueous solutions", J Radioanal Nucl Chem, v. 289, p. 75-81, 2011.

OLIVEIRA, A.G.; SOUZA, F. W.; MOREIRA, S. A.; NASCIMENTO, R. F.; BRITO, E. S.; "Remoção de metais de solução aquosa usando baguaçu de caju". Quim. Nova, v. 32, p. 1717-1722, 2009.

ORHAN, Y.; BUYUKGUNGOR, H.; "Removal of heavy metals by using agricultural wastes", Water Sci Technol, v. 28, p. 247-255, 1993

ORTIZ, N. "Estudo da utilização de magnetita como material adsorvente nos metais $\mathrm{Cu}^{2+}, \mathrm{Pb}^{2+}, \mathrm{Ni}^{2+}$ e $\mathrm{Cd}^{2+}$ em solução", 2000, Tese (Doutorado) Instituto de Pesquisas Energéticas e Nucleares

PARAB, H.; JOSHI, S.; SHENOY, N.; LALI, A.; SUDERSANAN, M.; "Determination of kinetic and equilibrium parameters of the batch adsorption of $\mathrm{Co}(\mathrm{II}), \mathrm{Cr}(\mathrm{III})$ and $\mathrm{Ni}(\mathrm{II})$ onto coir pith", Process Biochemistry, v. 41, p. 609-615, 2006.

PARK, Y; LEE, Y. C.; SHIN, W. S.; CHOI, S. J.; "Removal of cobalt, strontium and cesium from radioactive laundry waste water by ammonium molybdophosphatepolyacrylonitrile (AMP-PAN)", Chem Eng J, v. 162, p. 685-695, 2010

PARROTTA, JOHN A.; "Cocos nucifera L. Coconut, Coconut palm, Palma de coco. Palmae. Palm family.", New Orleans, LA: USDA Forest Service, International Institute of Tropical Forestry, 1993.

PAVIA, D.; LOMPMON, G.; KRIZ, G. S; VYVYAN, J. R; "Introdução à espectroscopia", Trad. $4^{\mathrm{a}}$ ed. Norte Americana, Cengage Learning, 2010.

PERGHER, S. B. C.; CAOVILLA, M.; DETONI, C.; MACHADO, N. R. C. F.; "Remoção de $\mathrm{Cu}^{+2}$ de soluções aquosas em zeólita NaX. Efeito da granulometria". Quím Nova, v. 28, p.397-401, 2005.

PINO, G. A. H.; "Biossorção de metais pesados utilizando pó de casca de coco verde", 2005, Dissertação (Mestrado) Pontifica Universidade Católica do Rio de Janeiro

RAHMAN, R. O. A.; IBRAHIUM, H. A.; HUNG, Y.T.; "Liquid Radioactive Wastes Treatment: A Review", Water, v. 3, p. 551-565, 2011.

RAZERA, I. A. T.; "Fibras lignocelulósicas como agente de reforço de compósitos de matriz fenólica e lignofeólica", 2006, Tese (Doutorado) Universidade de São Paulo

ROMANCHUK, A. Y.;SLESAREV, A. S.; KALMYKOV, S. N.; KOSYNKIN, D. V.; TOUR, J. M.; "Graphene Oxide for Effective Radionuclide Removal", Phys. Chem. Chem. Phys", v. 15, p. 2321- 2327, 2013. 
ROSA, M. F.; SANTOS, F. J. S.; MONTENEGRO, A. A. T.; ABREU, F. A.P; CORREIA, D.; ARAUJO, F. B. S.; NORÕES, E. R. V.; "Caracterização do pó de casca de coco verde usado como substrato agrícola", Comunicado Técnico N54, p. 1-6, 2001. Disponível em <http://www.cnpat.embrapa.br/publica/pub/ComTec /cot_54.pdf>, Acesso em 10 de dezembro de 2013.

RUTHVEN, D. M.; "Principles of adsorption and adsorption process". United States of America: Wiley - Interscience Publication, 1984.

SALIBA, E. O. S.; RODRIGUEZ, N. M.; MORAIS, S. A. L.; PILÓ-VELOSO, D. "Ligninas - métodos de obtenção e caracterização química". Ciência Rural, v.31, p. 917-928, 2001.

SANHUEZA, J. T.; "Métodos de remoção de cromo de águas residuais". Disponível em <http://www.icp.csic.es/cyted/Monografias/MonografiasTeneria/ capitulov.htm> Acesso em 20 de dezembro de 2013.

SHARMA, D. C.; FORSTER, C. F.; "A preliminary examination into the adsorption of hexavalent chromium using low-cost adsorbents", Bioresourche Technol. v. 47, p. 257-264, 1994.

SHUKLA, S. R.; ROSHAN, S. PAI.; SHENDARKAR, A. D.; "Adsorption of Ni(II), Zn(II) and Fe(II) on modified coir fibers", Sci Technol, v. 47, p. 141-147, 2006.

SHUKLA, S. R.; GAIKAR, V. G.; PAI, R. S.;SURYAVANSHI, U.S.; "Batch and Column Adsorption of $\mathrm{Cu}(\mathrm{II})$ on Unmodified and Oxidized Coir", Sci Technol, v. 44, p. 40-62, 2009.

SHULZ, W. W.; "The chemistry of Americium", Atlantic Richfield Hanford Company, Technical Information Center Energy Research and Development Administration, 1976. Disponível em <http://www.osti.gov/scitech/servlets/purl /7232133>. Acesso em 07 de dezembro de 2013.

SILVA, G. C.; "Mecanismo de acumulação de ferro e arsênio em biomassa vegetal fibrosa”, 2008, Dissertação (Mestrado) - Universidade Federal da Minas Gerais

SILVA, R. V.; SPINELLI, D.; FILHO, B. W. W.; NETO, S. C.; CHIERICE, G. O.; TARPANI, J. R.; "Fracture toughness of natural fibers/castor oil polyurethane composites". Compos Sci Technol, v.66, p.1328-1335, 2006.

SILVA, R. et al.; "Aplicações de fibras lignocelulósicas na química de polímeros e em compósitos". Quím. Nova, São Paulo , v. 32, p.661-671, 2009.

SILVEIRA, M. S.; “Aproveitamento das cascas de coco verde para produção de briquete em Salvador - BA", 2008, Dissertação (Mestrado) - Universidade Federal da Bahia

SINGH, K. K.; HASAN, S. H.; RASTOGI, R.; "Removal of cadmium from wastewater using agricultural waste rice polish", J Hazard Mater, v. 121, p.51-58, 2005 
SINHA, P.K.; LAL, K.B.; PANICKER, P.K.; KRISHNASAMY, V.; "A comparative study on indigenously available synthetic zeolites for removal of strontium from solutions by ion-exchange", Radiochem. Acta, v. 7, p.157-163, 1996.

SOUZA, F.W. et al; "Uso da casa de coco verde como adsorbente na remoção de metais tóxicos", Quim. Nova, v.30, p. 1153 - 1157, 2007.

STREET, K. J.; GHIORSO, A.; SEABORG, G. T.; "The Isotopes of Americium"; Physical Review, 1950, University of California, Berkeley. Disponível em <http://link.aps.org/doi/10.1103/PhysRev.79.530>, Acesso em 06 março de 2013.

TANOBE, V. O. A.; "Caracterização de fibras de esponjas de Luffa cylindrica para utilização em compósitos de matriz polimérica", 2007, Dissertação (Mestrado). Universidade Federal do Paraná

TAUHATA, L.; SALATI, I. P. A.; PRINZIO, R. D.; PRINZIO, A. D.; "Radioproteção e Dosimetria: Fundamentos", 2003, CNEN, 5 ed., Rio de Janeiro

TODD, T.A.; ROMANOVSKIY, V.N.; "A comparison of crystalline silicotitanate and ammoniummolybdophosphate-polyacrylonitrile composite sorbent for the separation of cesium from acidic waste", Radiochem. v. 47, p.398-402, 2005

TOMCZAK, F.; "Estudos sobre a estrutura e propriedades de fibras de coco e curauá do Brasil', 2010, Tese (Doutorado) Universidade Federal do Paraná

TRANTER, T. J.; HERBST, R. S.; TODD, T. A.;OLSON, A. L.;ELDREDGE, H. B.; "Evaluation ofammoniummolybdophosphate-polyacrylonitrile (AMP-PAN) as a cesium selective sorbent for the removal of 137Cs from acidic nuclear waste solutions", Adv. Environ. Res. v. 6, p.107-121, 2002.

TRIPATHI, S. C.; KANNAN, R.; DHAMI, P. S.; NAIK, P. W.; MUNSHI, S. K.; DEY, P. K.; SALVI, N. A.; CHATTOPADHYAY, S.; "Modified Rhizopusarrhizus biomass for sorption of ${ }^{241} \mathrm{Am}$ and other radionuclides", J Radioanal Nucl. Chem v. 287, p. 691-695, 2011.

VEGLIÓ, F.; BEOLCHINI, F.; GASBARRO, A.; "Biosorption of toxic metals: an equilibrium study using free cells of Athrobacter sp". Process Biochemistry v.32, p 99-105, 1997

VICENTE, R.; POTIENS, A. Jr.; SAKATA, S. K.; DELLAMANO, J.; "Experience in the management of disused lightning rods containg ${ }^{241} \mathrm{Am}$ in a Research Institute", Health Physics v.105, p 223-230, 2013

VIJAYARAGHAVAN, K.; YUN, Y. S.; "Bacterial biosorbents and biosorption", Biotech Adv v.26, p. 266-291, 2008.

VOLESKY, B.; "Biosorption and biosorbents". In: Volesky B., editor Biosorption of Heavy Metals. Florida; CRC press, 1990.

VOLESKY, B.; "Advances in biosorption of metals: selection of biomass types". FEMS Microb. Rev., v. 14, p. 291-302,1994. 
VOLESKY, B.; "Sorption and Biosorption", BV Sorbex edition, Montreal, Canada, 2004

VOLESKY, B.; "Biosorption and me", Water Res., v.41, p. 4017-4029, 2007.

VOLESKY, B.; YANG, J.; "Biossorption of uranium on Sargassum Biomass", Wat. Res, v. 33, p. 3357-3363, 1999

WANG, J.; CHAN, C.; "Biosorption of heavy metals by Saccharomyces cerevisiae: A review", Biotech. Adv, v. 24,p. 427-451, 2006.

WEBER, J. W. J.; "Adsorption Processes", The University of Michigan, College of Engineering, Ann Arbor, Michigan 48104, USA, 1974.

XIONG, Z.H.; FAN, X.H.; LUO, D.L.; WANG, T.; CHEN, Q.; "Treatment of simulated plutonium-containing wastewater by ultrafiltration-reverse osmosis technology", J. Nucl. Radiochem, v.30, p. 142-145, 2008.

YANG, H.; YAN, R.; CHEN, H.; LEE, D. H.; ZHENG, C.; "Characteristics of hemicellulose, cellulose and lignin pyrolysis", Fuel, v. 86, p. 1781-1788, 2007.

YANTASEE, W.; WARNER, C. L.; SANGVANICH, T.; ADDLEMAN, R. S.; CARTER, T. G.; WIACEK, R. J.; FRYXELL, G. E.; TIMCHALK, C.; WARNER, M. G.; "Removal of heavy metals from aqueous system with Thiel functionalizes superparamagnetic nanoparticles", Environ. Sci. Technol. v. 41, p. 5114-5119, 2007. 